B O N N E V I L L E P O W E R A D M I N I S T R A T I O

Numerically Simulating the Hydrodynamic and Water Quality Environment for Migrating Salmon in the Lower Snake River

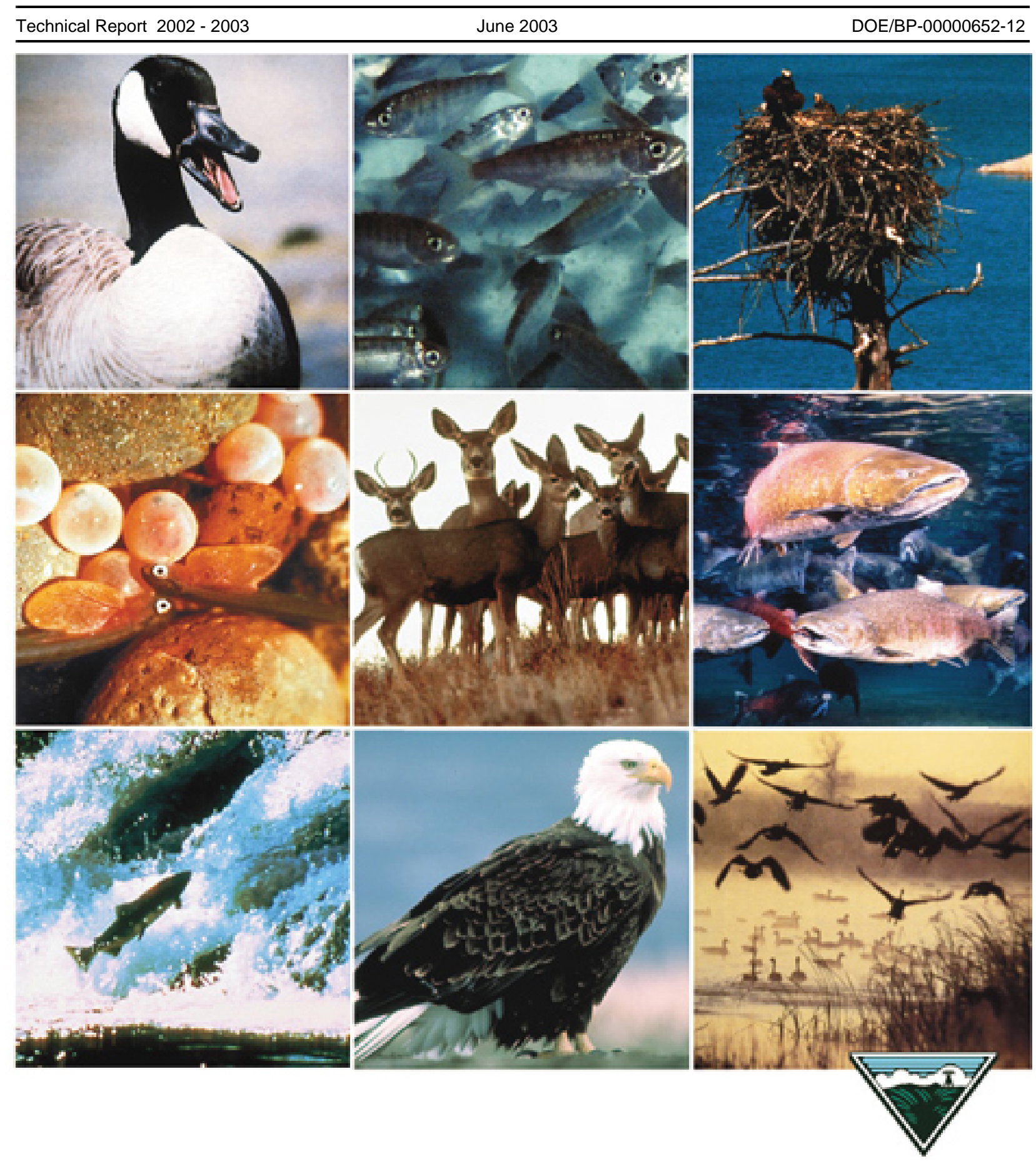


This Document should be cited as follows:

Cook, C., M. Richmond, A. Coleman, C. Rakowski, P. Titzler, M. Bleich, "Numerically Simulating the Hydrodynamic and Water Quality Environment for Migrating Salmon in the Lower Snake

River", 2002-2003 Technical Report, Project No. 200202700, 62 electronic pages, (BPA Report

DOE/BP-00000652-12)

\author{
Bonneville Power Administration \\ P.O. Box 3621 \\ Portland, OR 97208
}

This report was funded by the Bonneville Power Administration (BPA), U.S. Department of Energy, as part of BPA's program to protect, mitigate, and enhance fish and wildlife affected by the development and operation of hydroelectric facilities on the Columbia River and its tributaries. The views in this report are the author's and do not necessarily represent the views of BPA. 


\section{Numerically Simulating the Hydrodynamic and Water Quality Environment for Migrating Salmon in the Lower Snake River}
C.B. Cook
C.L. Rakowski
M.C. Richmond
S.P. Titzler
A.M. Coleman
M.D. Bleich

June 2003

Prepared for the Bonneville Power Administration, U.S. Department of Energy,

Under Contract DE-AC06-76RLO1830

Pacific Northwest National Laboratory

Richland, Washington 99352 


\title{
DISCLAIMER
}

This report was prepared as an account of work sponsored by an agency of the United States Government. Neither the United States Government nor any agency thereof, nor Battelle Memorial Institute, nor any of their employees, makes any warranty, express or implied, or assumes any legal liability or responsibility for the accuracy, completeness, or usefulness of any information, apparatus, product, or process disclosed, or represents that its use would not infringe privately owned rights. Reference herein to any specific commercial product, process, or service by trade name, trademark, manufacturer, or otherwise does not necessarily constitute or imply its endorsement, recommendation, or favoring by the

United States Government or any agency thereof, or Battelle Memorial Institute. The views and opinions of authors expressed herein do not necessarily state or reflect those of the United States Government or any agency thereof.

\author{
PACIFIC NORTHWEST NATIONAL LABORATORY \\ operated by \\ BATTELLE \\ for the \\ UNITED STATES DEPARTMENT OF ENERGY \\ under Contract DE-AC06-76RL01830
}

Printed in the United States of America
Available to DOE and DOE contractors from the Office of Scientific and Technical Information,
P.O. Box 62, Oak Ridge, TN 37831-0062;
ph: (865) 576-8401
fax: $(865) 576-5728$
email: reports@adonis.osti.gov

Available to the public from the National Technical Information Service, U.S. Department of Commerce, 5285 Port Royal Rd., Springfield, VA 22161

ph: (800) 553-6847

fax: $(703) 605-6900$

email: orders@ntis.fedworld.gov

online ordering: http://www.ntis.gov/ordering.htm 


\section{Summary}

Summer temperatures in the Lower Snake River can be altered by releasing cold waters that originate from deep depths within Dworshak Reservoir. These cold releases are used to lower temperatures in the Clearwater and Lower Snake Rivers and to improve hydrodynamic and water quality conditions for migrating aquatic species. This project monitored the complex threedimensional hydrodynamic and thermal conditions at the Clearwater and Snake River confluence and the processes that led to stratification of Lower Granite Reservoir (LGR) during the late spring, summer, and fall of 2002. Hydrodynamic, water quality, and meteorological conditions around the reservoir were monitored at frequent intervals, and this effort is continuing in 2003. Monitoring of the reservoir is a multi-year endeavor, and this report spans only the first year of data collection.

In addition to monitoring the LGR environment, a three-dimensional hydrodynamic and water quality model has been applied. This model uses field data as boundary conditions and has been applied to the entire 2002 field season. Numerous data collection sites were within the model domain and serve as both calibration and validation locations for the numerical model. Errors between observed and simulated data varied in magnitude from location to location and from one time to another. Generally, errors were small and within expected ranges, although, as additional 2003 field data becomes available, model parameters may be improved to minimize differences between observed and simulated values.

A two-dimensional, laterally-averaged hydrodynamic and water quality model was applied to the three reservoirs downstream of LGR (the pools behind Little Goose, Lower Monumental, and Ice Harbor Dams). A two-dimensional model is appropriate for these reservoirs because observed lateral thermal variations during summer and fall 2002 were almost negligible; however, vertical thermal variations were quite large (see USACE 2003). The numerical model was applied to each reservoir independently to simulate the time period between May 1 and October 1, 2002. Differences between observed and simulated data were small, although improvements to model coefficients may be performed as additional thermal data, collected in the reservoirs during 2003, becomes available. 


\section{Acknowledgements}

We sincerely appreciate the cooperation, assistance, and dedication of the following persons:

- Bonneville Power Administration

$\bigcirc \quad$ John Piccininni (Contracting Officer's Technical Representative)

- U.S. Army Corps of Engineers

- Kathryn Barko (Lower Snake data)

- Joe Carroll (technical review and Lower Snake data)

- Rick Emmert (permits for AgriMet station and technical review)

- U.S. Bureau of Reclamation

○ Peter Palmer (AgriMet station)

- U.S. Geological Survey

- Ken Tiffan (temperature data)

- U.S. Department of Energy

○ Nonproliferation and National Security Administration (satellite imagery)

- Sandia National Laboratories

- Tom Stueber (satellite image data and technical review)

- Pacific Northwest National Laboratory

- Tom Giever (on-site technician)

- George He (satellite imaging support)

- Dan Olivares (on-site technician)

- John Serkowski (graphics support)

- Darcy Short (editor)

- Jodi Stroklund (contracting support)

- Duane Ward (GIS and satellite imaging support) 


\section{Acronyms and Abbreviations}

$\begin{array}{ll}\text { 2-D } & \text { two-dimensional } \\ \text { 3-D } & \text { three-dimensional } \\ \text { ADCP } & \text { acoustic Doppler current profiler } \\ \text { BPA } & \text { Bonneville Power Administration } \\ \text { CFD } & \text { computational fluid dynamics } \\ \text { cm/s } & \text { centimeters per second } \\ \text { CTD } & \text { conductivity temperature depth } \\ \text { DEM } & \text { digital elevation model } \\ \text { DOQQ } & \text { digital orthographic quarter quadrangles } \\ \text { EFDC } & \text { Environmental Fluid Dynamic Code } \\ \text { FCRPS } & \text { Federal Columbia River Power System } \\ \text { GIS } & \text { Geographic Information System } \\ \text { GPS } & \text { Global Positioning System } \\ \text { IHR } & \text { Ice Harbor } \\ \text { kHz } & \text { kilohertz } \\ \text { LGR } & \text { Lower Granite Reservoir } \\ \text { LGS } & \text { Lower Goose } \\ \text { LMN } & \text { Lower Monumental } \\ \text { LWG FB } & \text { Lower Granite forebay } \\ \text { MAE } & \text { mean absolute error } \\ \text { MASS1 } & \text { Modular Aquatic Simulation System 1-D } \\ \text { mS/cm } & \text { milliSiemen/centimeter } \\ \text { MAE } & \text { mean absolute error (see equation 3.1) } \\ \text { MSE } & \text { mean square error (see equation 3.1) } \\ \text { MTI } & \text { Multi-spectral Thermal Imager } \\ \text { NAD83 } & \text { North American Datum of 1983 } \\ \text { NAVD88 } & \text { North American Vertical Datum of 1988 } \\ \text { NGVD29 } & \text { National Geodetic Vertical Datum of 1929 } \\ \text { NMEA } & \text { National Marine Electronics Associations } \\ \text { NGS } & \text { National Geodetic Survey } \\ \text { PNNL } & \text { Pacific Northwest National Laboratory } \\ \text { RM } & \text { river mile } \\ \text { RMS } & \text { average root mean square (see equation 3.1) } \\ \text { RTK } & \text { Real-Time Kinematic } \\ \text { TIN } & \text { Triangulated Irregular Network } \\ \text { US } & \text { United States } \\ \text { USACE } & \text { United States Army Corps of Engineers } \\ \text { USGS } & \text { United States Geological Survey } \\ \text { WGS } & \text { World Geodetic System } \\ & \end{array}$




\section{Contents}

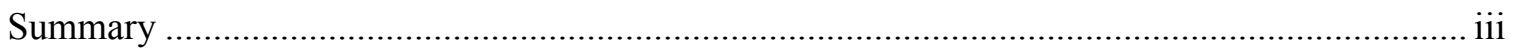

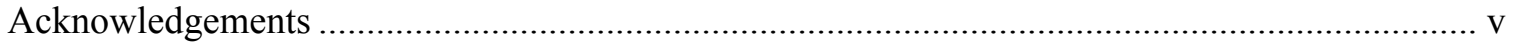

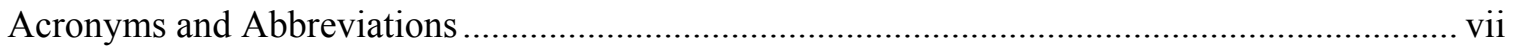

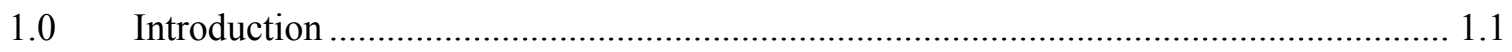

2.0 Field Monitoring Program in Lower Granite Reservoir ............................................... 2.1

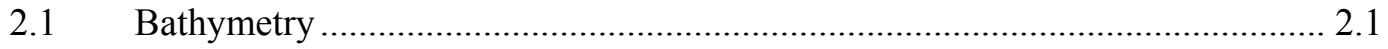

2.1.1 Bathymetry Data Collection Methods ................................................. 2.1

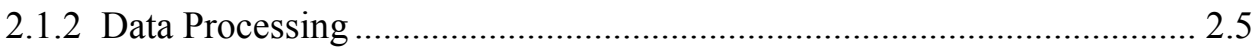

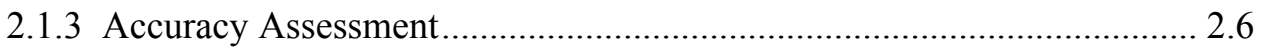

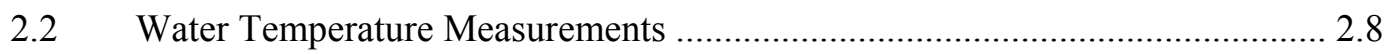

$2.3 \quad$ Water Velocity Measurements ................................................................... 2.11

2.4 Longitudinal Water Surface Variations......................................................... 2.12

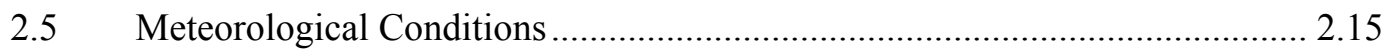

3.0 Numerical Modeling of Lower Granite Reservoir ..................................................... 3.1

3.1 Description of the 3-D Numerical Model....................................................... 3.1

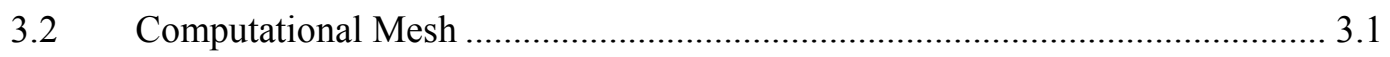

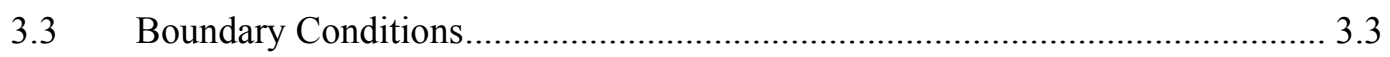

3.3.1 Downstream and Meteorological Boundary Conditions ........................ 3.3

3.3.2 MASS1: Generation of Upstream EFDC Boundary Conditions .............. 3.3

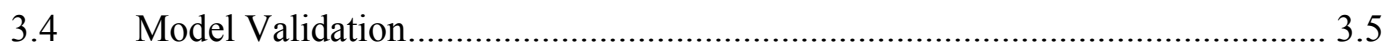

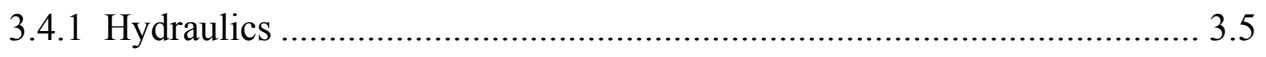

3.4.2 Temperature .............................................................................. 3.6

4.0 Velocity and Thermal Structure of Lower Granite Reservoir ....................................... 4.1

4.1 Observed Stratification Cycle ...................................................................... 4.1

4.2 Weak to No Stratification Circulation .............................................................. 4.1

4.3 Strong Stratification Circulation .................................................................. 4.2

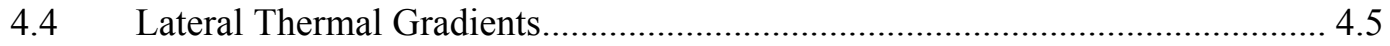

5.0 Numerical Modeling of Three Lower Snake Reservoirs................................................ 5.1

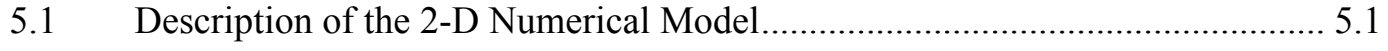

$5.2 \quad$ Construction of the Numerical Grid ............................................................... 5.1

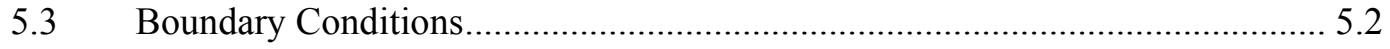

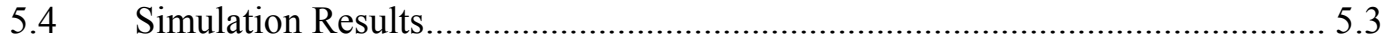


5.4.1 Little Goose Simulation Results ............................................................ 5.3

5.4.2 Lower Monumental Simulation Results ................................................ 5.6

5.4.3 Ice Harbor Simulation Results .......................................................... 5.8

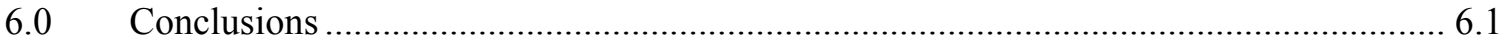

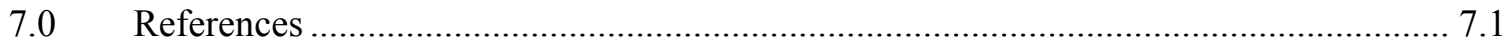

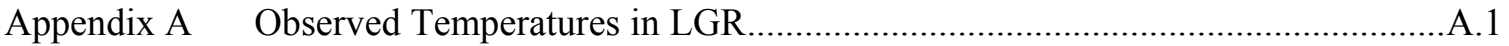




\section{Figures}

1.1. Location of the Clearwater and Lower Snake Rivers........................................................... 1.1

2.1. Bathymetry collection zones, as defined by collection methodology ................................ 2.3

2.2. Spatial distribution of RTK GPS collected water surface elevations ................................... 2.4

2.3. Sample of various datasets used to compile bathymetry data ............................................ 2.5

2.4. Final processed bathymetry dataset in the Snake and Clearwater River confluence zone.... 2.7

2.5. Open-water temperature logger deployment schematic. ................................................... 2.9

2.6. Bridge pier temperature logger deployment schematic....................................................... 2.9

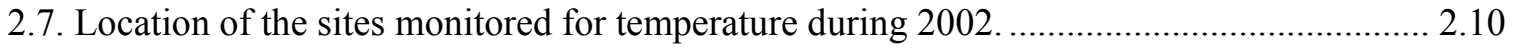

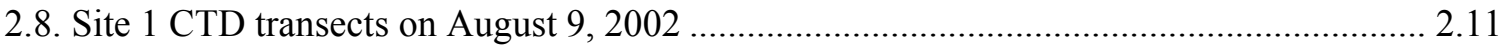

2.9. ADCP measurement locations in Lower Granite Reservoir during 2002 ......................... 2.12

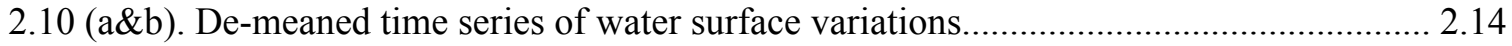

2.11. Variations in water surface elevation at site 5 and Lower Granite Dam ......................... 2.15

3.1. EFDC computational mesh near the Snake and Clearwater River confluence...................... 3.2

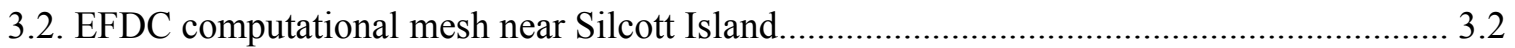

3.3. Forebay water surface elevation at Lower Granite Dam in 2002 ...................................... 3.3

3.4. Inflows to the MASS1 model for the simulation period. ........................................................ 3.4

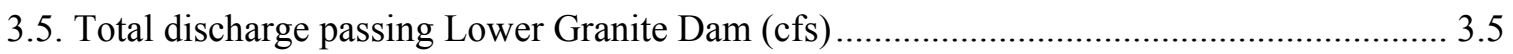

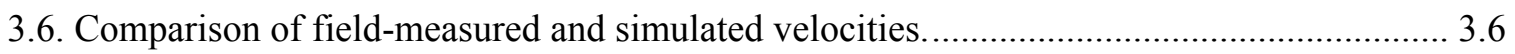

3.7. Comparison of observed and simulated thermal data upstream of the Snake and Clearwater

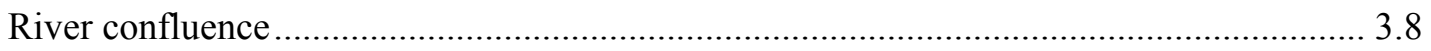

3.8. Comparison of logger and simulation data well downstream of the confluence ................... 3.9

3.9. Comparison of logger and simulation data downstream of the confluence........................ 3.10

4.1. Water temperature data from the Snake and Clearwater Rivers........................................ 4.1

4.2. Infrared satellite image taken at midnight, April 4, 2002, of the confluence zone................ 4.2

4.3. MTI satellite derived surface water temperatures on July 21, 2002 at 11 a.m.................... 4.3

4.4. Temperature loggers data (SBE39) within the top 3 centimeters on July 21, 2002 ............ 4.3

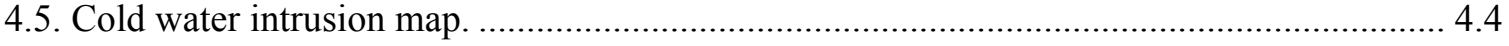

4.6. Isosurfaces, which were created between the vertical profiles, were extended horizontally until they intersected the bathymetric surface. ................................................................... 4.4

4.7. Time series of lateral temperatures, 2 miles downstream of the confluence........................ 4.5 
$4.8(\mathrm{a} \& \mathrm{~b})$. Time series of the difference is temperature between the north and south pier loggers at Red Wolf Bridge.

$4.9(\mathrm{a} \& \mathrm{~b})$. Times series of the difference in temperature between the north and south pier upstream of Silcott Island 4.6

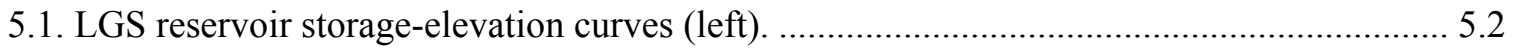

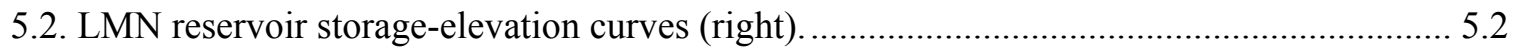

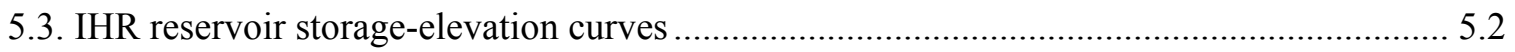

5.4. Downstream water surface elevation for LGS reservoir ................................................... 5.4

5.5. LGS reservoir temperature comparison summary ........................................................... 5.5

5.6. Downstream water surface elevation for LMN reservoir .................................................. 5.6

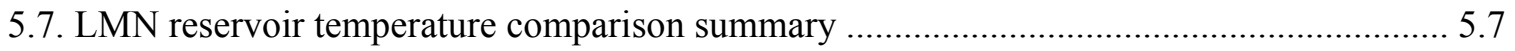

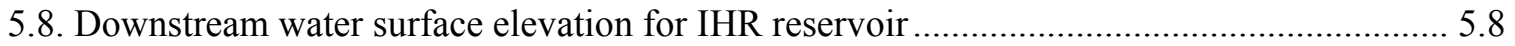

5.9. IHR reservoir temperature comparison summary. ................................................................ 5.9

A.1. Summer season temperature results at sites 1 through 4 ...................................................1

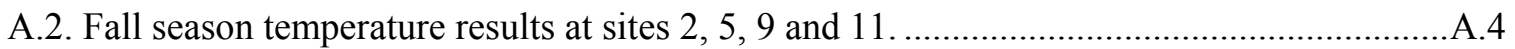

\section{Tables}

2.1. A sample of spatially distributed water surface elevations collected with a RTK GPS and compared to gage-measured elevations at Lower Granite Dam ....................................... 2.4

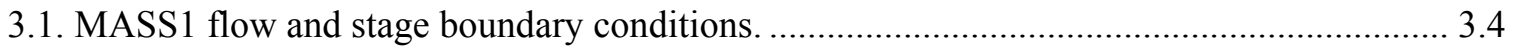

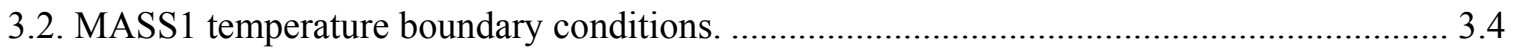

3.3. Summary statistics for August ADCP velocity measurements (ft/second) ......................... 3.6

5.1. Statistical comparison of results for Little Goose Reservoir............................................... 5.3

5.2. Statistical comparison of results for Lower Monumental Reservoir. ................................... 5.6

5.3. Statistical comparison of results for Ice Harbor Reservoir.................................................. 5.8

A.1. Calendar and location of logger deployments. ................................................................... 1 


\subsection{Introduction}

Summer flow augmentation is implemented annually from Dworshak Reservoir (Clearwater River) and Upper Snake River reservoirs to increase water velocities and decrease water temperatures in Lower Granite Reservoir (LGR) when juvenile fall Chinook salmon are rearing and migrating seaward. This period of summer flow augmentation also corresponds with adult fall Chinook salmon and steelhead movements into the Lower Snake River system. Historical profiles of water temperatures just upstream of Lower Granite Dam show that the water column remains stratified through the augmentation period because releases from Dworshak Reservoir are below equilibrium temperature. Before this study, little was known regarding the threedimensional (3-D) water velocity and temperature variations downstream of the Snake and Clearwater River confluence and how this thermal stratification is maintained in the reservoirs downstream of the confluence.

Figure 1.1. Location of the Clearwater and Lower Snake Rivers.

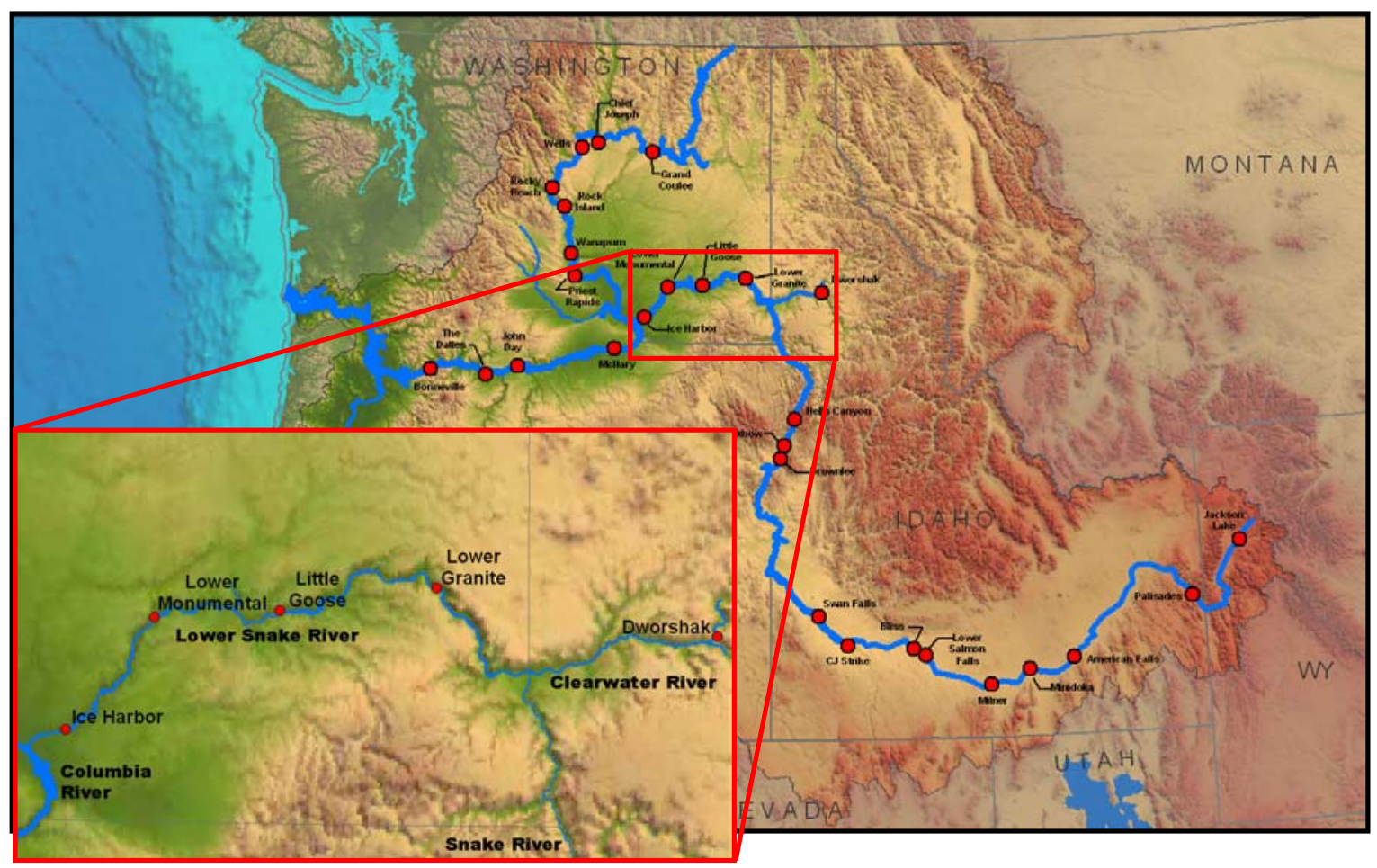

Temperature is an important driver of many salmon life history processes. For example, temperature has been observed to affect swimming performance (Brett 1967), physiological development (Ewing et al. 1979), and disease susceptibility (Fryer and Pilcher 1974). Furthermore, sub-lethal heat stress has been shown to increase the vulnerability of fish to predation (Sylvester 1972; Coutant 1973). The precise thermal level at which lethal heat stress can occur was examined by Brett (1952) who found the upper incipient lethal temperature to be $24^{\circ} \mathrm{C}$ for juvenile Chinook salmon, while Baker et al. (1995) reported the upper incipient lethal temperature to be $23^{\circ} \mathrm{C}$ for hatchery-raised fall Chinook salmon in the Sacramento-San Joaquin Delta. Regardless of the exact level, temperatures in excess of $24^{\circ} \mathrm{C}$ are routinely observed in the upper portion of the water column along the entire Lower Snake River system during summer. This suggests that temperature levels may be critical in determining the health and survival of endangered salmonids in the Lower Snake River system. 
Two goals during the first year of this multi-year study were to provide information on the physical river environment and to continue multi-dimensional modeling research on the four Lower Snake River reservoirs. Hydrodynamic and water quality information obtained using direct measurement in LGR were used to validate and refine the 3-D computational fluid dynamics (CFD) model of LGR developed by Perkins et al. (2001).

In addition to the field data collected by Pacific Northwest National Laboratory (PNNL) during 2002, a large quantity of data were collected by others. These data described water temperature conditions downstream of LGR and were used to calibrate and verify two-dimensional (2-D), laterally-averaged hydrodynamic and water quality models of the pools behind Little Goose (LGS), Lower Monumental (LMN), and Ice Harbor (IHR) Dams.

This suite of CFD models will be used in future years to simulate periods with alternative release strategies (e.g., increased/decreased flows and/or increased/decreased temperatures) from upstream reservoirs. In combination with analyses conducted on fish movement and behavior, this work will provide a better understanding of how potential flow augmentation strategies could influence the migration and health of salmonids in the Lower Snake River.

Results from these simulations are of use to various river managers (e.g., fisheries and hydropower) that are examining locations of concern throughout the Lower Snake River system. Information generated by this study will also help meet Action Items 141 (monitoring water temperature in the Lower Snake River during juvenile migration season) and 143 (monitoring and modeling Snake River water temperatures under various alternative release strategies) of the 2000 Biological Opinion (FCRPS 2000). 


\subsection{Field Monitoring Program in Lower Granite Reservoir}

At the start of this program, little detailed information was available regarding bathymetry, meteorology, velocity, and temperature variations downstream of the Snake and Clearwater River confluence. To close these data gaps and to collect data sufficient to calibrate and verify a three dimensional (3-D) hydrodynamic and water quality model, data were collected between June and December 2002. Bathymetry data were collected at the beginning of the program (June to July 2002). More than 70 self-contained temperature loggers were deployed throughout the reservoir. These loggers collected data at 15-minute (or less) intervals until September (19 loggers remained deployed between September and December). Water velocity surveys were performed in August and September to gather 3-D measurements at locations covering a large portion of the reservoir. Finally, a meteorological station was deployed in July on Silcott Island (Chief Timothy State Park) that continually records atmospheric conditions at 15-minute increments and posts these data to a website in almost real time.

\subsection{Bathymetry}

\subsubsection{Bathymetry Data Collection Methods}

Bathymetry data were acquired in July 2002 using three methods of collection. Figure 2.1 depicts the spatial extents of the Methods 1 and 2 described below. The spatial extents of Method 3 are concentrated around bridge structures, as annotated in Figure 2.1.

Method 1. Data were collected using a Trimble 5700 RTK (Real-Time Kinematic) Global Positioning System (GPS), guided with Trimble's HydroPro software and a survey-grade fathometer (Innerspace 455). The RTK base station was set up on a National Geodetic Survey (NGS) benchmark (PID RZ1076) located in Clarkston, Washington, at:

Horizontal: NAD83 ${ }^{1}-\mathrm{N}^{\circ} 6^{\circ} 25^{\prime} 33.07218^{\prime \prime} \mathrm{W} 117^{\circ} 02^{\prime} 58.21778^{\prime}$
Vertical: NAVD88 - 236.634 meters $(776.36$ feet)

Data were collected in a series of cross-sections (perpendicular to the channel) and three longitudinal (parallel to the channel) transects to form a grid of bathymetry points. This method of collection was used from river mile (RM) 131.0 (Silcott Island area) to RM 143.0 on the Snake River and RM 0.0 to RM 3.5 on the Clearwater River. Cross-sections were spaced 100 feet apart from RM 132.0 to RM 140.5 on the Snake River and from RM 0.0 to RM 1.0 on the Clearwater River. All other cross-sections using this methodology were spaced 350 feet apart. RTKstyle bathymetry collection provides a high level of horizontal and vertical accuracy (within a range of 3 to 20 centimeters). More than 147,000 bathymetry points were collected using this method.

\footnotetext{
${ }^{1}$ All elevation values were collected in the North American Vertical Datum of 1988 (NAVD88). All horizontal coordinates were collected in the Washington Stateplane South Zone, North American Datum of 1983 (NAD83), with the horizontal and vertical units in U.S. Survey Feet.
} 
Method 2. Data were collected using a Trimble GeoExplorer 3 with a beacon (for real-time differential correction) and a survey-grade fathometer (Innerspace 455). To obtain a more accurate channel-bottom elevation, a mean water surface elevation was collected using the RTK GPS. As a result, horizontal data from the GeoExplorer, depth data from the fathometer, and real-world water surface elevation values from the RTK GPS were processed to develop a bathymetric point dataset. Data were collected in a series of 1000-foot cross-sections and two longitudinal transects. Data collected using this method extend from RM 116.5 to RM 131.0. The GeoExplorer-style bathymetry collection is reasonably easy to set up, obtains sub-meter horizontal accuracy, and is completely contained in the survey boat, making troubleshooting easier. The primary disadvantage to this method is the need to independently collect surface water elevations with a high-accuracy survey method (traditional survey or RTK GPS) because the vertical accuracy of the GeoExplorer is approximately 2 to 5 meters. More than 26,000 bathymetry points were collected using this method.

Method 3. Data for areas around and under bridges were collected using a Trimble GeoExplorer3 with a beacon (for real-time differential correction) and a survey-grade fathometer (Innerspace 455). Bridges pose a problem for GPS-based bathymetry collection because overhead structures block the GPS signal. Using a shore-based laser rangefinder, coupled with the GPS, generally helps resolve such issues; however, the bridge pillars block the line-of-sight for the rangefinder. Data were collected in a grid pattern around the bridge, always starting and ending with full GPS signals. Post-processing the data with a linear interpolation reassigned missing GPS data where needed. Elevation values for bathymetric points were determined using a mean water surface elevation and fathometer data. Using this method, data were collected for areas around and underneath Red Wolf Bridge (State Route 193 north/south crossing of the Snake River), Blue Bridge (U.S. Highway 12 east/west crossing the Snake River), Southway Bridge, Clearwater Railroad Bridge (crossing the Clearwater River north out of Lewiston, Idaho), and the ClearwaterMemorial Bridge (U.S. Highway 12 north/south crossing of the Clearwater River from Lewiston, Idaho). More than 1,800 bathymetry points were collected using this method.

To ensure the various methods of bathymetry collection were reasonable, areas of overlap were obtained, processed, and compared. The approximate elevation difference between the collection methods was two feet. RTK-collected survey values were converted from the North American Vertical Datum of 1988 (NAVD88) to the National Geodetic Vertical Datum of 1929 (NGVD29) to conform to the reported values at the dam gage.

During the process, the longitudinal slope of the water surface in June 2002 was determined to be less than 0.5 feet in elevation over $30+$ miles in river length (approximately negligible). Table 2.1 shows the values of various RTK survey points on the upper half of the reservoir (between RM 131 to 142), as compared to the staff gage located at the dam (RM 108). The assumption of a flat water surface downstream of Silcott Island was used in the processing of the Trimble GeoExplorer 3 data, as outlined in Method 2 above. 


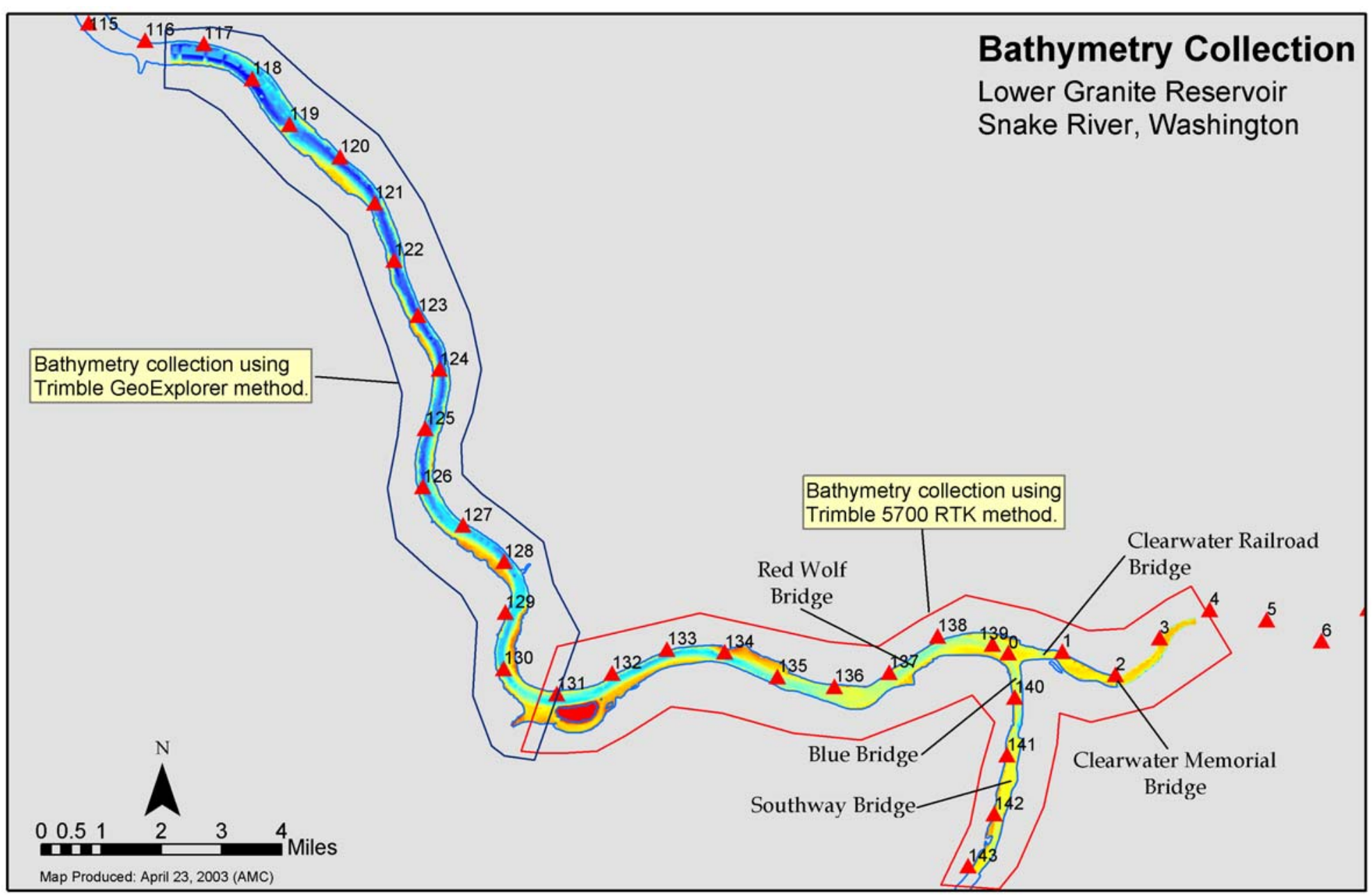

Figure 2.1. Bathymetry collection zones, as defined by collection methodology. Blue polygon represents data collected using GeoExplorer 3 methodology, and red polygon represents the area where the RTK GPS method was used to collect bathymetry. Area bridges are annotated for reference. River miles are annotated with red triangles. 


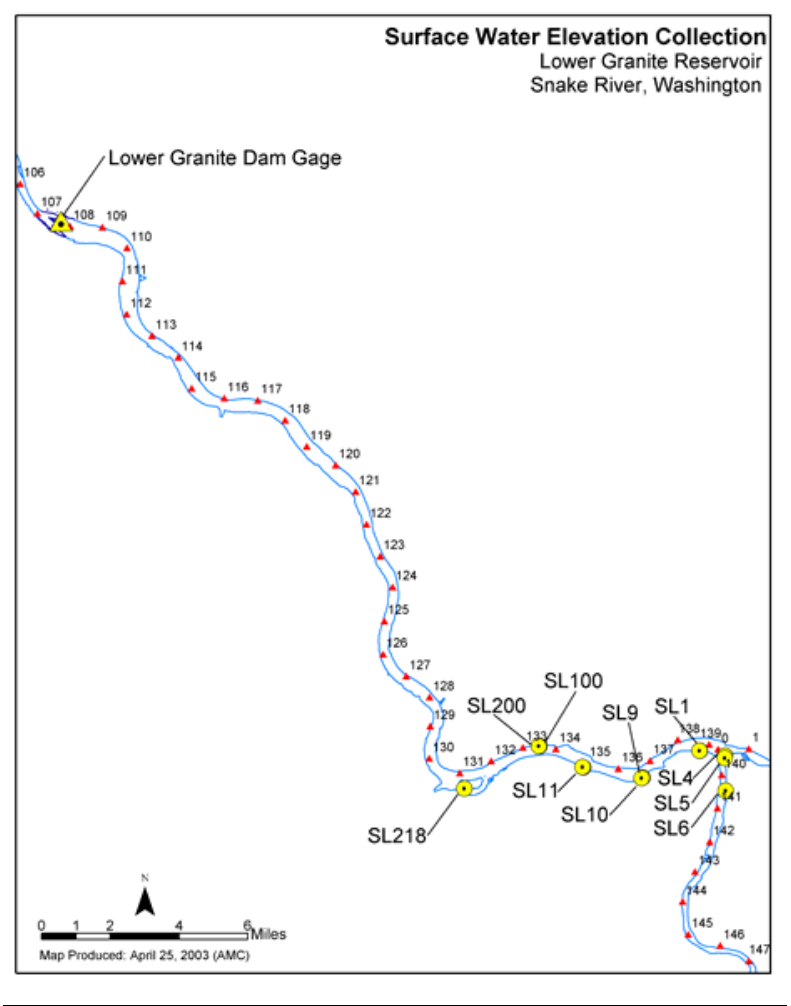

Figure 2.2. Spatial distribution of RTK GPS collected water surface elevations. Elevation data were compared to gage-measured elevations at Lower Granite Dam to determine a water surface slope.

Table 2.1. A sample of spatially distributed water surface elevations collected with an RTK GPS and compared to gage-measured elevations at Lower Granite Dam. Collection of data covers a three-day period. All elevations are in feet.

\begin{tabular}{|l|c|c|c|c|c|c|c|}
\hline $\begin{array}{l}\text { Survey } \\
\text { Point }\end{array}$ & Date & Time & X-Coord & Y-Coord & $\begin{array}{c}\text { RTK } \\
\text { Elev. }\end{array}$ & $\begin{array}{c}\text { Gage } \\
\text { Elev. }\end{array}$ & $\begin{array}{c}\text { Delta } \\
\text { Elev. }\end{array}$ \\
\hline s11 & $6 / 25 / 2002$ & $3: 05: 45 \mathrm{PM}$ & 2510234.936 & 417713.355 & 734.87 & 734.40 & 0.47 \\
\hline s14 & $6 / 25 / 2002$ & $4: 09: 33 \mathrm{PM}$ & 2514138.961 & 416958.609 & 734.85 & 734.33 & 0.52 \\
\hline s16 & $6 / 25 / 2002$ & $4: 23: 02 \mathrm{PM}$ & 2514213.606 & 411589.592 & 735.17 & 734.28 & 0.89 \\
\hline s19 & $6 / 25 / 2002$ & $6: 08: 49 \mathrm{PM}$ & 2501472.774 & 413636.453 & 734.34 & 734.24 & 0.1 \\
\hline s111 & $6 / 25 / 2002$ & $6: 26: 03 \mathrm{PM}$ & 2492324.69 & 415189.332 & 734.45 & 734.21 & 0.24 \\
\hline s112 & $6 / 25 / 2002$ & $6: 35: 41 \mathrm{PM}$ & 2492219.258 & 415245.799 & 734.44 & 734.22 & 0.22 \\
\hline s1100 & $6 / 26 / 2002$ & $11: 26: 15 \mathrm{AM}$ & 2485564.031 & 418448.881 & 734.79 & 734.71 & 0.08 \\
\hline s1200 & $6 / 27 / 2002$ & $9: 57: 42 \mathrm{AM}$ & 2485577.072 & 418451.015 & 734.34 & 734.67 & -0.33 \\
\hline
\end{tabular}




\subsubsection{Data Processing}

Field-collected bathymetry data, using the three methods described above, were post-processed from a National Marine Electronics Association (NMEA) format into a comma-delimited X,Y,Z ASCII-data format and incorporated into a Geographic Information System (GIS) database using ESRI's Arc/Info v.8.2. Beyond the processed bathymetry data, several pieces of data were incorporated into the processing of the final dataset, which helped to better define the channel. First, a vector-based mesh of the Lower Granite pool was created and a directional interpolation process was developed to fill in areas with sparse bathymetry data. Second, contour data were developed for some of the near-shore and shallow areas, which the survey boat could not access, using a combination of the collected bathymetry data and U.S. Geological Survey (USGS) 10meter digital elevation models (DEMs). Third, USGS 10-meter DEM point data were used along the shorelines throughout the study area to provide near-channel topographic data. Figure 2.3 illustrates the various datasets used in the processing of relatively coarsely spaced bathymetry data near RM 128 (downstream of Silcott Island). Using Arc/Info, these datasets were processed into a Triangulated Irregular Network (TIN) model to form a continuous 3-D surface. The resulting TIN model was then transformed into a raster-based GRID dataset at a 10-foot resolution. Figure 2.4 shows a sample of the bathymetry collected in the Snake and Clearwater River confluence zone.

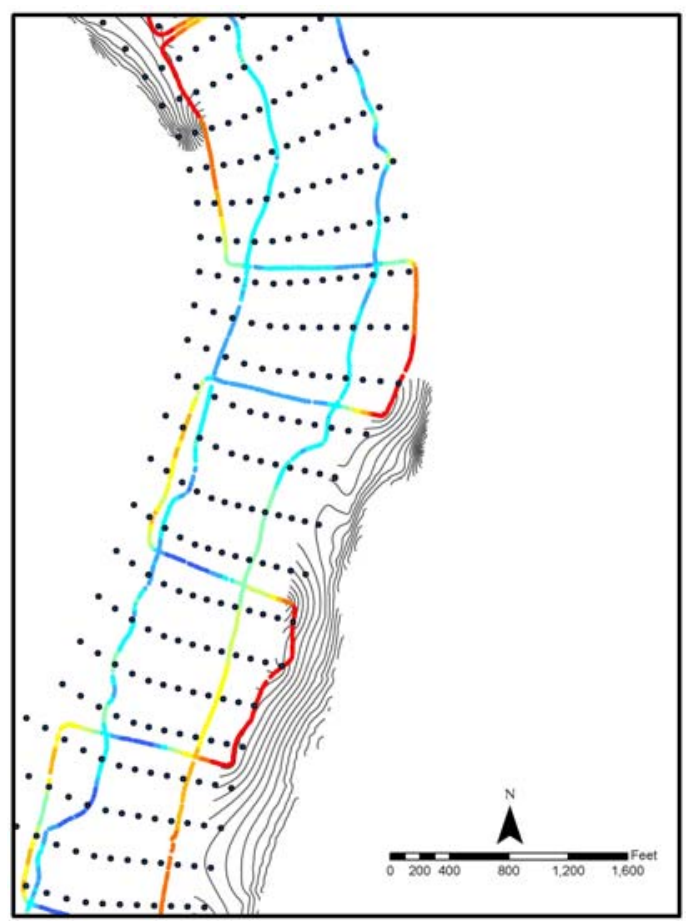

Figure 2.3. Sample of various datasets used to compile bathymetry data. Colored lines depict boat-gathered depth data classified by elevation; dots represent data developed from directional interpolation method (not classified); and gray lines represent shallow, near-shore contours. 


\subsubsection{Accuracy Assessment}

Data accuracy was determined using several factors including source benchmark error, horizontal and vertical GPS error, fathometer error, and average pitch/roll of the survey boat. Conservative data collection errors for the bathymetry survey are:

Method 1 (Trimble 5700 RTK collected data):

Method 2 (Trimble GeoExplorer collected data):
Horizontal: \pm 0.5 feet

Vertical: \pm 3.0 feet

Horizontal: \pm 5.0 feet

Vertical: \pm 5.0 feet 


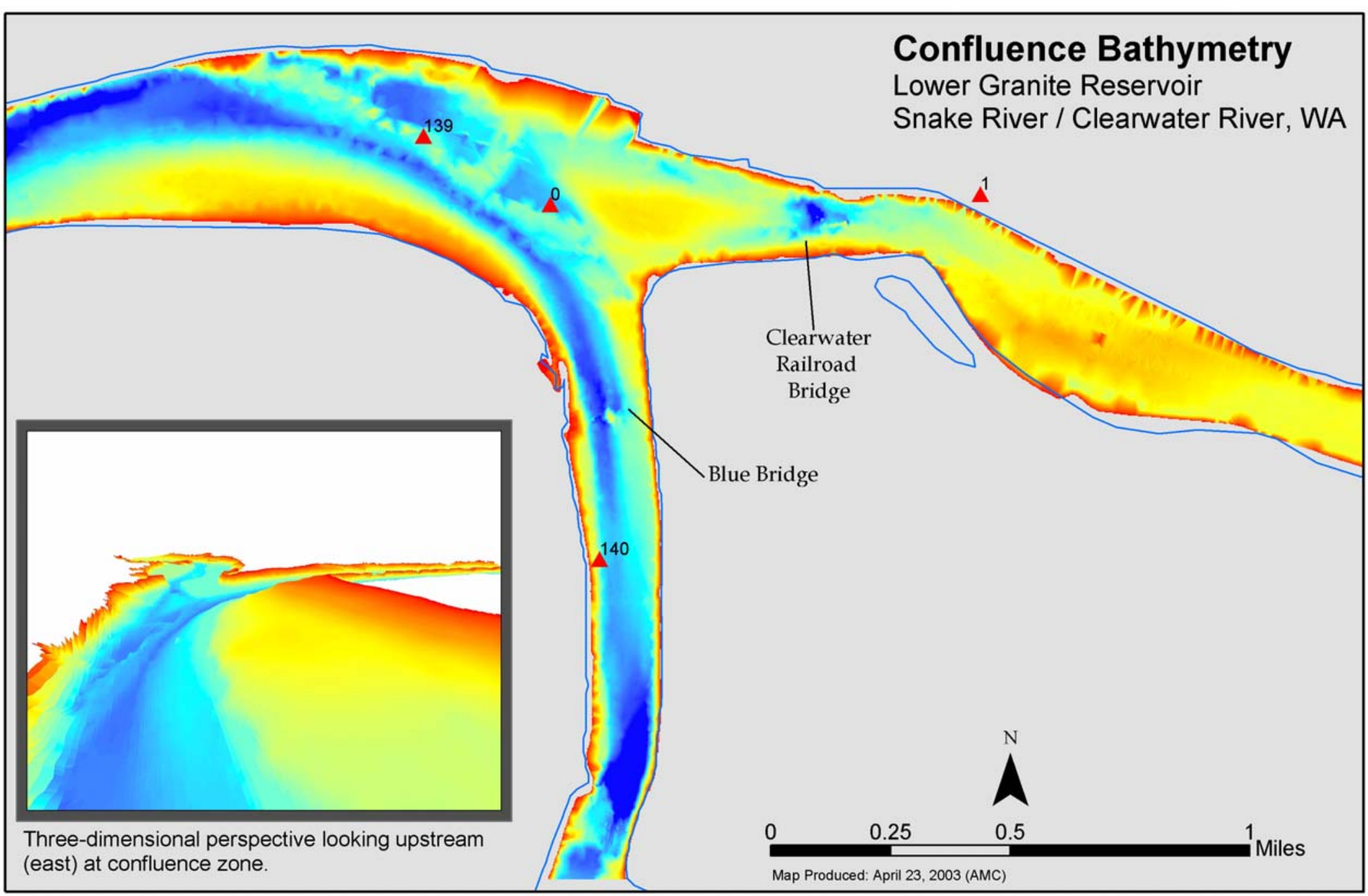

Figure 2.4. Sample of the processed bathymetry dataset of the Snake and Clearwater River confluence zone. Color shading represents elevation, with blue colors representing lower (deeper) values. 


\subsection{Water Temperature Measurements}

Two types of instruments were used during the study to measure water temperature: selfcontained temperature loggers and a portable conductivity-temperature-depth (CTD) probe. The majority of the temperature loggers used during the study were manufactured by Onset Computer Corporation under the brand name Optic StowAways. These loggers have a manufacturer's stated accuracy of $\pm 0.2^{\circ} \mathrm{C}$ within the temperature range of $-5^{\circ} \mathrm{C}$ to $37^{\circ} \mathrm{C}$; however, all loggers were also confirmed to be within this specification using a constant temperature water bath both before and after deployment. Five SeaBird SBE39 temperature and pressure loggers were used in the study at various locations around the reservoir. SBE39 thermistors were individually calibrated by the manufacturer to be accurate within $\pm 0.002^{\circ} \mathrm{C}$ (drift of $0.0002^{\circ} \mathrm{C}$ per month) between $-5^{\circ} \mathrm{C}$ to $35^{\circ} \mathrm{C}$. SBE39 pressure sensors used for this study had a depth range of 20 or 100 meters and were calibrated to be within accurate 0.1 meter (drift of 0.004 meters per month). The portable CTD was manufactured by the Hydrolab-Hach Company under the brand name MiniSonde4a. The CTD was calibrated by the manufacturer to a stated accuracy of $\pm 0.10^{\circ} \mathrm{C}$ within the temperature range of $-5^{\circ} \mathrm{C}$ to $50^{\circ} \mathrm{C}$. The CTD also measures pressure (100-meter water depth range, accurate to \pm 0.3 meters) and conductivity ( $\pm 1 \%$ of reading $\pm 0.001 \mathrm{mS} / \mathrm{cm}$ ).

Temperature loggers were deployed at 11 sites throughout Lower Granite Reservoir (LGR) and were generally concentrated near the confluence zone (Figure 2.7). Locations of each site were measured by a real-time differential GPS. Appendix A gives a complete list of the site locations, as well as contour plots of temperature throughout the season.

At each site loggers were suspended vertically in the water column using one of two methods. At sites 1, 2, 3, 4, 6, and 7, the two-weight open-water method was used (Figure 2.5). The thalweg weight with a sub-surface buoy attached was lowered near the deepest portion of the channel. After lowering the weight into position, the depth of the weight was measured using the CTD. At sites 2, 3, 4, and 7, a SBE39 pressure sensor, mounted on the sub-surface buoy, was used as a redundant measure to confirm the depth. The largest difference between the CTD and SBE39 calculated depths was 0.3 meters. The depth of the weight was also verified by comparing CTD temperature profiles with logger data. If the weight's depth was incorrect, the depth of the thermocline would not agree between CTD and temperature logger data. At all sites and for all deployments, the error was verified to be within the accuracy of the CTD pressure sensor.

From the thalweg weight, two lines emanated, one to a sub-surface buoy that hung at least 4.3 meters (14 feet) beneath the water surface and a second connecting an additional weight. The second weight was positioned close to shore and out of the navigation channel. This weight was also attached to second line that went up to a surface buoy. Distances between the two weights varied between 35 meters and 145 meters; however, it was confirmed by multiple CTD transects across each open-water site that surface temperature differences between the sub-surface and surface buoy were negligible. A typical comparison of lateral temperatures across the channel is shown in Figure 2.8. To simplify reporting, data gathered by the surface temperature loggers have been reported at the horizontal location of sub-surface buoy.

SBE39s with pressure sensors were mounted on sub-surface buoys at sites $2,3,4$, and 7 . These data were used to monitor vertical movements of the buoys, which may have occurred if a large drag force caused by the buoy/thermistor line (and induced by swiftly moving water at the site) was sufficient to counteract the upward buoyancy of the sub-surface buoy. As shown in Figure $2.10(\mathrm{a} \& \mathrm{~b})$, although the depth of the sensor changed over time, the pattern matched the overall 
water surface fluctuation of the reservoir. Independent, drag-induced movements of the buoy/thermistor lines were not observed.

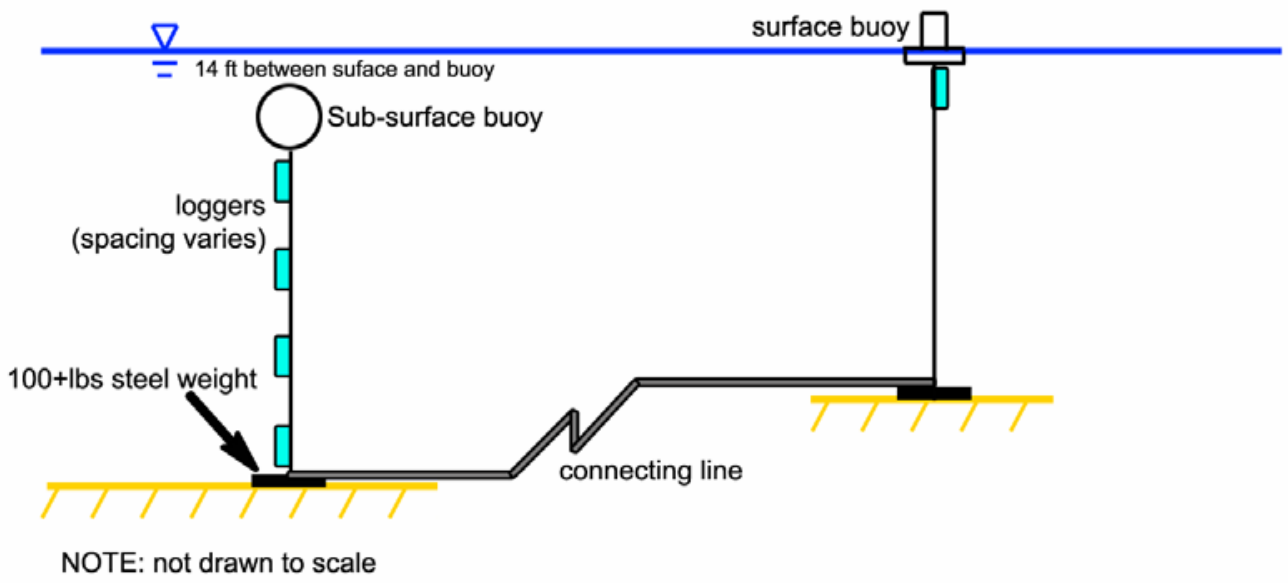

Figure 2.5. Open-water temperature logger deployment schematic.

At the remainder of the sites $(5,8,9,10$, and 11$)$, bridge piers were used as the upper support for the wire rope. Only a single weight was used, which was placed upstream of the bridge pier (Figure 2.6). At sites 9 and 11, the weight was placed alongside the bridge pier (a much easier location to place the weight). Multiple CTD profiles confirmed that the water column was well mixed vertically upstream and to the side of the pier at these sites, and placement of the weight to the side of the pier is assumed to not alter results. After the weight was deployed, the depth of the weight was measured using the CTD, as done for the open-water sites. The angle of the line extending up to the bridge pier was measured before and after deployment to calculate the logger depth. Negligible angle changes were detected at all sites, except sites 8 (June to August, only) and 10. Depth placement errors at bridge sites where the angle did not change are similar to those of the open-water sites (approximately 0.3 meters). At sites 8 (July to August, only) and 10, depth errors could potentially be as large as 1.5 meters due to vandalism induced angle changes. All bridge site logger measurements were also compared with CTD profiles for agreement in the vertical placement of the loggers.

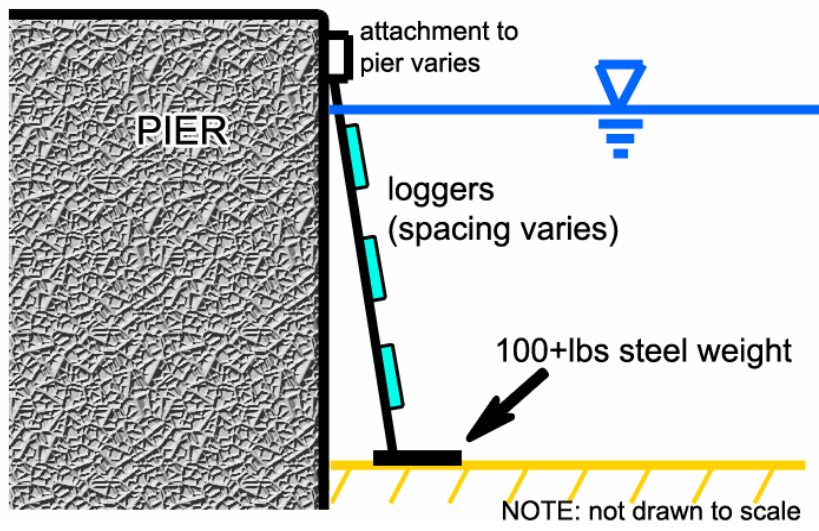

Figure 2.6. Bridge pier temperature logger deployment schematic. 


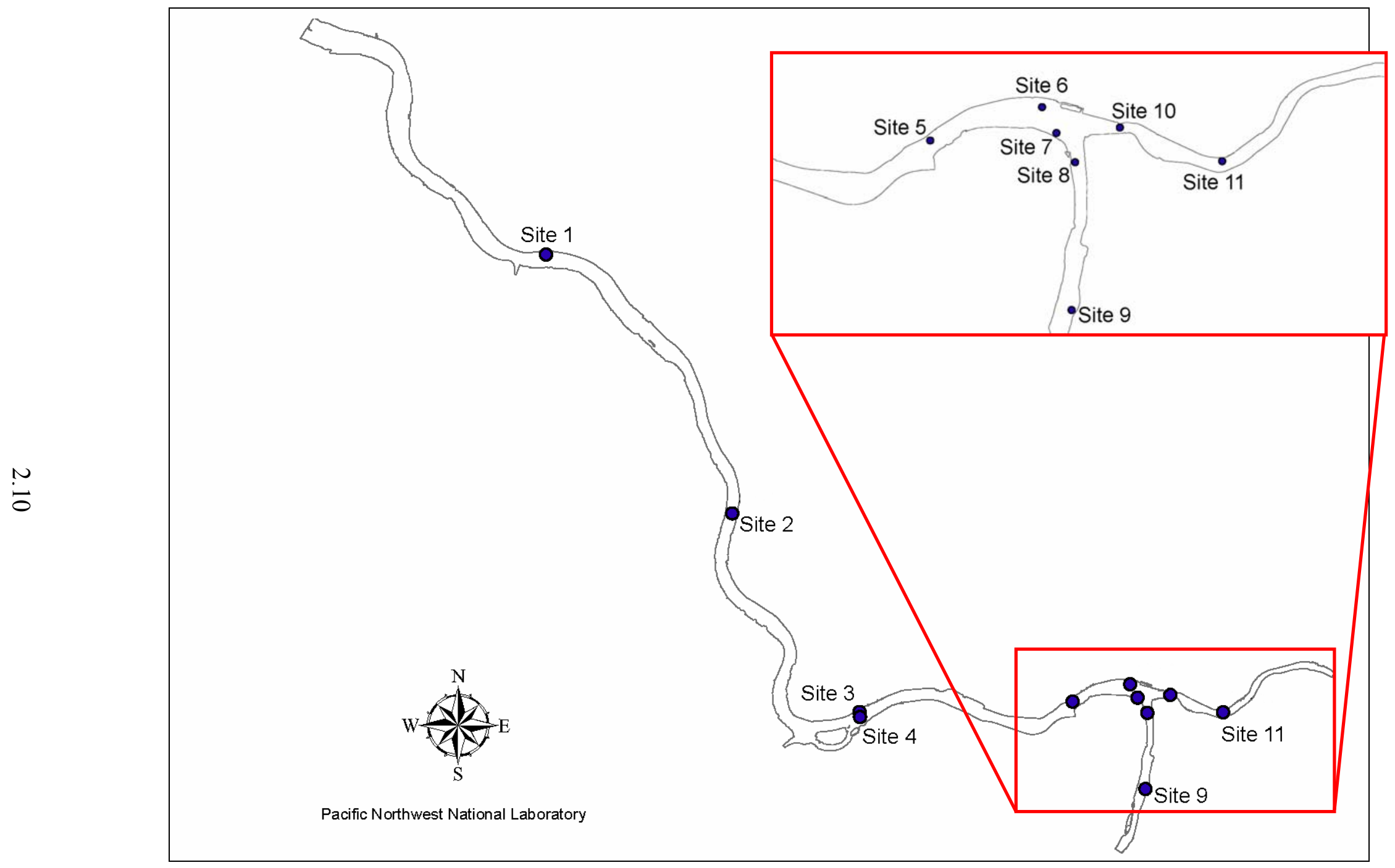

Figure 2.7. Location of the sites monitored for temperature during 2002. 


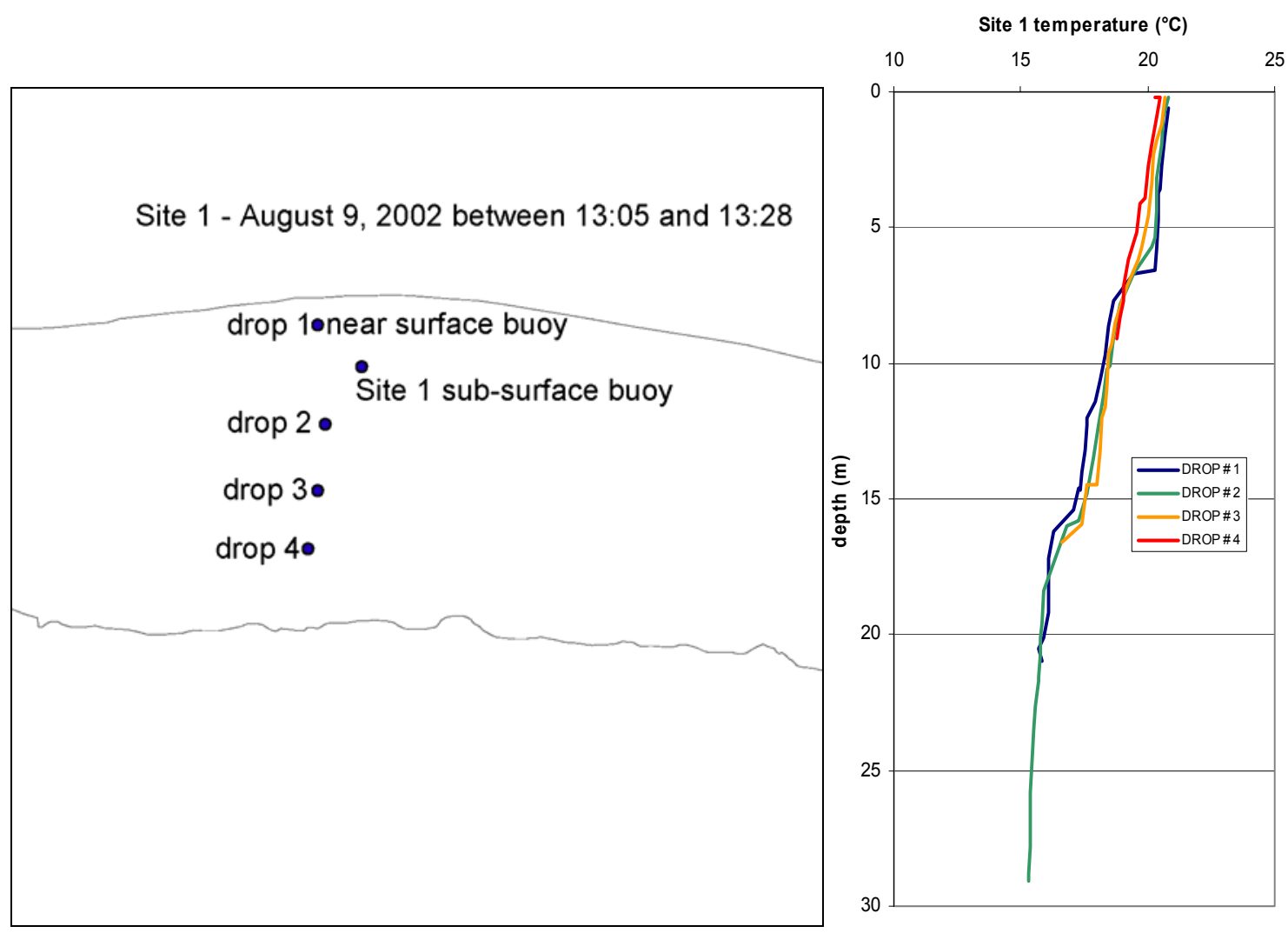

Figure 2.8. Site 1 CTD transects on August 9, 2002. Left indicates the location of the various CTD profiles, starting from the surface buoy. Temperature versus depth profiles shown at right.

\subsection{Water Velocity Measurements}

Water velocity measurements were performed during two multi-day periods between August 22 to 24 and September 4 to 6, 2002. During both collection periods, an RD Instruments acoustic Doppler current profiler (ADCP) was used.

In August, the $600-\mathrm{kHz}$ Broadband unit was set to record data at 1-meter increments throughout the water column. Each ADCP velocity measurement was composed of several individual acoustic pings averaged together. By averaging the pings, the ensemble error standard deviation was decreased, although it is assumed that during the sampling period the overall structure of the velocity field did not change. Twenty-two pings were used to produce an ensemble standard deviation of $1.5 \mathrm{~cm} / \mathrm{s}$ that took approximately 11 seconds to record.

In September, a 300-kHz Workhorse unit was used. Generally, the lower the frequency, the farther the ADCP can profile. However, lower frequency units produce measurements with larger per ping standard deviations, assuming equal bin size. To compensate, the bin size was increased to 1.5 meters and the number of pings was increased to 31. The ADCP consequently produced measurements with an ensemble standard deviation of $1.5 \mathrm{~cm} / \mathrm{s}$ that took approximately 11 seconds to record.

Both surveys collected data along 13 cross-sections (Figure 2.9). Cross-sections were selected to cover the major hydrodynamic phenomenon in the reservoir; however, the data were concentrated 
near the confluence zone. Data were collected at four discrete points along each cross-section. At each data collection, the following steps were followed:

- The boat was anchored to minimize drift.

- Horizontal position was gathered using a real-time differential GPS with sub-meter accuracy.

- Water velocity and GPS data were collected for at least 10 minutes at each point.

- A temperature profile was collected using the CTD.

- During the 10-minute period, the boat was maintained within 10 meters of the starting location.

ADCP data were processed to produce a vertical profile of velocity vector means and standard deviations at each point ( 4 points/cross-section $\times 13$ cross-sections $=52$ points $/$ survey). The horizontal datum for these data is WGS-84 (latitude/longitude). Processed data were corrected to true north by applying an offset of 16.8 degrees (USGS 2002). The vertical reference for the ADCP data is depth beneath the water surface. The mean total water column depth measured by the ADCP and the standard deviation of these measurements during the sampling period are reported.

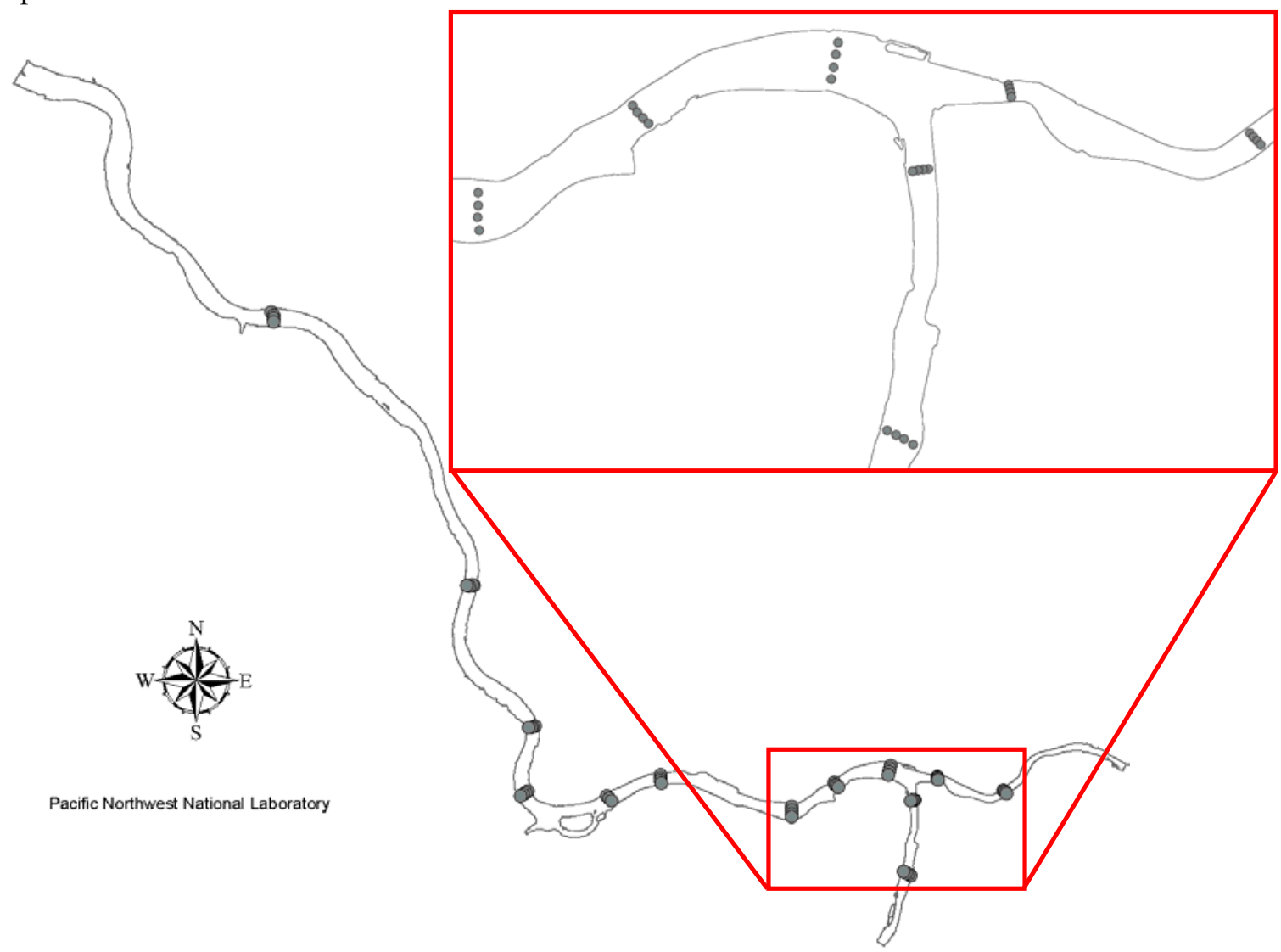

Figure 2.9. ADCP measurement locations in LGR during 2002.

\subsection{Longitudinal Water Surface Variations}

One key element in capturing the hydrodynamic and thermal variations in LGR was the correct observation of temporal and spatial variations in longitudinal water surface elevation. It was first 
observed that the longitudinal slope of the LGR pool between the confluence and the dam was small (less than 0.5 feet in elevation over 30+ miles in river length) at the end of June 2002 using the RTK GPS (Table 2.1).

Another key element for this project was to monitor the depth of the sub-surface buoys and to ensure that they were not being pushed lower into the water column due to drag forces exerted on them by the flow. Depths of the sub-surface buoys were monitored by attaching Sea Bird SBE39 loggers on the wire ropes near to where the buoys were attached. These loggers measured pressure at 10-minute intervals throughout the season and were placed at sites 2, 3, 4, 6, and 7. Boat traffic and/or vandalism led to the loss of pressure data at site 6 and site 7 after July 12 . Figures $2.10(\mathrm{a} \& \mathrm{~b})$ display time histories of water surface elevation at the different sites. These data were calculated by subtracting the mean of each time series recorded during the period from each instantaneous observation. During these periods flows through the reservoir changed dramatically; however, depth variations measured at the buoys mimicked the fluctuations observed at the dam, implying the buoys had sufficient positive buoyancy to counteract the downward force exerted by body drag as water flowed around the buoy.

(a)

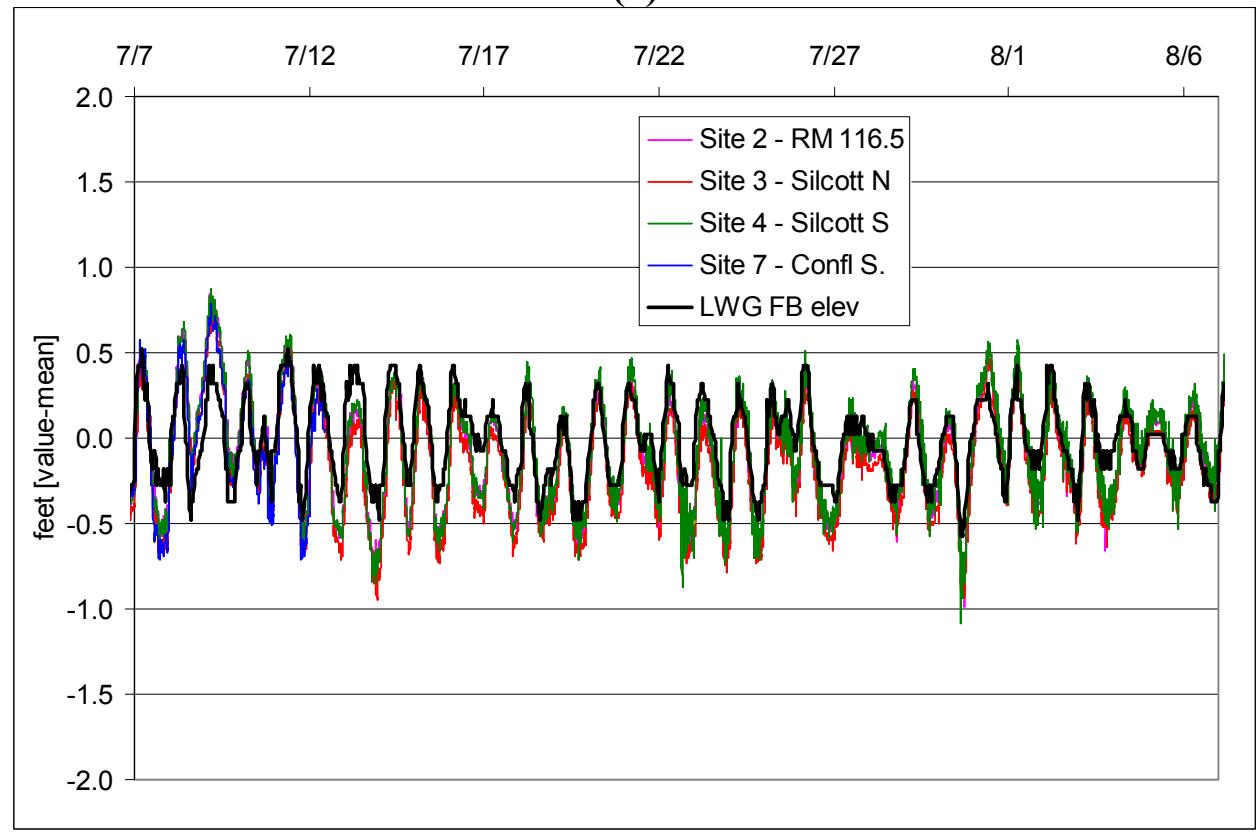


(b)

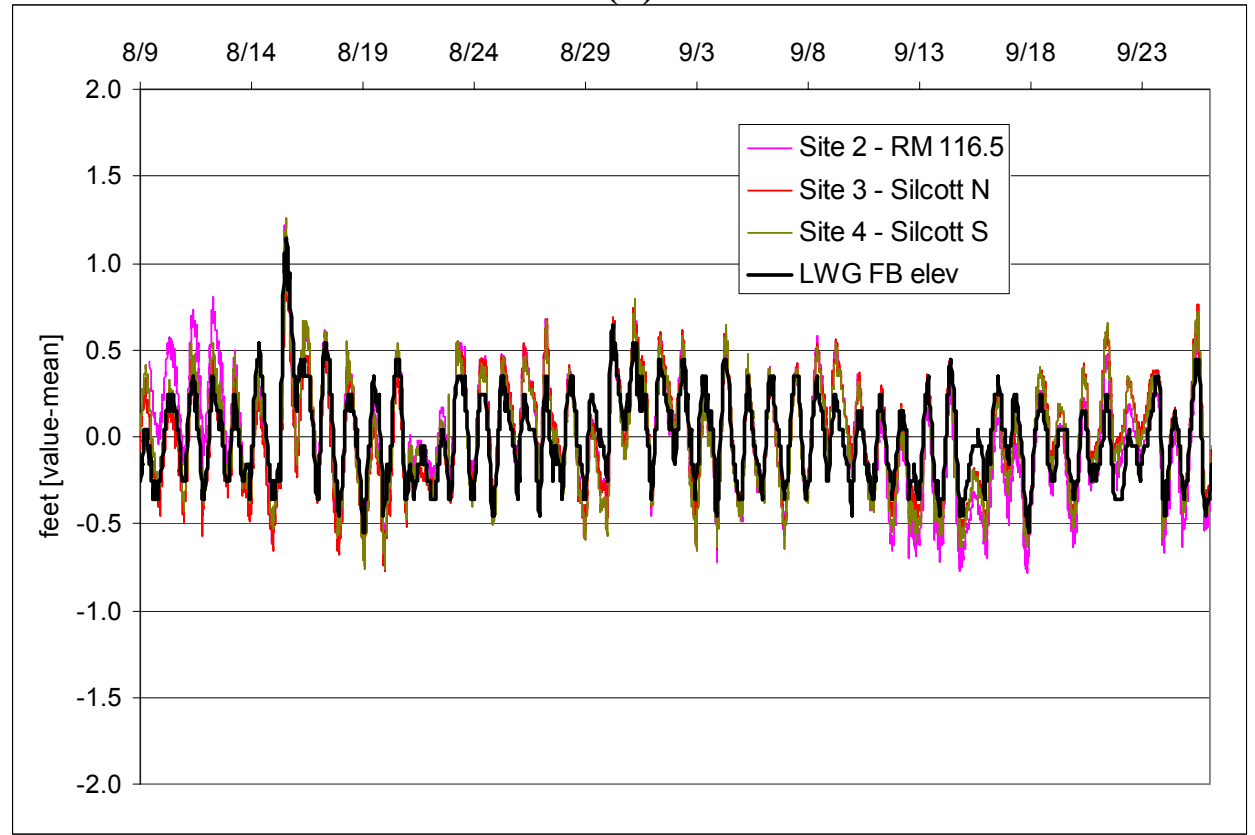

Figure 2.10 (a\&b). De-meaned time series of water surface variations. LWG FB represents forebay elevations measured at Lower Granite Dam and reported by the U.S. Army Corps of Engineers.

Variations of the water surface in LGR were noted to fluctuate through one cycle approximately every 24 hours. This strong diurnal cycle was noticeable throughout the entire sampling period. At site 5 (30 miles upstream from the dam), a pressure logger was attached to the bottom weight to check for a lag in the surface elevation period between the site and the stage recorder at the dam. Within the accuracy of the logger (recording every 10 minutes) and the stage recorder at the dam (reporting every 60 minutes), little difference in the surface elevation was observed (Figure 2.11). The magnitude of surface elevation appears to be larger at site 5 than at the dam; however, the corresponding mean absolute error (MAE) between the two sites is 0.33 feet, and the average error residual is -0.1 feet (close to the accuracy of the logger). This is in agreement with the RTK GPS measurements (Table 2.1) and indicates that the longitudinal elevation change of LGR was less than 0.5 feet during the late spring/summer period. 


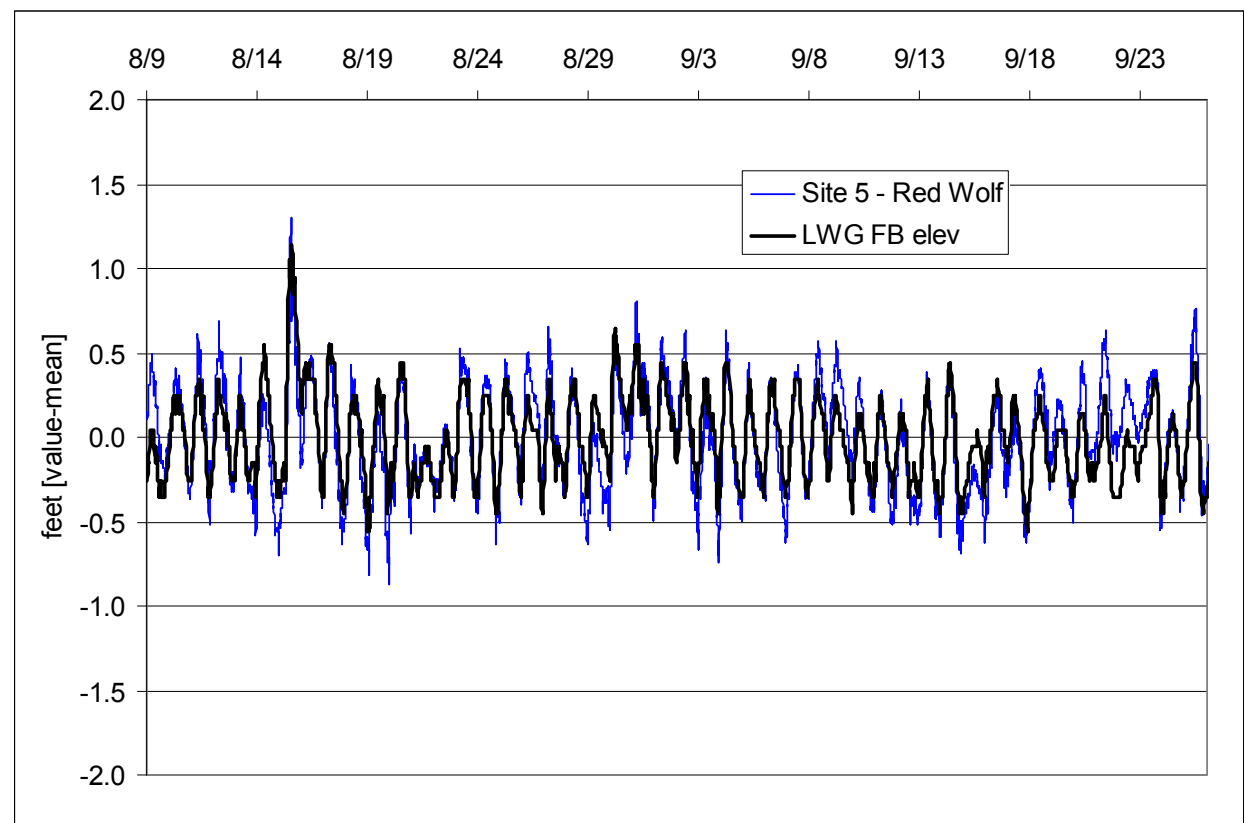

Figure 2.11. Variations in water surface elevation at site 5 and Lower Granite Dam. Time series values have been de-meaned.

\subsection{Meteorological Conditions}

Meteorological conditions for the area were measured at Silcott Island (Chief Timothy State Park). This station was installed and calibrated by AgriMet, U.S. Bureau of Reclamation, with funds from this project. The station is located at latitude $\mathrm{N}^{\circ} 6^{\circ} 25^{\prime} 07^{\prime}$ ' and longitude $\mathrm{W} 117^{\circ} 11^{\prime}$, $05^{\prime}$ and has been in continual operation since July 17, 2002. Wind speed and direction, air temperature, relative humidity (and derivatives), atmospheric pressure, solar radiation, and precipitation are recorded at 15-minute intervals. A full listing of the types of sensors used on the AgriMet station can be found at http://mac1.pn.usbr.gov/agrimet/aginfo/sensors.html.

Data from the station are uploaded to the AgriMet website at close to real time. In addition, historical time-series data at 15-minute intervals can be downloaded from the following website: http://mac1.pn.usbr.gov/agrimet/webagdayread.html. 



\subsection{Numerical Modeling of Lower Granite Reservoir}

The hydrodynamic and water quality parameters monitored in Section 2.0 were used to calibrate and verify a three dimensional (3-D) computational fluid dynamics (CFD) model of the reservoir. The objective of this modeling work was to expand upon work previously started at Pacific Northwest National Laboratory (PNNL) (Perkins et al. 2001) and understand the complex flow structure of the reservoir, particularly near the Snake and Clearwater River confluence zone.

\subsection{Description of the 3-D Numerical Model}

The Environmental Fluid Dynamic Code (EFDC) was used to simulate Lower Granite Reservoir (LGR). EFDC solves the unsteady equations of motion for water in three dimensions. It uses an orthogonal, curvilinear grid in the horizontal and a stretched, or $\sigma$, coordinate system in the vertical to include motion of the free-surface. EFDC can also solve the coupled unsteady transport equation for various constituents including salinity, dissolved oxygen, temperature, and sediment. Wetting and drying of cells can also be simulated. EFDC is able to account for variable fluid density brought on by variations of temperature and/or salinity, and, consequently, can simulate reservoir stratification. The equations of motion and solution scheme are simplified by making the hydrostatic pressure approximation. Turbulent flow conditions are simulated using the Mellor-Yamada level 2.5 closure scheme. The governing equations are numerically approximated using finite-difference techniques. A summary of EFDC is given by Jin et al. (2000) and a complete theoretical description is given by Hamrick (1992).

This particular CFD model was selected for several reasons. The model has been applied extensively to simulate flows in coastal, estuarine, and riverine environments. The model also has routines to simulate contaminant and sediment transport. Some recent examples of its use can be found in Ji et al.(2001), Moustafa and Hamrick (2000), and Jin et al. (2000). The EFDC model is written in Fortran 77 and can be compiled to run on operating systems such as Windows and Linux. All simulations were performed on computers running the Linux operating system.

\subsection{Computational Mesh}

The computational mesh is the domain over which the equations of fluid and scalar motion are solved. The configuration used to simulate LGR extends between Snake River miles 106.5 (Lower Granite Dam) to 141.8 (Southway Bridge, temperature logger string site 9) and approximately 2 miles up the Clearwater River to just downstream of temperature logger site 11 .

The mesh was developed based on shorelines digitized from U.S. Geological Survey (USGS) digital orthographic quarter quadrangles (DOQQs) photographed in July 1997. These shorelines were imported into Gridgen ${ }^{\circledR}$, a grid generation software from Pointwise Inc., and used as the lateral extent of the computational domain. A structured 2-D mesh was created with separate blocks for the Snake and Clearwater Rivers and around Silcott Island. The grid cells were arranged to maintain an aspect ratio at the upstream end near 1:1; however, the aspect ratio was allowed to grow to 1:4 near the downstream end of the reservoir. The average area of the computational cells was $6100 \mathrm{ft}^{2}$. Elevations for the mesh points were extracted from the GIS bathymetric surface (see Section 2.1.2) and the data reformatted for EFDC. The number of vertical layers was set to a uniform ten layers for these simulations. Figure 3.1 displays the computational mesh for the upstream extent of the model. Color contours displayed on the mesh 
represent the underlying bathymetric surface. Figure 3.2 displays similar information for the domain near Silcott Island.

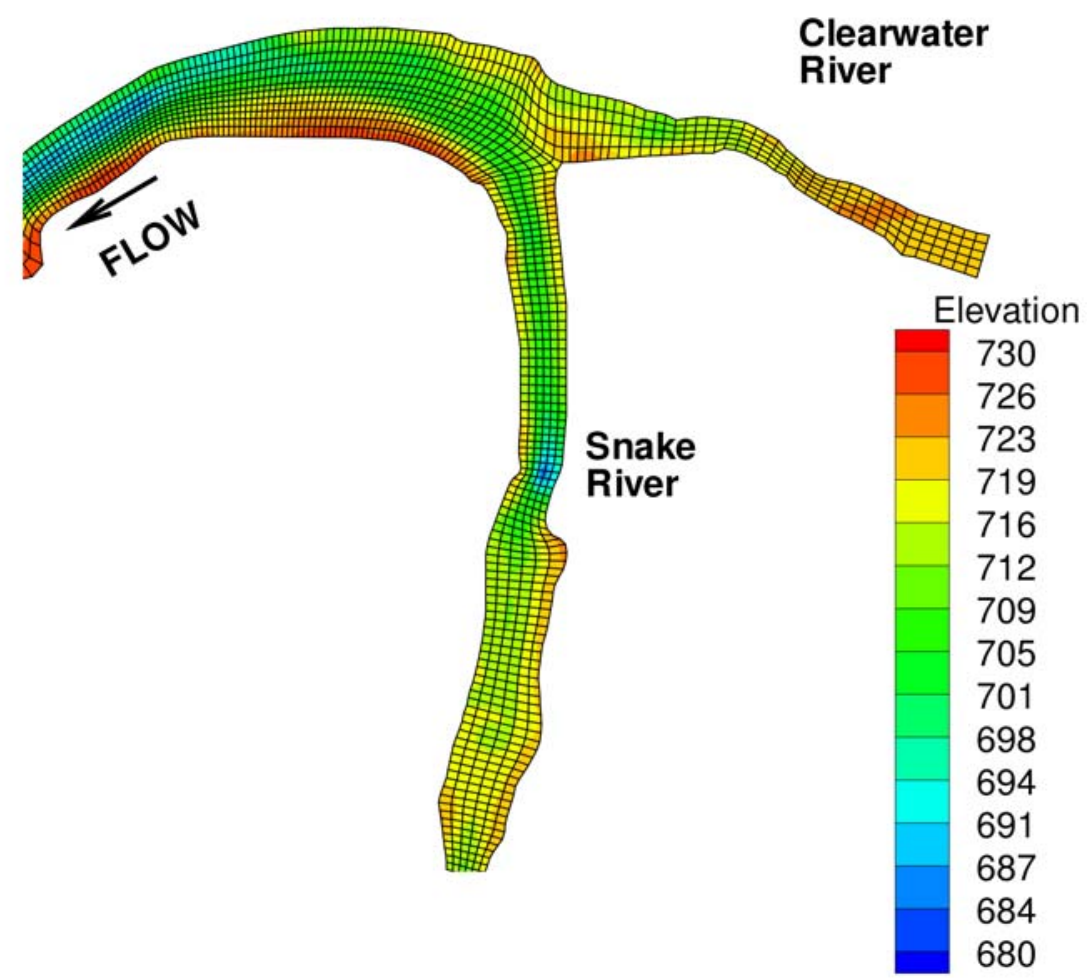

Figure 3.1. EFDC computational mesh near the Snake and Clearwater River confluence.

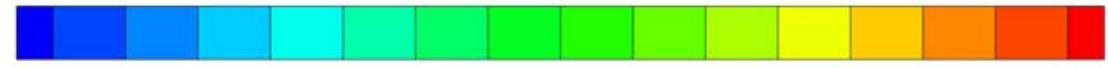

Elevation: 680684687691694698701705709712716719723726730

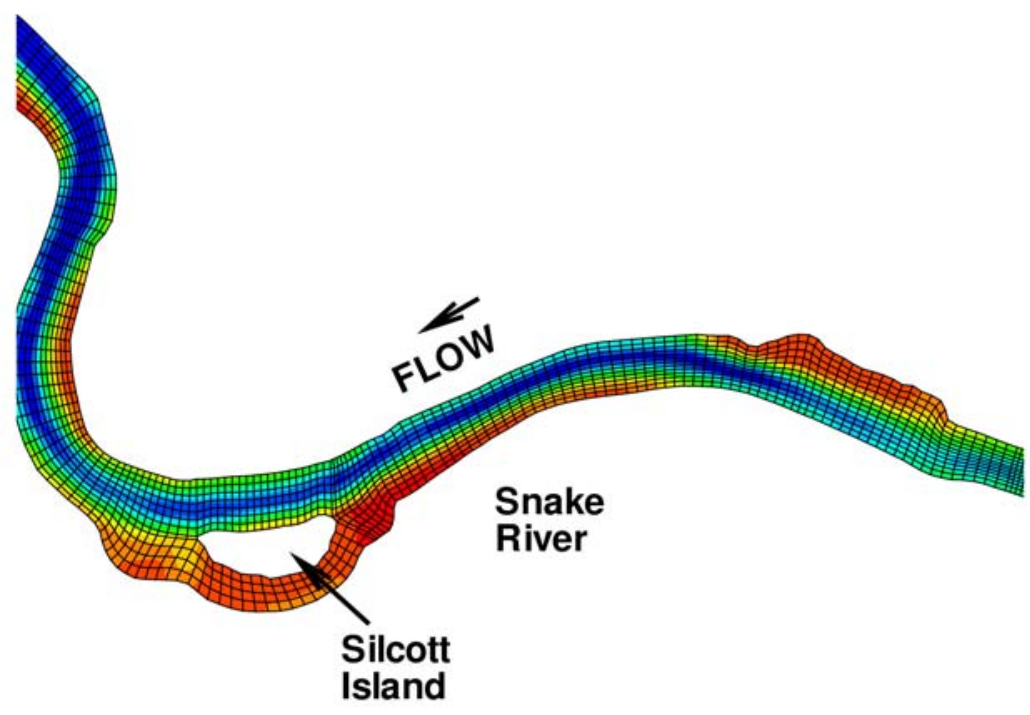

Figure 3.2. EFDC computational mesh near Silcott Island. 


\subsection{Boundary Conditions}

EFDC simulations of LGR were driven by specifying the quantity and temperature of the flow entering at the upstream boundaries, water surface elevation (stage) at the downstream end, and meteorological conditions at the water surface.

\subsubsection{Downstream and Meteorological Boundary Conditions}

At the downstream end of the model, a stage boundary condition was specified (Figure 3.3). Data for this boundary were provided by the U.S. Army Corps of Engineers (USACE 2003).

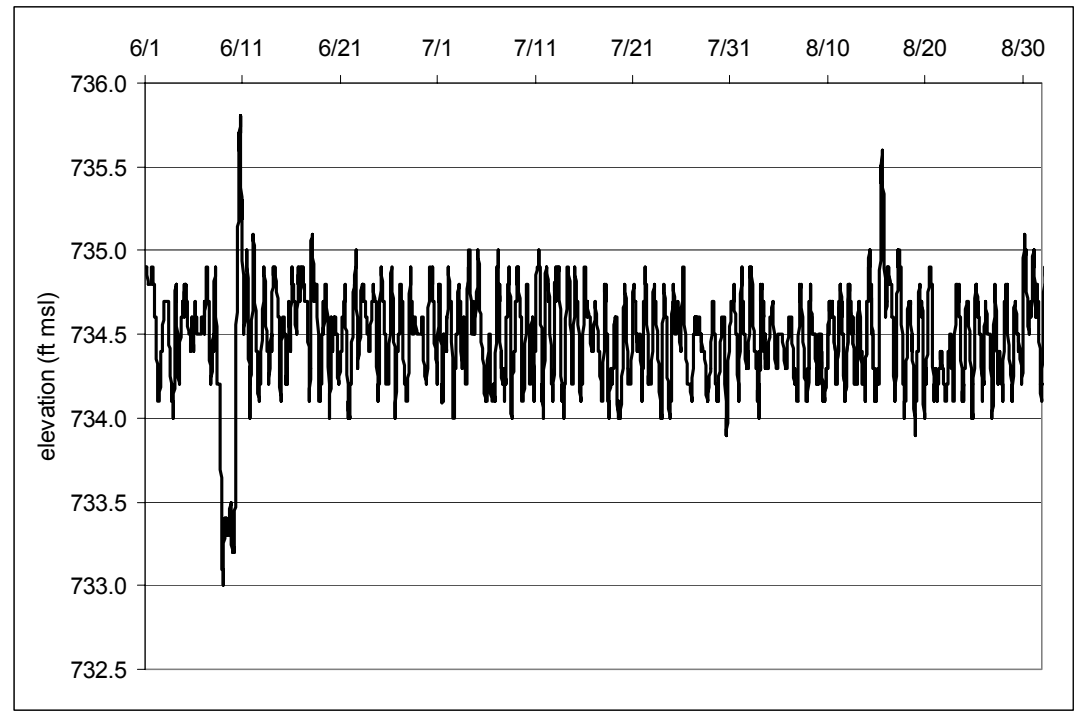

Figure 3.3. Forebay water surface elevation at Lower Granite Dam in 2002.

The simulation of thermal transport in LGR required the following parameters be specified as meteorological boundary conditions: wind speed and direction, atmospheric pressure, air temperature, relative humidity, incoming shortwave solar radiation, and cloudiness fraction (sky cover). These parameters were specified hourly in input files for the model; however, not all data originated from the same source. The majority of the data used during the simulation period were from the AgriMet Station installed on Silcott Island. All parameters necessary for the model were observed by this station except sky cover which was obtained from observations at Hanford, Washington. In addition, the station was installed on July 17, which is after the start of the simulation period. Simulated days before July 17 used meteorological boundary conditions derived from the Lewiston Airport.

\subsubsection{MASS1: Generation of Upstream EFDC Boundary Conditions}

The quantity of flow entering the domain was computed using the MASS1 (Modular Aquatic Simulation System 1-D) model to route water from upstream gaged locations. Inflow thermal boundary conditions for the Clearwater and Snake Rivers were assigned using field data collected at sites 9 and 11, or using MASS1 model output simulations during periods when field measurements were not available. 
MASS1 is a one-dimensional, unsteady hydrodynamic and water quality model for river systems. It was developed for use on branched (tree-like) channel systems and has been extensively applied by PNNL to the Columbia and Snake Rivers. The model simulates cross-sectional average values; only single values of water surface elevation, discharge, velocity, concentration, and temperature are computed at each point in the model and at each time interval.

MASS1 was configured and run as described in Perkins and Richmond (2001), except only the Lower Snake River was simulated rather than the entire Columbia River Basin. MASS1 boundary conditions for the LGR are summarized in Tables 3.1 and 3.2 and Figure 3.4.

Table 3.1. MASS1 flow and stage boundary conditions.

\begin{tabular}{|l|l|l|}
\hline \multicolumn{1}{|c|}{ Location } & USGS Gage & \multicolumn{1}{c|}{ Source } \\
\hline N. Frk Clearwater @ Dworshak & & Dworshak Operations data \\
\hline Clearwater River & 13340000 & USGS Clearwater River At Orofino, ID \\
\hline Snake River & 13334300 & USGS Snake River Nr Anatone, WA \\
\hline Lower Granite Forebay stage & & Lower Granite USACE data. \\
\hline
\end{tabular}

Table 3.2. MASS1 temperature boundary conditions.

\begin{tabular}{|l|l|l|}
\hline \multicolumn{1}{|c|}{ Location } & \multicolumn{1}{c|}{ Frequency } & \multicolumn{1}{c|}{ Data Source } \\
\hline North Fork Clearwater @ Dworshak & hourly & FMS DWQI \\
\hline Clearwater River & daily & USGS Gage 13340000 \\
\hline Snake River & hourly & USGS Gage 13334300 \\
\hline
\end{tabular}

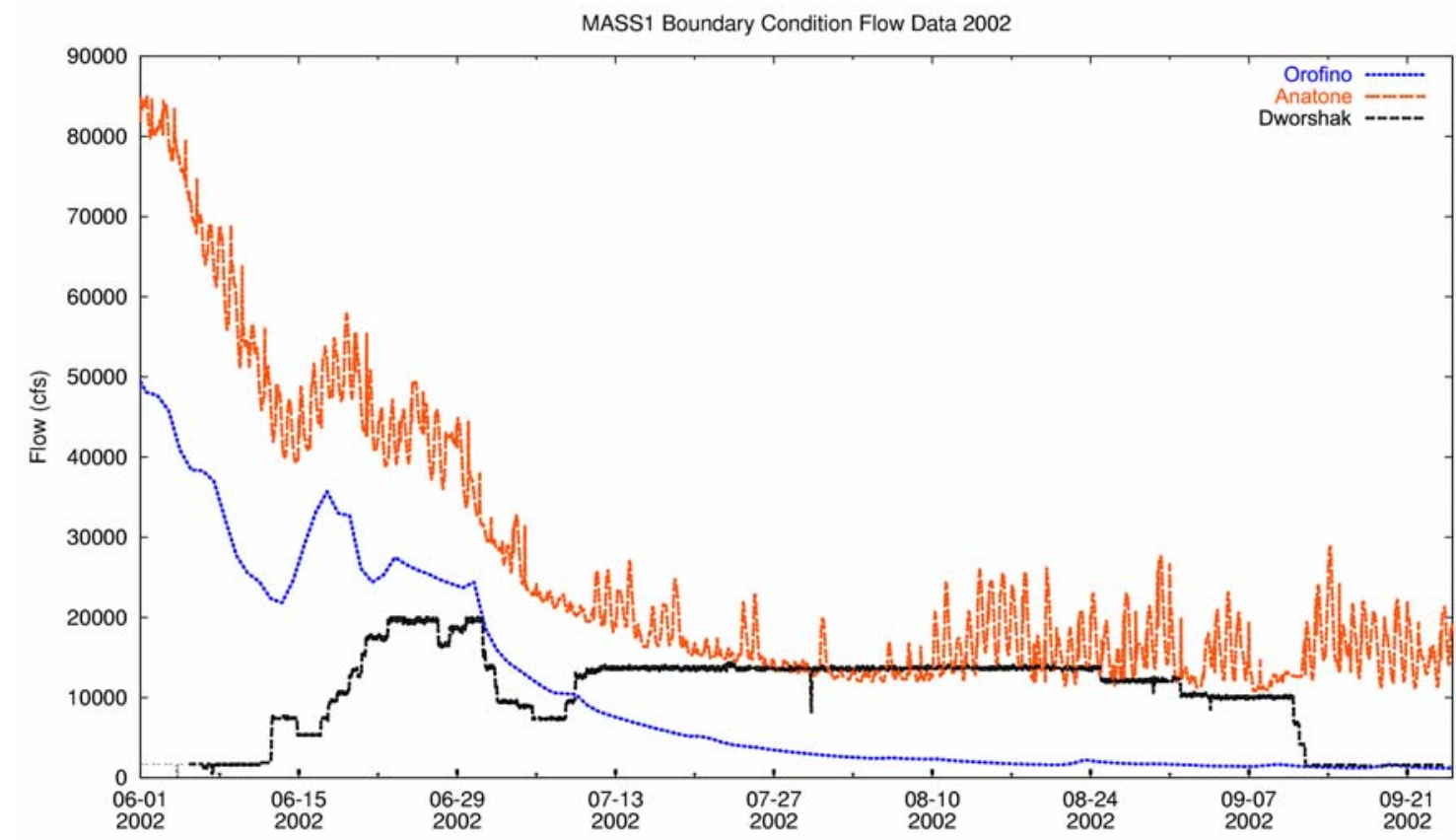

Figure 3.4. Inflows to the MASS1 model for the simulation period. Flows reported at Orofino and Dworshak combine together to produce the total flow in the Clearwater River at the Snake and Clearwater River confluence. The USGS gage near Anatone monitors the discharge of the Snake River upstream of the Snake and Clearwater River confluence. 


\subsection{Model Validation}

Model validation was performed for both the simulated hydrodynamics and thermal transport. The former used field-measured ADCP velocities for comparison; the latter used field-measured temperatures from the temperature loggers discussed in Section 2.2.

\subsubsection{Hydraulics}

As a part of model validation, simulations were run for the periods corresponding to the ADCP measurements discussed in Section 2.3. These simulations used MASS1 calculated inflows for the Snake and Clearwater Rivers and the observed Lower Granite forebay water surface elevation as the downstream boundary. It should also be noted that the quantity of discharge passing the dam varies dramatically throughout the course of a day (Figure 3.5).

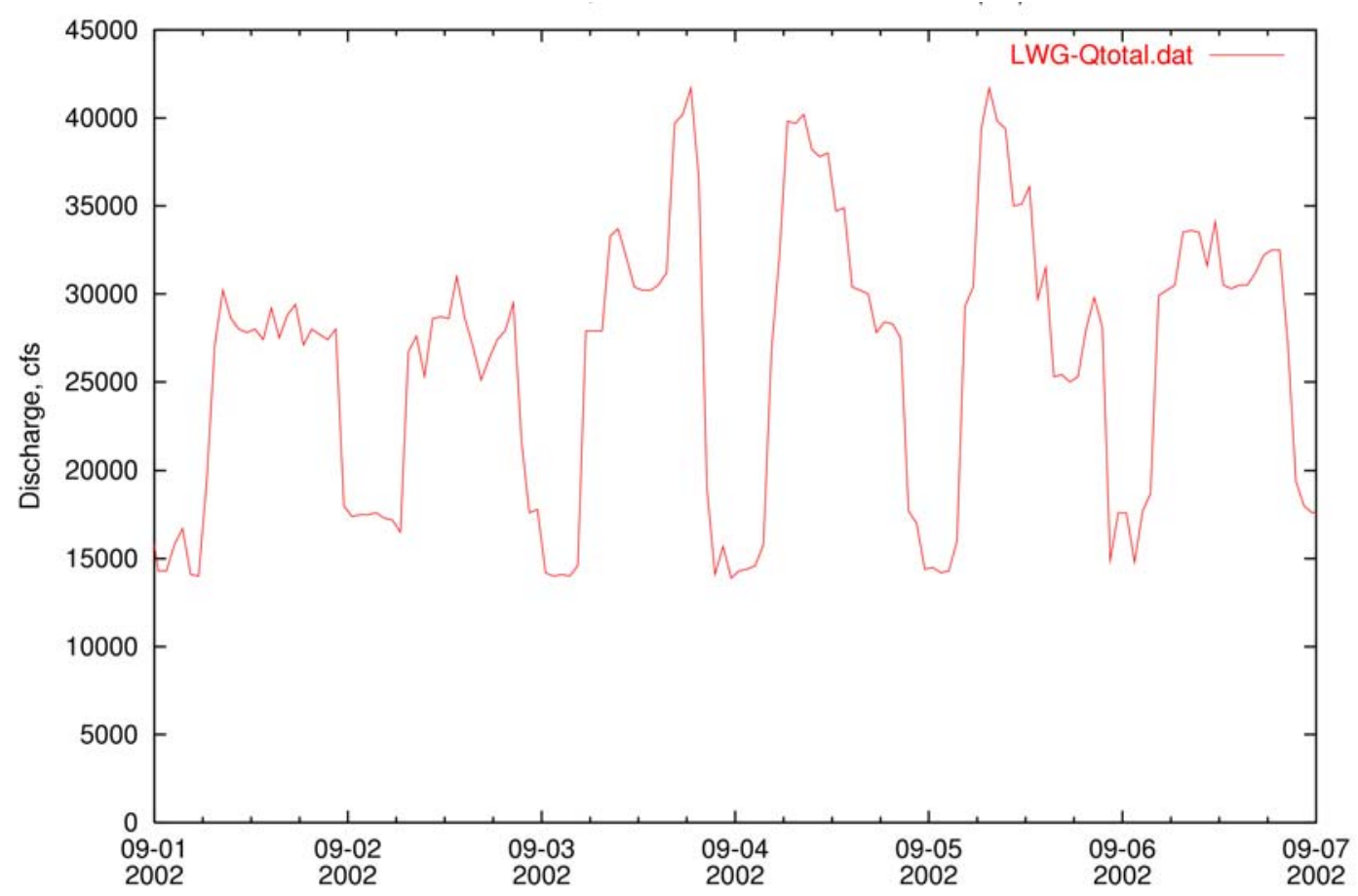

Figure 3.5. Total discharge passing Lower Granite Dam (cfs) during the first week of September 2002 .

The numerical model adequately represented the flow field at the locations where ADCP measurements were made. Table 3.3 displays summary statistics of differences between observed (ADCP) and simulated values. These statistics are defined as follows:

$$
\begin{aligned}
R M S & =\sqrt{\frac{1}{n} \sum_{n}^{1}\left(y_{i}-y_{\text {obs }}\right)^{2}} & \text { MSE } & =\frac{1}{n} \sum_{n}^{1}\left(y_{i}-y_{\text {obs }}\right)^{2} \\
M A E & =\frac{1}{n} \sum_{n}^{1}\left|y_{i}-y_{o b s}\right| & \text { bias } & =\frac{1}{n} \sum_{n}^{1}\left(y_{i}-y_{o b s}\right)
\end{aligned}
$$


where RMS is root mean square, MSE is mean square error, and MAE is mean absolute error. The numerical model simulated the ADCP-measured velocities collected during August. The field measurements were binned into 1-hour periods and compared to the closest hourly output from the numerical model. The numerical model results were interpolated onto the 3-D coordinate for each of the ADCP measurements. Figure 3.6 compares the simulated and measured velocities for each station and location, both for northing and easting velocity components and the velocity magnitude. As demonstrated by Figure 3.6, the overall agreement between the simulation results and the ADCP measurements is quite good. Summary statistics for these measurements are in Table 3.3.

Table 3.3. Summary statistics for August ADCP velocity measurements ( $\mathrm{ft} / \mathrm{second})$.

\begin{tabular}{|c|c|c|c|c|c|}
\cline { 2 - 6 } \multicolumn{1}{c|}{} & $\mathbf{R}^{\mathbf{2}}$ & avg. RMS & MSE & MAE & bias \\
\hline Easting velocity & 0.878 & 0.158 & 0.025 & 0.116 & -0.039 \\
\hline Northing velocity & 0.918 & 0.131 & 0.017 & 0.100 & 0.106 \\
\hline Velocity Magnitude & 0.707 & 0.187 & 0.035 & 0.149 & 0.087 \\
\hline
\end{tabular}

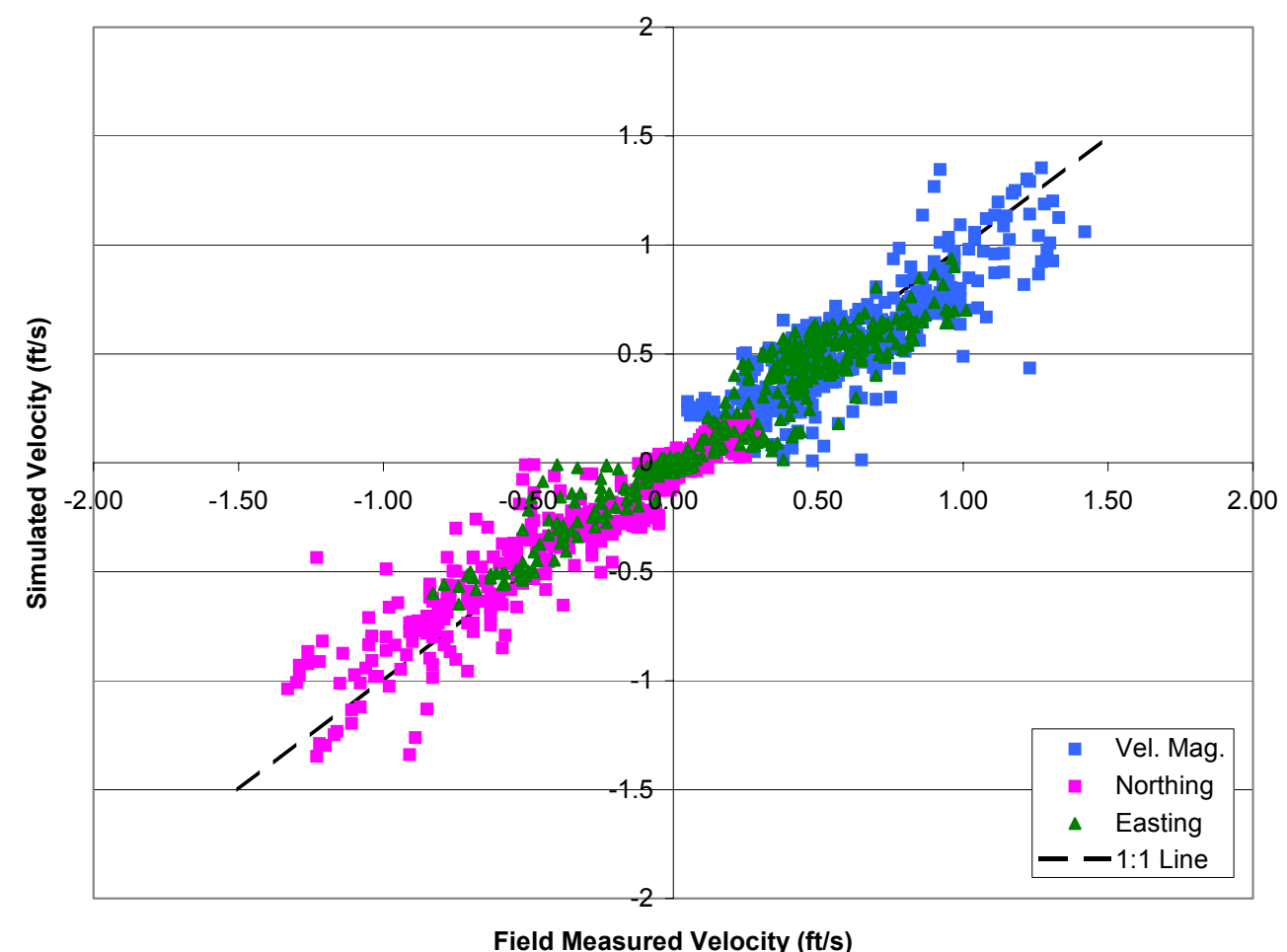

Figure 3.6. Comparison of field-measured and simulated velocities in ft/second for August 2002 .

\subsubsection{Temperature}

EFDC allows the output of time-series data at specified grid locations in the numerical model. Temperature logger locations (Figure 2.5) were determined relative to the EFDC grid, and simulation results for temperature were saved at those locations. Results for a 3-day period are shown in Figures 3.7 through 3.9. Results are limited to a short duration to show the daily 
variation simulated by the numerical model. Comparisons are shown with the field-measured data on the top, simulation results in the middle, and a contour difference plot on the bottom.

Simulation results for temperatures above the confluence of the Snake and Clearwater were very similar to those measured by the temperature loggers (Figure 3.7). Initial results indicated that the upstream location of the Clearwater boundary (about one mile upstream) was too close to the confluence and needed to be moved further upstream. This was required because field observations showed that later in the summer there was some movement of warmer water from the Snake River into the mouth of Clearwater River. With the original Clearwater inflow boundary so close to the confluence, these types of flows could not be simulated. After moving the Clearwater inflow boundary upstream and nearer to site 11, the flow and temperature results for this location were improved; the warm water intrusion into the Clearwater were simulated. As shown in Figure 3.7, all simulation results for this improved model above the confluence were within $\pm 1^{\circ} \mathrm{C}$. The locations shown in Figure 3.7 are at least a mile below the inflow boundaries.

Further downstream, near RM 125, and upstream of Silcott Island, the simulation results were mostly within $\pm 1^{\circ} \mathrm{C}$ (Figure 3.8), although the simulation results were not as stratified as those measured by the loggers. The numerical model appears to have captured the general increase in reservoir temperature and the timing of that increase.

The region immediately downstream of the confluence is the area most difficult to simulate numerically because of the convergence of flows from different directions. The effects of buoyancy driven flows are also strongest in this region; resulting in complex three-dimensional motions. Model results for sites 4 and 5, downstream of the confluence, are compared to logger data in Figure 3.9. Site 4,on the south bank upstream of Silcott Island, is more strongly stratified than its nearby thalweg counterpart, site 3, but similar to site 5 (on the north pier of Red Wolf Bridge) in stratification. At sites 4 and 5, the numerical model captured the overall temperature trends and their timing, including the cooler water in the lower portions of the reservoir at Site 5. As seen at sites 2 through 5, stratification computed by the model was weaker, although the timing of temperature pulses adequately was captured numerically.

Although the numerical results were acceptable in the confluence area and downstream to site 1, there are some numerical model artifacts near the downstream boundary at Lower Granite Dam that require further investigation. These appear to be related to how the model calculates water density at the downstream boundary. This issue is currently being investigated and improvements will be included in future work. 

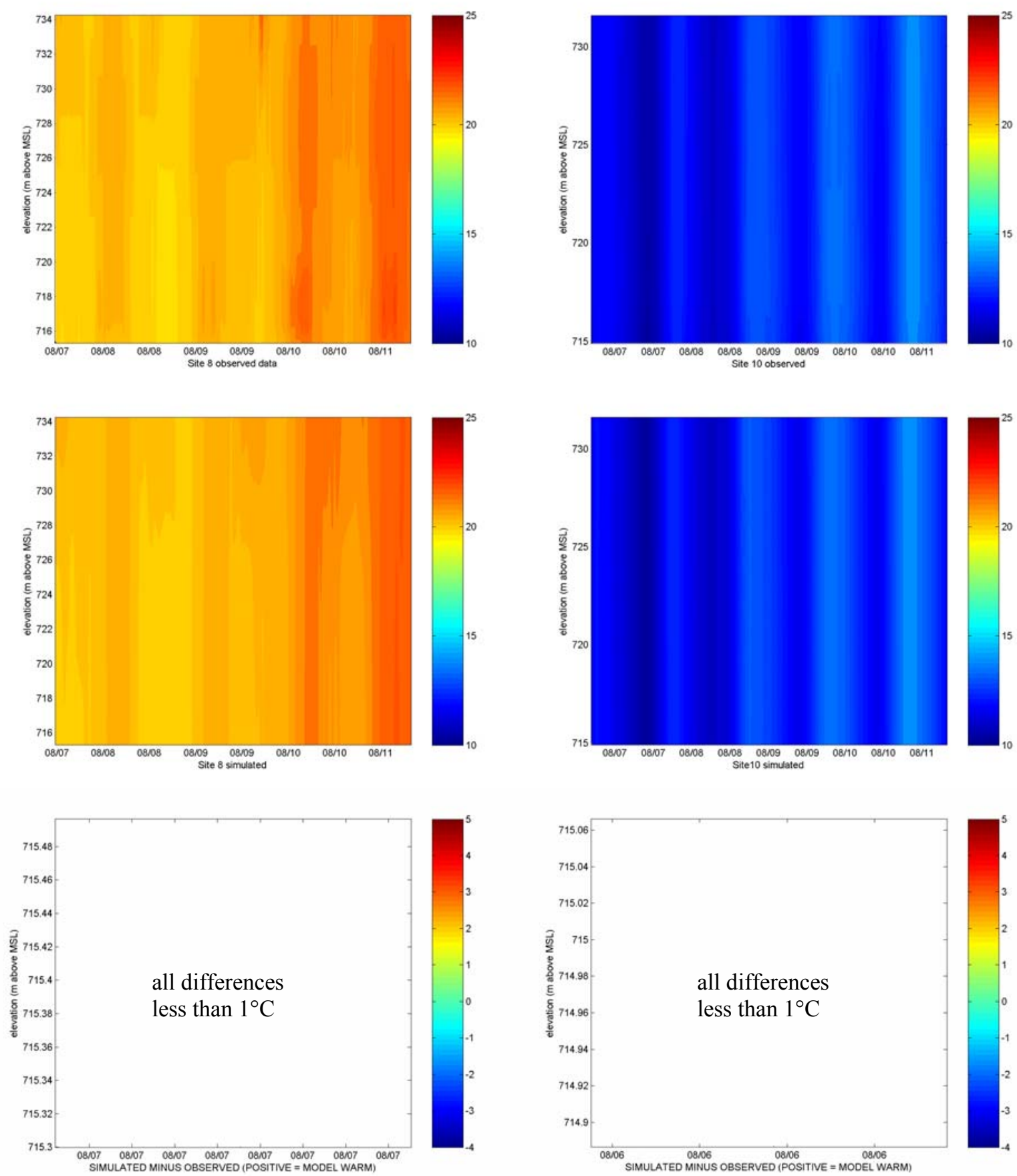

Figure 3.7. Comparison of observed and simulated thermal data upstream of the Snake and Clearwater River confluence. Site 8 (left) is on the Snake River; site 10 (right) is on the Clearwater. 

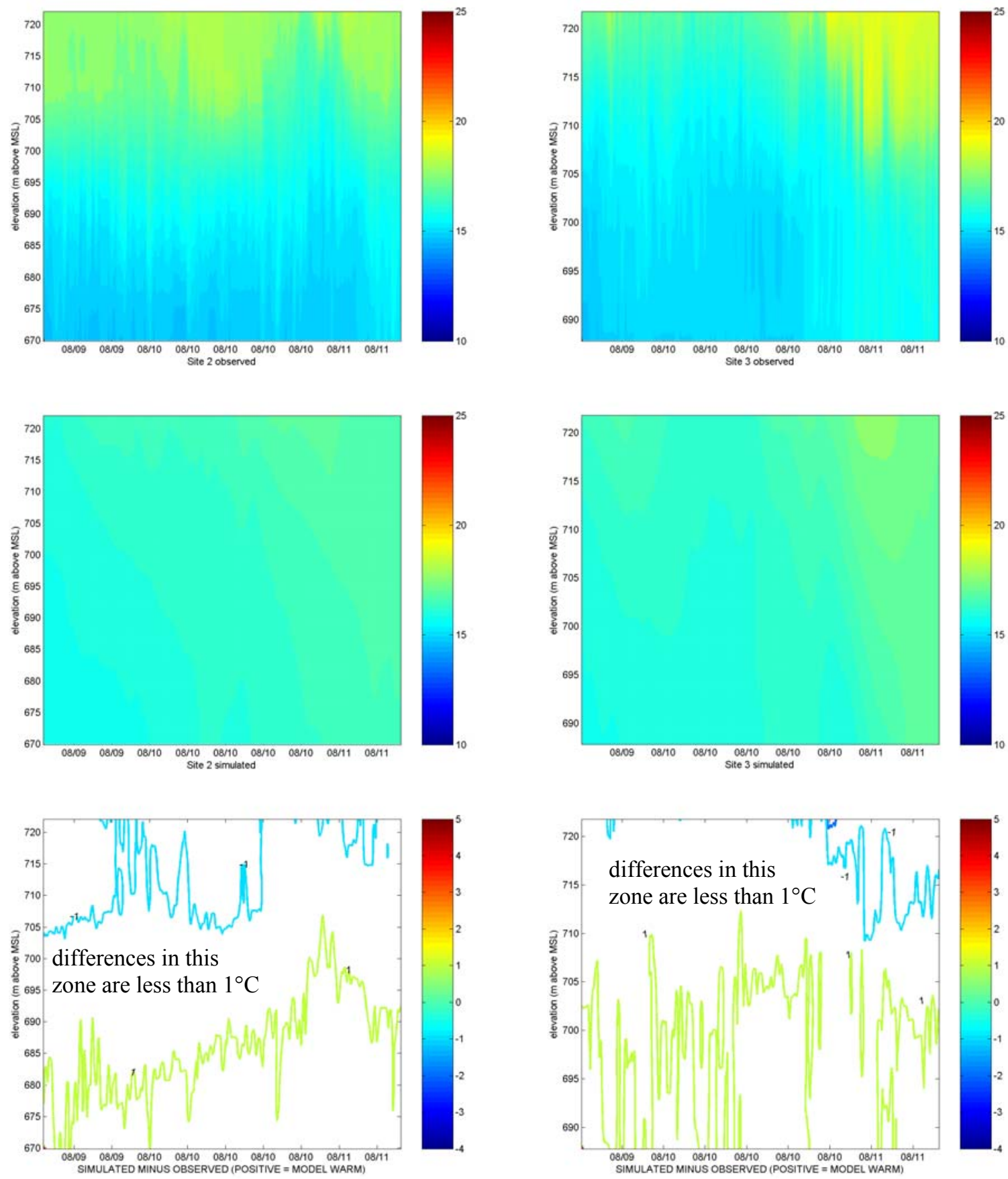

Figure 3.8. Comparison of logger and simulation data well downstream of the confluence. Site 2 (left) is located in the thalweg near RM 125 and Site 3 (right) is slightly upstream of Silcott Island and in the thalweg. 

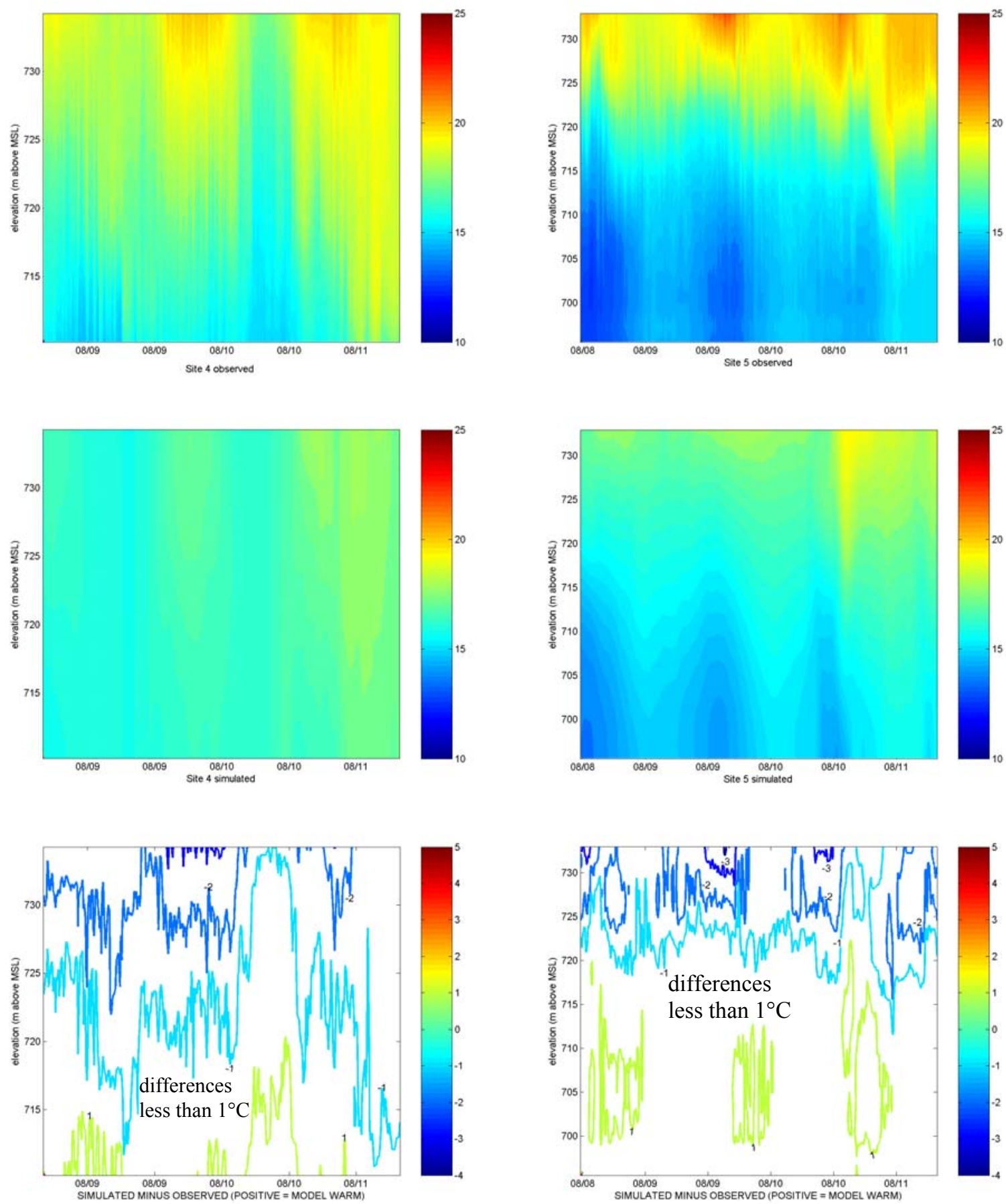

Figure 3.9. Comparison of logger and simulation data downstream of the confluence. Site 4 (left) is located upstream of Silcott Island on the south bank and Site 5 (right) is on the north pier of Red Wolf Bridge. 


\subsection{Velocity and Thermal Structure of Lower Granite Reservoir}

\subsection{Observed Stratification Cycle}

Lower Granite Reservoir (LGR) has the potential to stratify vertically, depending on inflows from the Clearwater and Snake Rivers. Releases from deep depths within Dworshak Reservoir can produce temperatures during the spring and summer months that are significantly below the equilibrium temperature of the river. Understanding and managing these cold water resources is one of the drivers for this project.

To better characterize the current structure of the reservoir, the vertical structure was broken into two modes: weak to no stratification and strong stratification. The differences in water current and thermal structure between these two modes are dramatic, especially in the confluence zone.

\subsection{Weak to No Stratification Circulation}

Figure 3.4 displays the releases from Dworshak Reservoir during the late spring and summer months of 2002. Releases from the dam increased dramatically near the middle of June and continued through the middle of September. These cold waters cause stratification to develop in the reservoir below.

Before the middle of June, water temperature data are limited (thermistors were deployed towards the end of June); however, a limited amount of data is available from two loggers that were put in place at sites 8 (U.S.-12 Bridge, Snake River) and 10 (Railroad trestle, Clearwater River) for several days at the beginning of April (Cook et al. 2002). As Figure 4.1 shows, temperature differences at the beginning of April between the two rivers were approximately $1^{\circ}$ to $2^{\circ} \mathrm{C}$. A Multi-spectral Thermal Imager (MTI) satellite image of the confluence zone during this period illustrates the lack of mixing between the two rivers (Figure 4.2). The two rivers meet at the confluence and then flow parallel to each other downstream. This pattern is expected during periods of weak stratification when the two rivers have approximately the same discharge. Under these conditions, horizontal momentum forces overcome the weaker buoyancy forces that cause the Clearwater River to subduct under the Snake River at other times of the year.

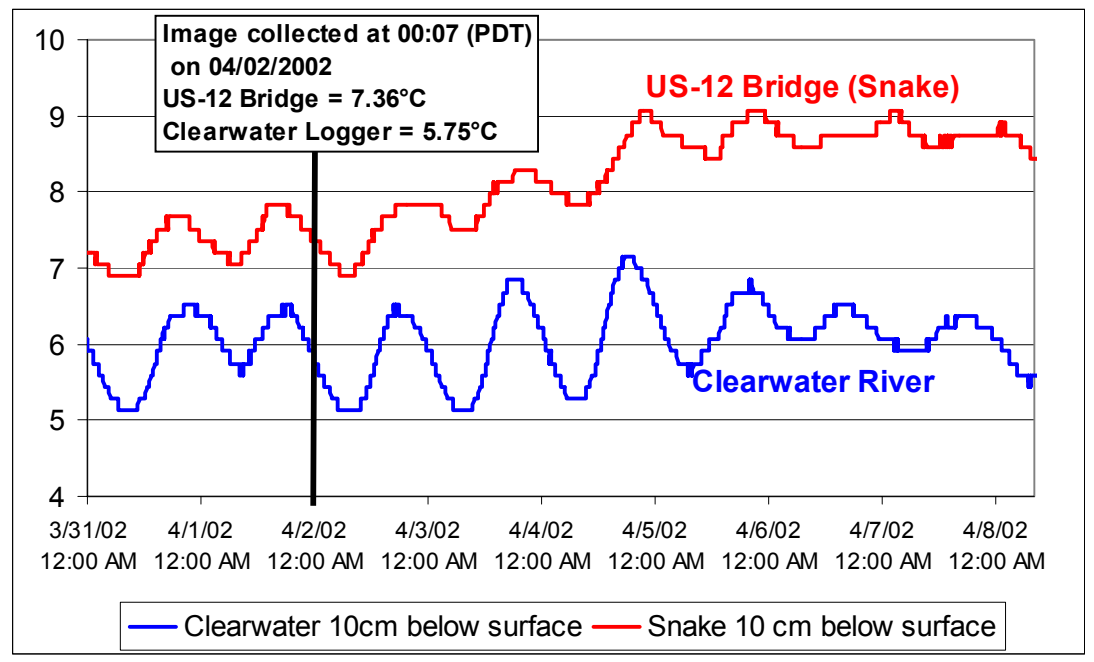

Figure 4.1. Water temperature data in degrees Celsius from the Snake and Clearwater Rivers. 


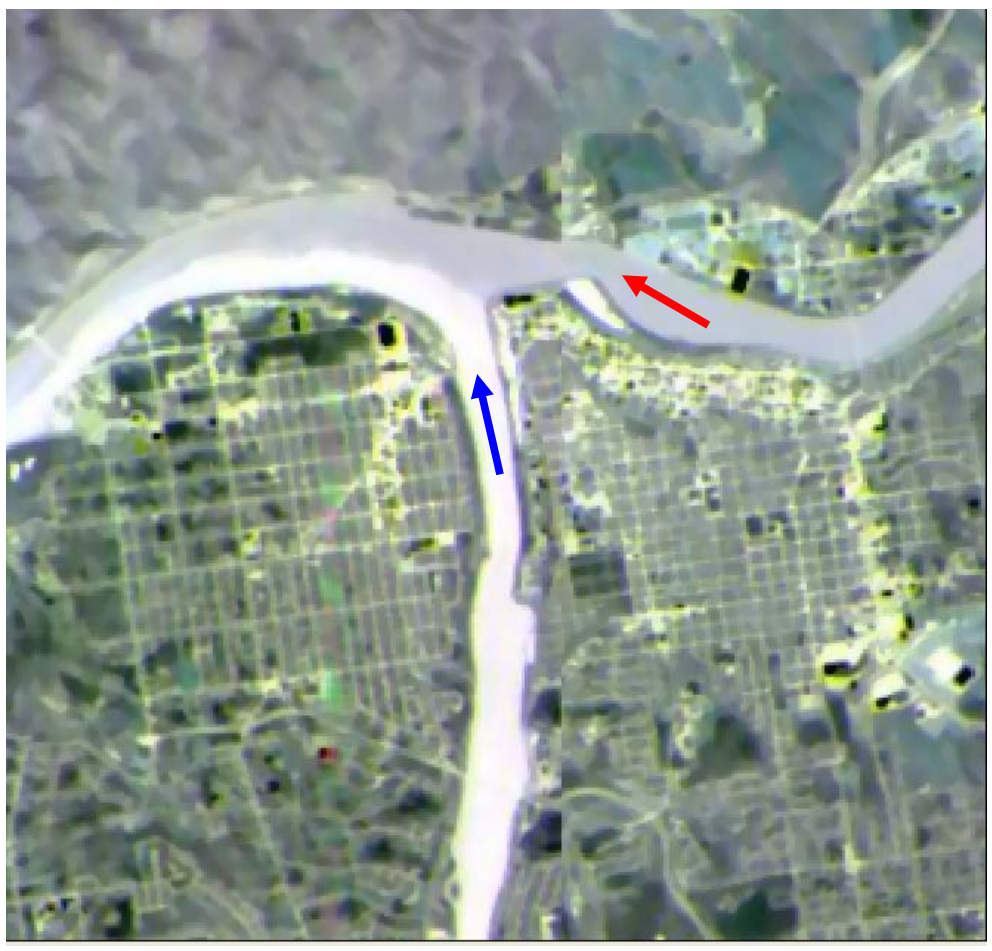

Figure 4.2. Infrared satellite image taken at midnight, April 4, 2002, of the confluence zone. The red arrow indicates the direction of flow for the Clearwater River, while the blue arrow indicates the direction of flow for the Snake River.

\subsection{Strong Stratification Circulation}

Large vertical differences in temperature were observed throughout the reservoir downstream of the confluence (see Appendix A) between logger deployment (June 25 to 27) and the end of September. Observed temperature differences between epilimnetic (upper water column, above the thermocline) and hypolimnetic (lower water column, below the thermocline) waters peaked in July 2002. The strength of stratification varied from site to site; however, differences in excess of $10^{\circ} \mathrm{C}$ were observed.

Large differences in temperature, and hence, large difference in density, causes the Clearwater River flow to plunge beneath the Snake River flow at the confluence. Additional study is required to understand the hydrodynamic characteristics of the plunge zone, including the temperature/discharge ratio at which this phenomenon occurs, turbulent mixing parameters, and the extent of cold intrusion up the Snake arm (see below). These phenomenon will all be studied in greater detail during 2003.

Currently, the plunge point for the Clearwater River is known to be a sharp line at the surface. Figure 4.3 displays a color contour plot of temperature taken on July 21. During the same time, SBE39 temperature loggers were floated at the surface and observed water temperatures within 3 centimeters of the surface (Figure 4.4). As the loggers and satellite image show, $23^{\circ} \mathrm{C}$ water is observed at the surface of the Snake both upstream and downstream of the confluence zone. The Clearwater River was approximately $10^{\circ} \mathrm{C}$ cooler, and abruptly plunges beneath the Snake River. Downstream of the confluence and through the bend downstream, surface water temperatures 
remain constant in the satellite image, indicating stratification of the river. This can be confirmed by examining temperature logger data at sites 1 through 7 .

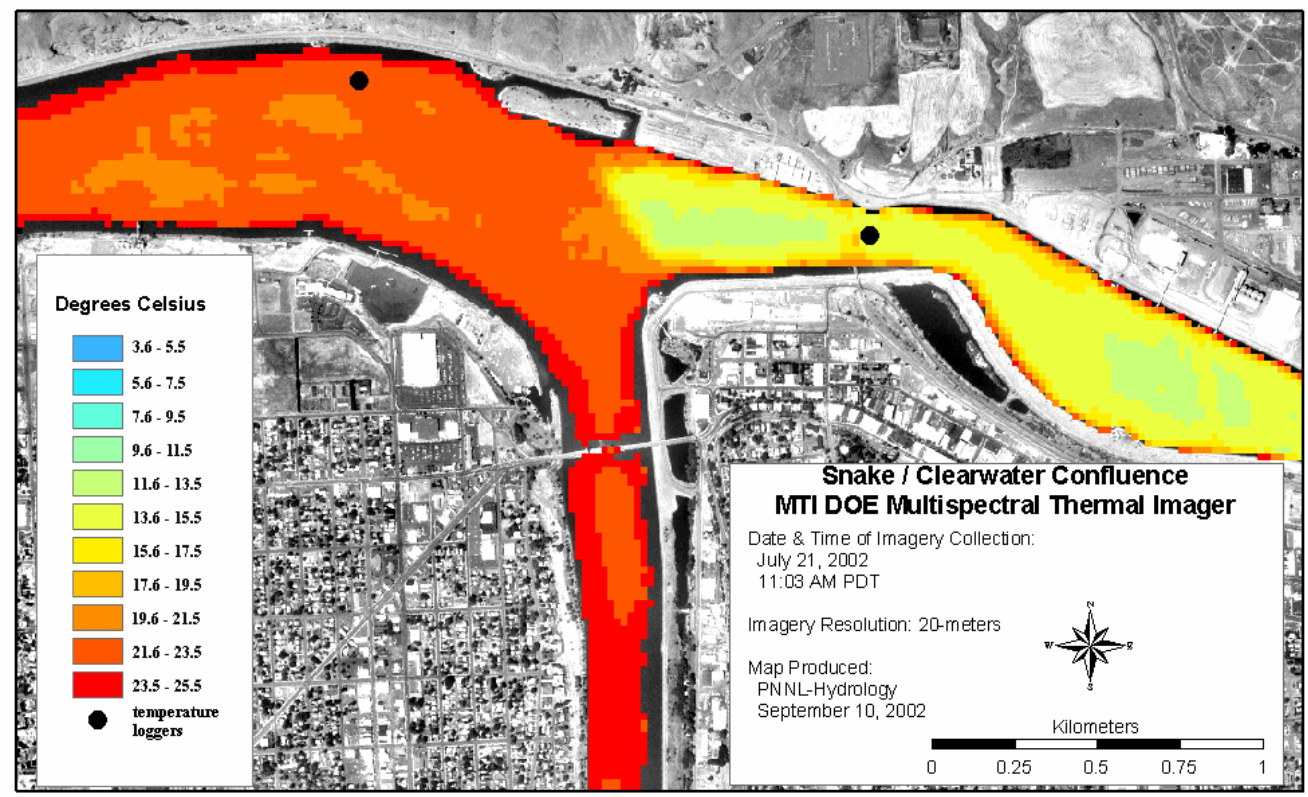

Figure 4.3. MTI satellite derived surface water temperatures on July 21, 2002 at 11 a.m.

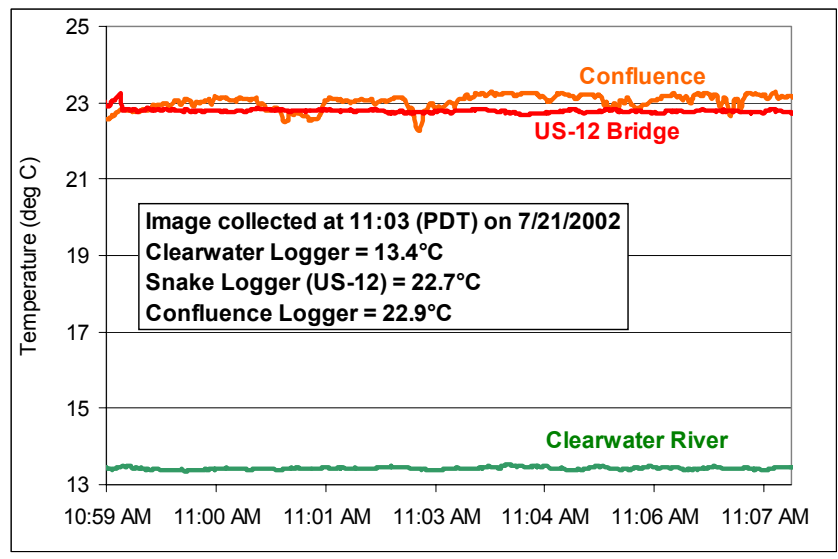

Figure 4.4. Temperature loggers data (SBE39) within the top 3 centimeters on July 21, 2002.

The figures above describe the surface thermal distribution when the Clearwater River plunges beneath the Snake. Beneath the surface, the hydrodynamic phenomenon becomes more complicated. Cold Clearwater River flow, driven by gravity and density differences, has the potential to migrate upstream along the bottom of the Snake River. The extent of this cold water intrusion depends on density and momentum (discharge) differences between the two rivers. This phenomenon was observed in the field by both temperature loggers placed at site 8 (see Appendix A, Summer). The phenomenon was mapped out between 17:30 and 18:30 on August 7 by performing nine vertical profiles using the CTD probe (Figure 4.5). The probe was used when large temperature differences were present, and discharges in both rivers were approximately equal. To give context to the CTD profile data, isosurfaces of temperature were created between the vertical profiles. These isosurfaces were extended horizontally until they intersected the bathymetric surface, the results of which are shown in Figure 4.6. 


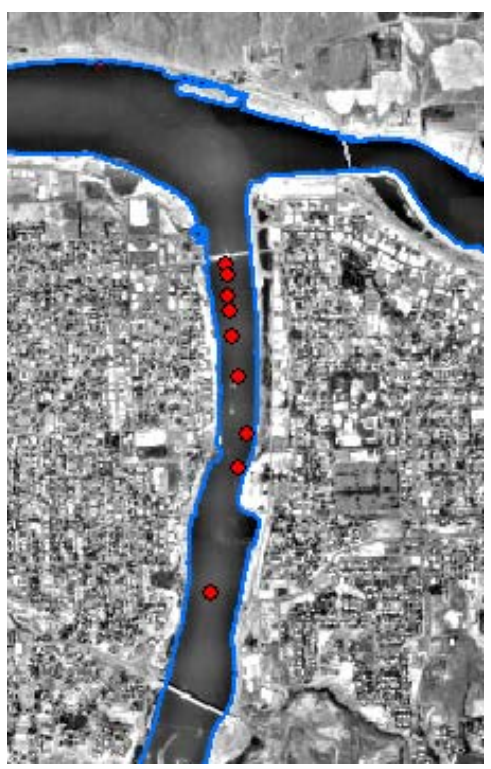

Figure 4.5. Cold water intrusion map. Nine vertical profiles were measured using the CTD probe at the red circles shown above.

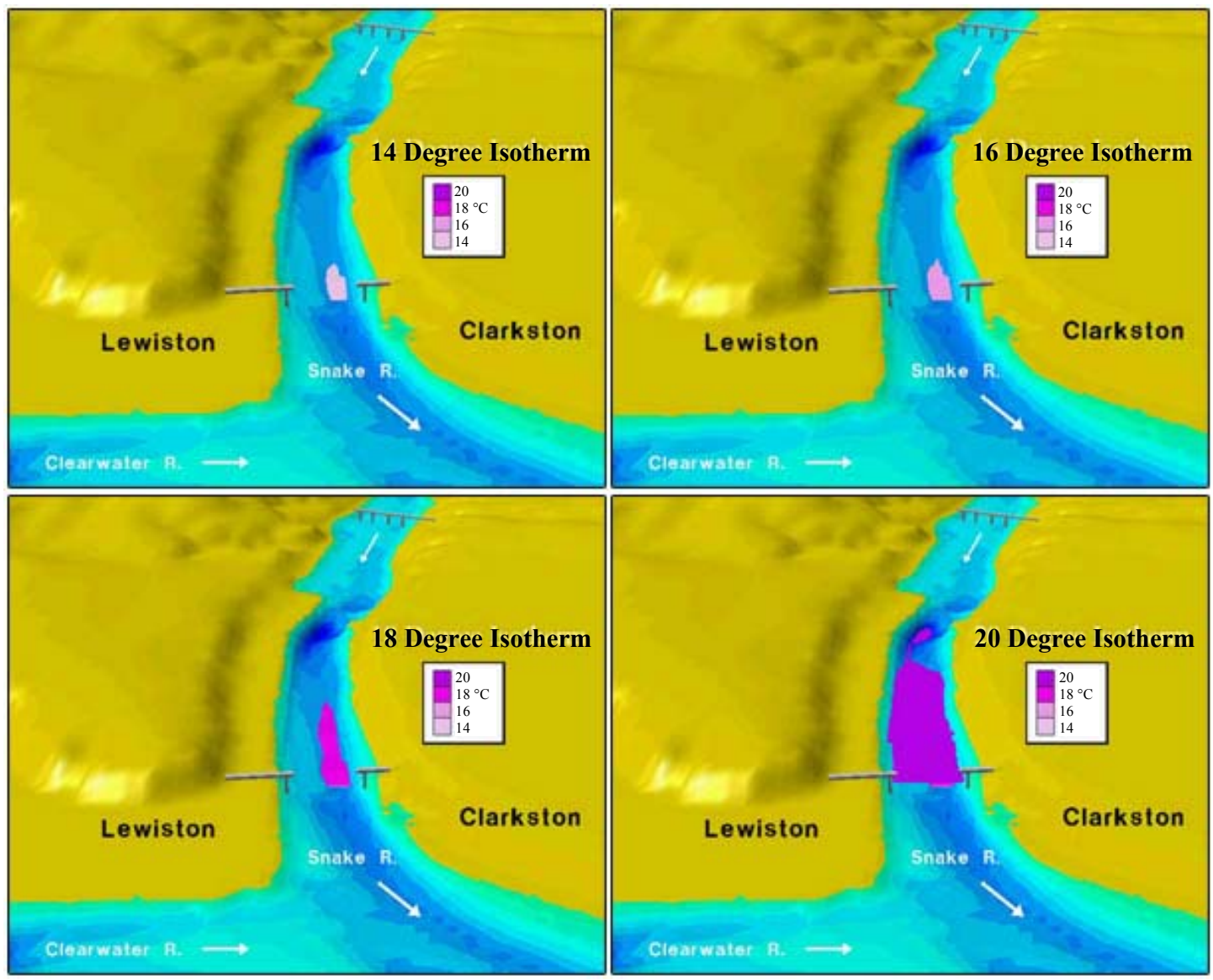

Figure 4.6. Isosurfaces, which were created between the vertical profiles, were extended horizontally until they intersected the bathymetric surface. 


\subsection{Lateral Thermal Gradients}

During much of the summer 2002, temperature differences between the Clearwater and Snake Rivers were larger than $10^{\circ} \mathrm{C}$. Discharges in both of the rivers were approximately equal to each other during the period (Figure 3.4). Note that flows reported at Orofino and Dworshak combine together to produce the total flow in the Clearwater River at the Snake and Clearwater River confluence. Given the roughly equal quantities of momentum in both rivers, a dynamic mixing environment was set up at the confluence zone, especially with the added complexity of the diurnal pumping caused by flow oscillations in the upper Snake River. Although dynamic seiching of isotherms that occurs within close proximity to the confluence is still being studied, consistently large thermal lateral gradients were observed downstream of the confluence.

Time series of temperature gathered laterally across the river, 2 miles downstream of the confluence (Red Wolf Bridge), illustrates this phenomenon. The north time series is site 5, while data from the south site originate from Ken Tiffan of the U.S. Geological Survey (USGS) (Figure 4.7). Black lines across each temperature contour plot signify the depth at which the Onset temperature loggers were placed. Also, please note that the vertical and temporal scales between the two figures are not equal. Vertical lines and arrows have been placed on the figure to help illustrate temporal and vertical overlap between the two time series.

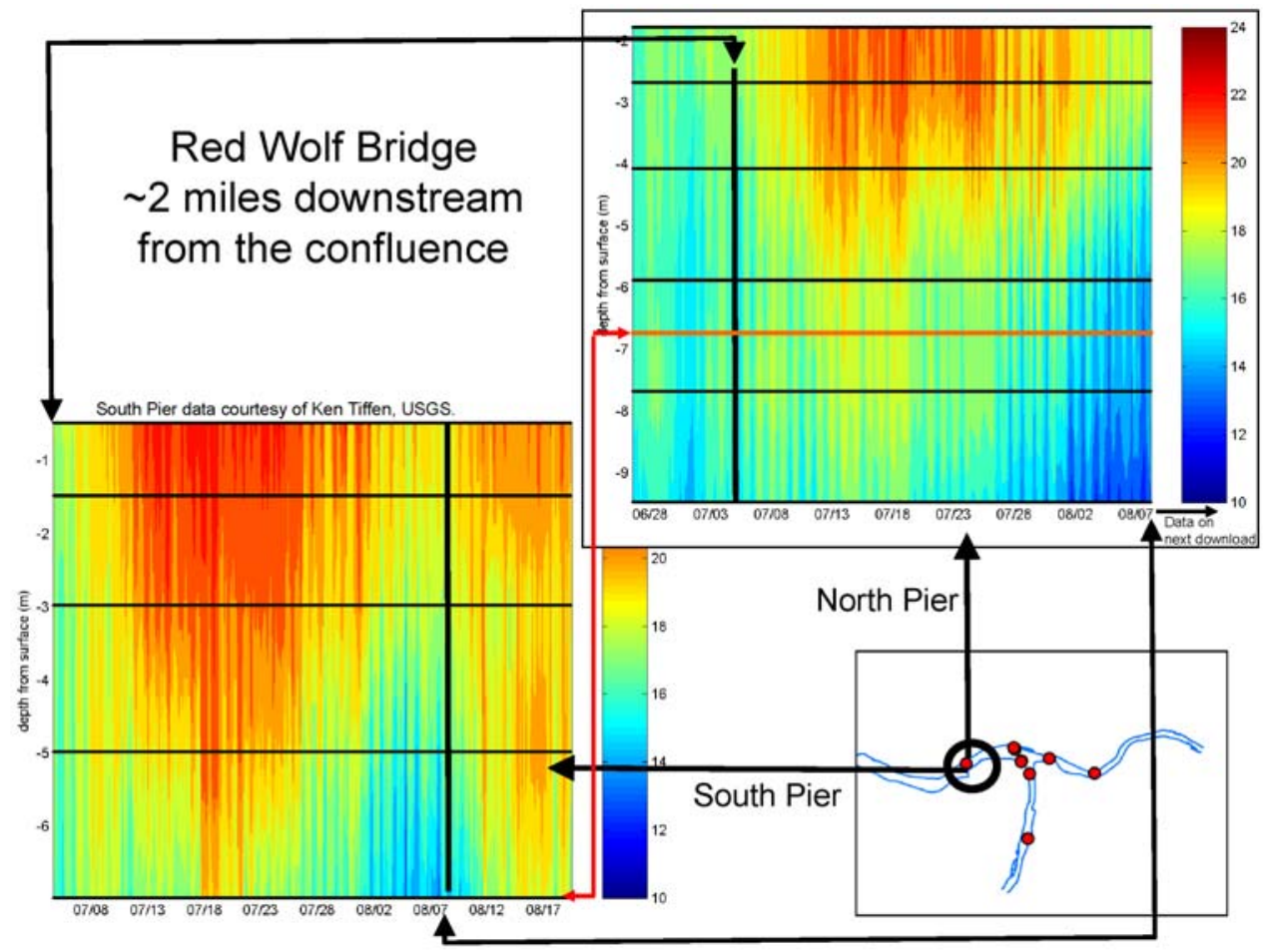

Figure 4.7. Depth versus time contour plots of lateral temperatures at Red Wolf Bridge.

The overlapping vertical and temporal domains between the two time series were then interpolated to a common grid. The north grid was then subtracted from the south grid to produce a contour map of lateral thermal differences (Figure 4.8 (a)). Positive values indicate the north side of the river was warmer than the south. Although the contour plot is noisy, a distinct trend is observed through time. Differences are noted to be both positive and negative, ranging between $\pm 3^{\circ} \mathrm{C}$. To better understand the temporal variations, the temperature data was depth averaged to produce the time history plot shown in Figure 4.8 (b). Depth-averaged differences range between 
+1 and $-2^{\circ} \mathrm{C}$. This time series contains both high and low frequency (period $>1$ day) oscillations. These oscillations will be further studied during the next field season.
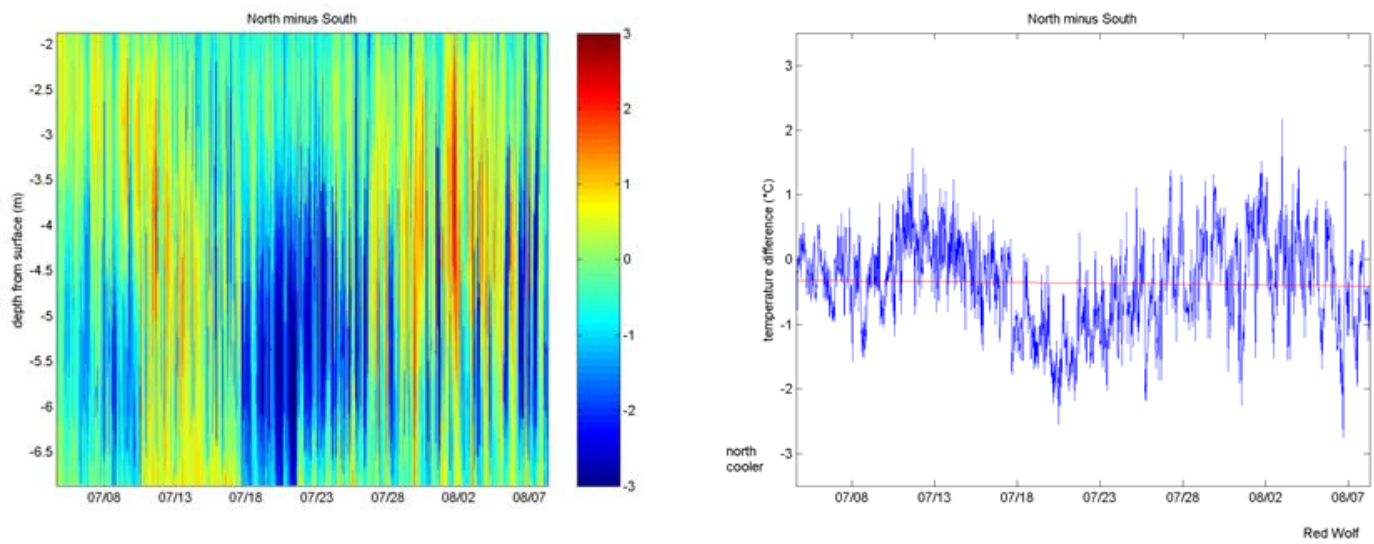

Figure 4.8 $(\mathbf{a} \& \mathbf{b})$. Time series of the difference is temperature between the north and south pier loggers at Red Wolf Bridge. The graphic on the right is a depth-average.

Approximately 7.5 miles downstream of the confluence, lateral variations in temperature were observed at sites 3 and 4 (upstream of Silcott Island). A similar procedure was applied to these sites, and time series of temperature data collect at these sites can be found in Appendix A. A contour plot of temperature differences is shown in Figure 4.9 (a). Temperature differences through most of the season are quite small, except for some high frequency oscillations deep in the water column.
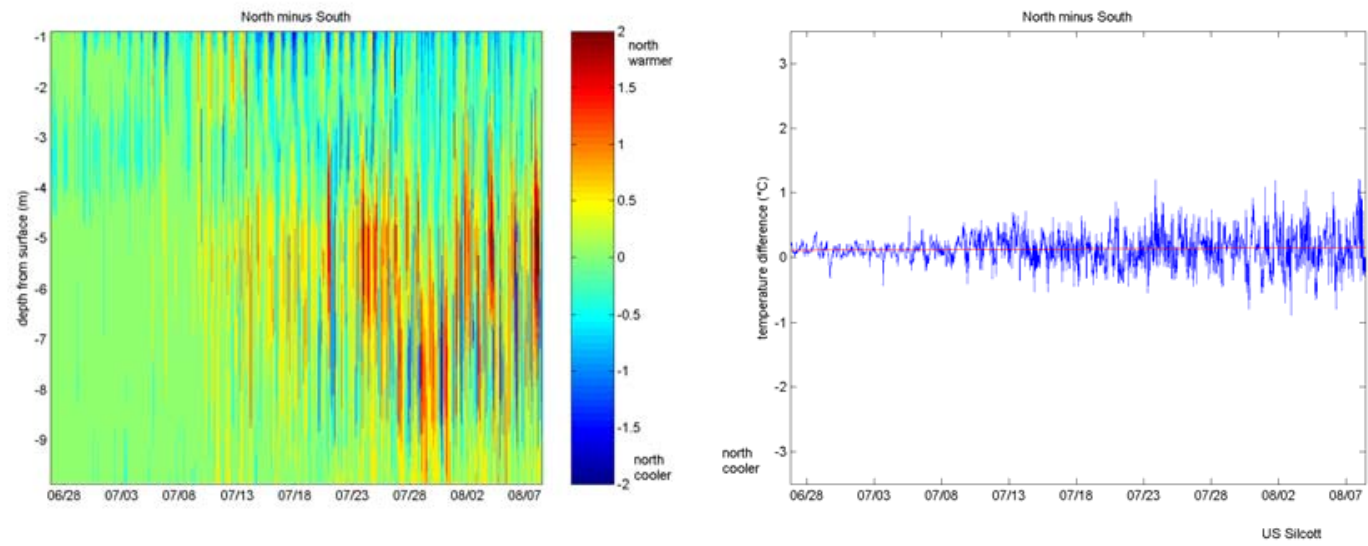

Figure 4.9 (a\&b). Times series of the difference in temperature between the north and south pier upstream of Silcott Island. The graphic on the right is a depth-average.

Depth averaging of these lateral differences produced the time series of data shown in Figure 4.9 (b). Although the calculated differences become larger as the season progresses, the differences fluctuates around zero, indicating only weak and highly transient lateral temperature differences.

Lateral differences in temperature downstream of Silcott Island were monitored by collecting lateral profile transects using the CTD probe (Figure 2.8). These profiles transects were preformed both in bends and straight sections of the river. Although strong vertical stratification was observed during most of the sampling period, negligible lateral differences were observed downstream of Silcott Island. It is therefore concluded that although strong lateral gradients in temperature exist at and downstream of the confluence, lateral gradients downstream of Silcott Island could be assumed negligible during the 2002 sampling season. 


\subsection{Numerical Modeling of Three Lower Snake Reservoirs}

A two-dimensional (2-D), laterally-averaged hydrodynamic and water quality model was applied to reservoirs upstream of Little Goose (LGS), Lower Monumental (LMN), and Ice Harbor (IHR) dams. Although several numerical models were previously applied to these reservoirs (Richmond et al. 2000; Perkins and Richmond 2001), CE-QUAL-W2 was selected for use in this project for several reasons including a) software is open source and freely available, b) the model has been favorably applied to similar reservoirs by a large number of users, and c) the software is well documented (Cole and Wells 2002). This model was also selected for use by the RPA143 working group and meets the requirements set out by Action Item 143 of Federal Columbia River Power System (FCRPS) 2000.

\subsection{Description of the 2-D Numerical Model}

CE-QUAL-W2 is a general, 2-D, longitudinal/vertical, hydrodynamic, and water quality numerical model. The model assumes complete lateral homogeneity and is therefore best suited for water bodies with negligible lateral gradients. Version 3.1 of the model implements numerous improvements over earlier versions. It is available through consultation with the principal investigator for Version 3.1, Mr. Thomas Cole, Waterways Experiment Station, U.S. Army Corps of Engineers, or through a website set up for users of the model (http://www.ce.pdx.edu/w2/index.html).

The model solves the conservative form of the Navier-Stokes equations, and the hydrostatic pressure assumption has been applied to simplify the vertical momentum equation. Turbulence terms have been approximated using an eddy viscosity approach, although several methods have been implemented. The Boussinesq approximation was also been applied, so the fluid is always assumed incompressible. Complete details on the numerical schemes, various water quality options, and turbulence options can be found in the model documentation (Cole and Wells 2002). The model documentation also references more than 25 peer-reviewed publications that are used or associated with CE-QUAL-W2.

\subsection{Construction of the Numerical Grid}

As with the three dimensional (3-D) model, a numerical grid was developed to approximate the river's bathymetry. A large dataset of bathymetric data was previously obtained for use in the MASS1 river model (see Section 3.4 and Richmond et al.2000). Available outputs from MASS1 are the geometric properties (depth, width, wetted perimeter, hydraulic radius, etc.) at each crosssection. This information was then used to construct the CE-QUAL-W2 grid, which was developed as a uniform Cartesian grid with longitudinal segment lengths of 804.6 meters $(0.5$ miles) and vertical layers 1.0 meter thick. This resulted in the following grid sizes for the three reservoirs: LGS had 77 segments and 49 layers, LMN had 60 segments and 45 layers, and IHR had 67 segments and 41 layers. The orientation of each segment was determined with respect to true north and the Manning's n for each reservoir was uniformly set at 0.028 .

Geometric data used to describe each reservoir were checked by comparing the elevation versus volume ratios computed by CE-QUAL-W2 to those reported in the U.S. Army Corps of Engineers Water Control Manual for each reservoir. The normal operating range at each dam is much less than the elevation range shown in the storage curves below (Figures 5.1 through 5.3). 
Storage differences between the Water Control Manual and CE-QUAL-W2 at the normal operating elevation are as follows:

- LGS at elevation 193 meters (633 feet) $=4.6 \%$

- $\quad$ LMN at elevation 164 meters (538 feet $)=9.4 \%$

- $\quad$ IHR at elevation 134 meters (440 feet $)=4.7 \%$.
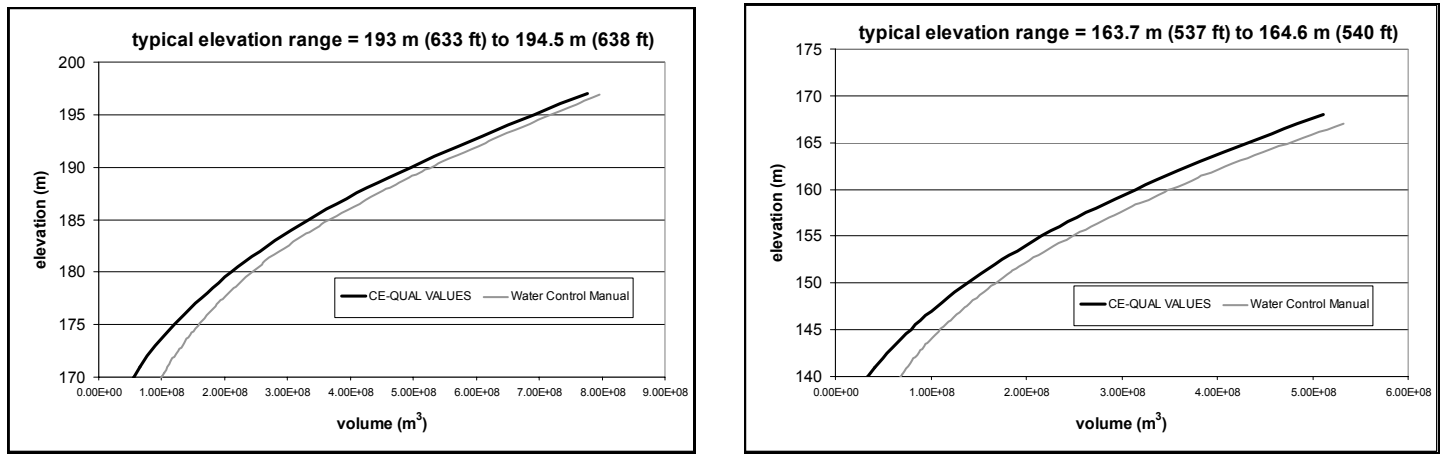

Figure 5.1. LGS reservoir storage-elevation curves (left).

Figure 5.2. LMN reservoir storage-elevation curves (right).

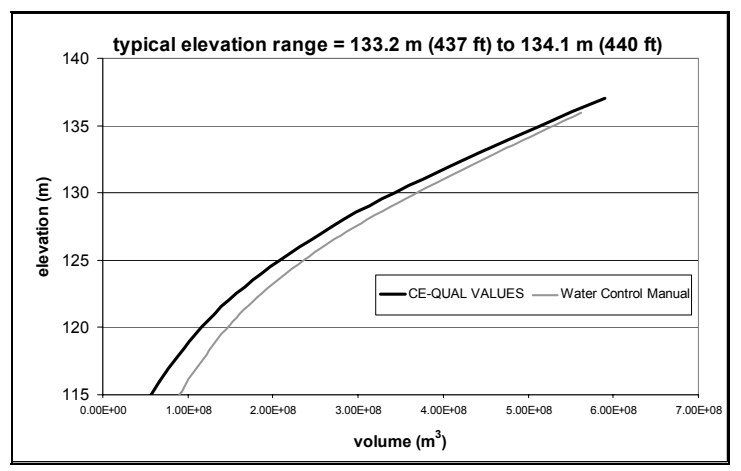

Figure 5.3. IHR reservoir storage-elevation curves.

\subsection{Boundary Conditions}

Operation of the numerical model requires specification of conditions around the boundary of the domain. The upstream boundary conditions were hourly specified inflow temperatures and discharges. These data were obtained from the Columbia River Operation Hydromet Management System (CHROMS) database, as reported in USACE (2003).

Meteorological conditions used for modeling all three reservoirs were collected on the shores of the LGS pool (i.e., Rice Bar on Lake Bryan). The station was installed and calibrated by AgriMet, U.S. Bureau of Reclamation. It has been in continual operation since April 19, 2002. The station is located at latitude $\mathrm{N}^{\circ} 6^{\circ} 41^{\prime}$ '51' and longitude W117 $39^{\prime} 15^{\prime}$ '. This station records wind speed and direction, air temperature, relative humidity (and derivatives), atmospheric pressure, solar radiation, and precipitation. A full listing of the types of sensors used on the AgriMet station can be found at http://mac1.pn.usbr.gov/agrimet/aginfo/sensors.html. Data from the station are uploaded to the AgriMet website at close to real time. In addition, historical data at 15-minute intervals can be downloaded from http://mac1.pn.usbr.gov/agrimet/webagdayread.html. 
The downstream boundary conditions for the model were hourly discharges measured at the dam. These data were also obtained from the CHROMS database, as reported in USACE (2003). Differences in mass conservation between the upstream inflow and downstream outflow caused water surface elevations in the reservoir to deviate from observed values. To correct for this mass flow imbalance, a distributed tributary was added to each reservoir. Tributary discharges were iteratively adjusted until a satisfactory water surface elevation at the downstream end of the model was obtained. Flows in the tributary were specified at a daily interval and were generally small compared to the total river discharge (average adjustments for each reservoir were as follows: $\mathrm{IHR}=3 \%$, $\mathrm{LGS}=-2 \%$, and $\mathrm{LMN}=-1 \%$ ).

\subsection{Simulation Results}

Water surface elevation at the upstream and downstream boundary plus water temperatures at the downstream boundary computed by CE-QUAL-W2 were compared to values observed in the field. Water elevation data were obtained from the CHROMS database as reported in USACE (2003). Water temperature data collected near each dam were collected by the Corps of Engineers and are reported in USACE (2003). These data were collected using self-contained Onset temperature loggers, similar to those described in Section 2.0 and were deployed from surface buoys. At each dam, several temperature strings were deployed to measure the existence of lateral thermal variations. Although some lateral variations were noted close to the surface, thermal differences deeper in the water column were negligible. This observation underscores the applicability of applying a 2-D, laterally-averaged model to these reservoirs. Water temperature data used to calibrate the numerical model were from the forebay temperature logger site with the greatest water column depth or the most complete dataset during the simulation period.

CE-QUAL-W2 was applied to each reservoir for a 152-day period between May 1 and October 1, 2002. This period corresponds to the Lower Granite data-collection period and covers the period of strong stratification in the Lower Snake River. Each simulation took less than 15 minutes to complete on a $2.4 \mathrm{GHz}$ Intel Pentium 4 processor running Windows XP.

\subsubsection{Little Goose Simulation Results}

The water surface elevation of LGS reservoir fluctuated by approximately 1.5 meters during the simulation period. The numerical model accurately captured these variations, the largest of which occurred in early September 2002. Figure 5.4 displays both observed and simulated downstream water surface elevations. In addition, Table 5.1 presents the bias, MAE and RMS (see Equation 3.1) between simulated and observed water surface elevations.

Table 5.1. Statistical comparison of results for Little Goose reservoir.

\begin{tabular}{|c|c|}
\hline \multicolumn{2}{|c|}{ Little Goose Reservoir } \\
Downstream Elevation $(\mathrm{m})$ & Downstream Temperture $\left({ }^{\circ} \mathrm{C}\right)$ \\
\cline { 2 - 2 } bias $=-0.01$ & bias $=-0.02$ \\
$\mathrm{MAE}=0.03$ & $\mathrm{MAE}=0.23$ \\
$\mathrm{RMS}=0.04$ & $\mathrm{RMS}=0.29$ \\
\hline
\end{tabular}




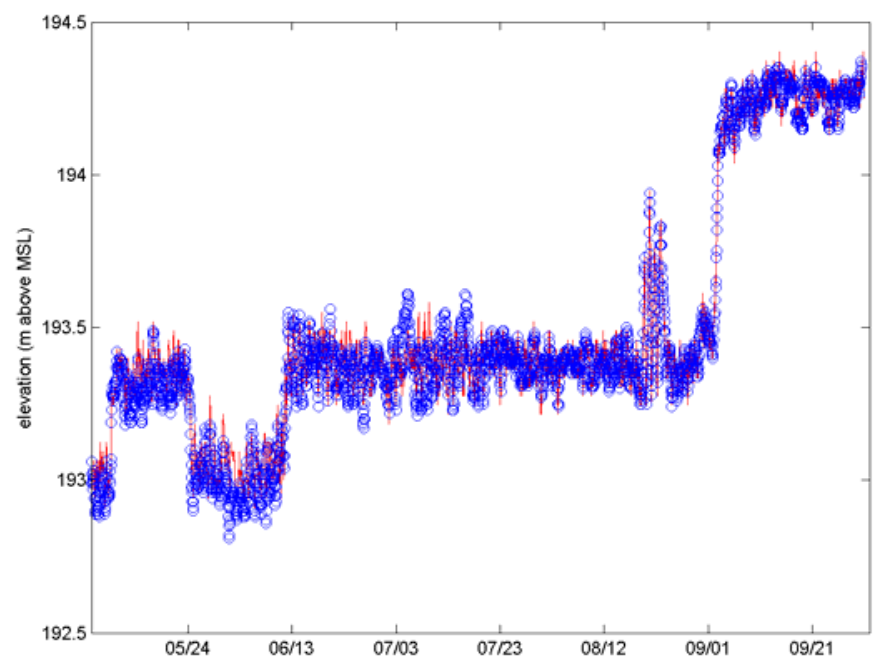

Figure 5.4. Downstream water surface elevation for LGS reservoir. Red line is observed, and blue circles are simulated.

Water temperatures in the reservoir followed a seasonal pattern. Before July, water temperatures in the forebay were approximately uniform in the vertical direction. Between July and September, stratification of LGS was noted, with the strongest stratification occurring in July and early August.

The numerical model correctly simulated both the rapid onset and fading of stratification in the reservoir. Differences between simulated and observed values were generally less than $\pm 1^{\circ} \mathrm{C}$ at all depths, although the largest differences occur in the upper layers of the reservoir near the water surface. Differences were also depth averaged, and a running residual was calculated. Residuals are positive and negative, and basic statistics generated from these residuals are shown in Table 5.1 above. All differences and residuals were calculated as simulated data minus observed data. Positive differences and residuals therefore indicate that the model value is warmer than the observed data point and vice versa. 

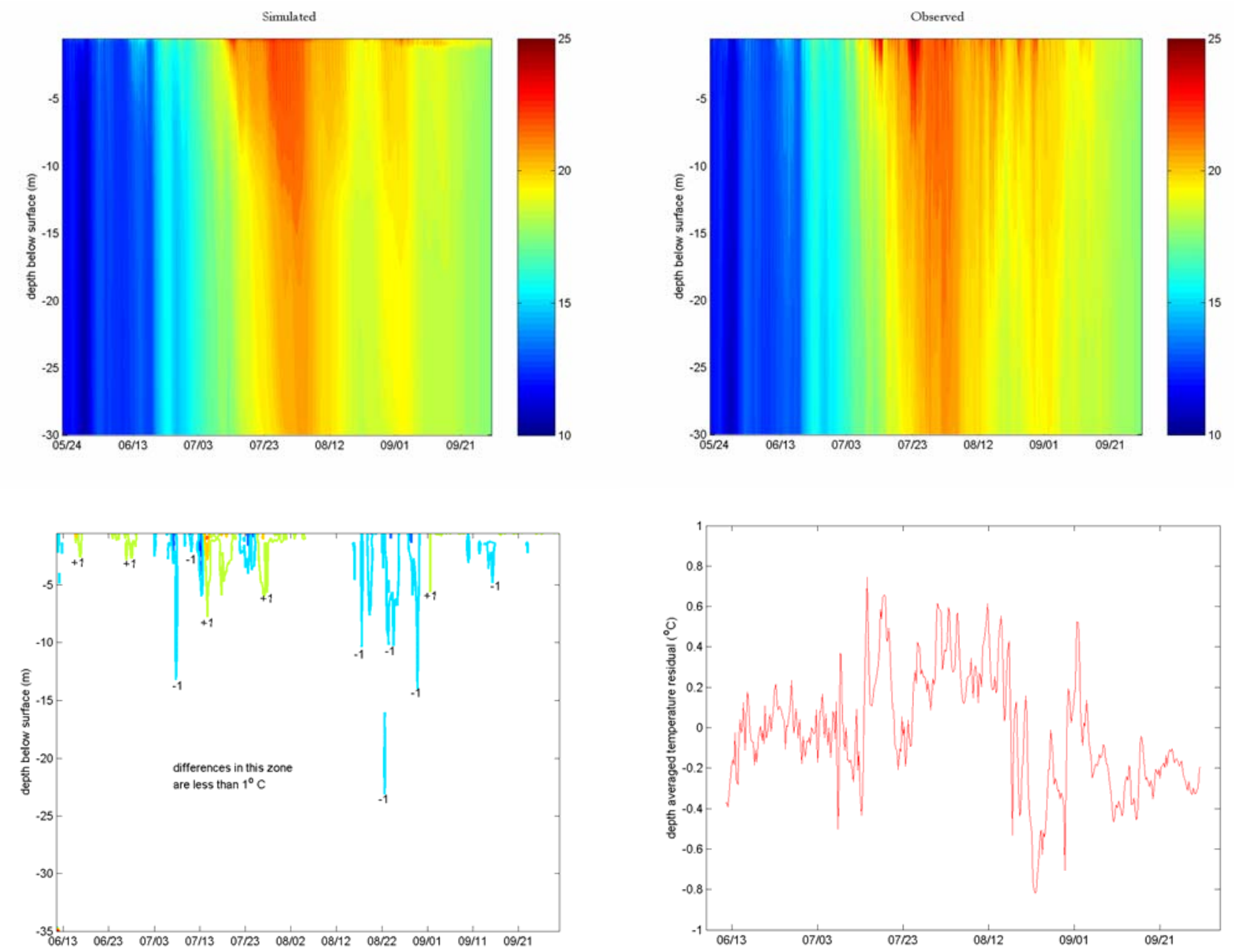

Figure 5.5. LGS reservoir temperature comparison summary. Clockwise from upper left are simulated temperatures, observed temperatures, depth averaged residuals (simulated minus observed), and difference contours (simulated minus observed). 


\subsubsection{Lower Monumental Simulation Results}

The water surface elevation of LMN reservoir fluctuated with the same general pattern LGS reservoir, although the overall magnitude was slightly less. The numerical model accurately captured the low-frequency and large-amplitude variations; however, it did not capture higherfrequency variations observed at the gage. The high-frequency variations were small in amplitude and generally only ranged between 0.1 and 0.2 meters. Water surface elevation mean error, average mean error, and root mean square errors for LMN are larger than for LGS; however, they are still quite small.

Table 5.2. Statistical comparison of results for Lower Monumental reservoir.

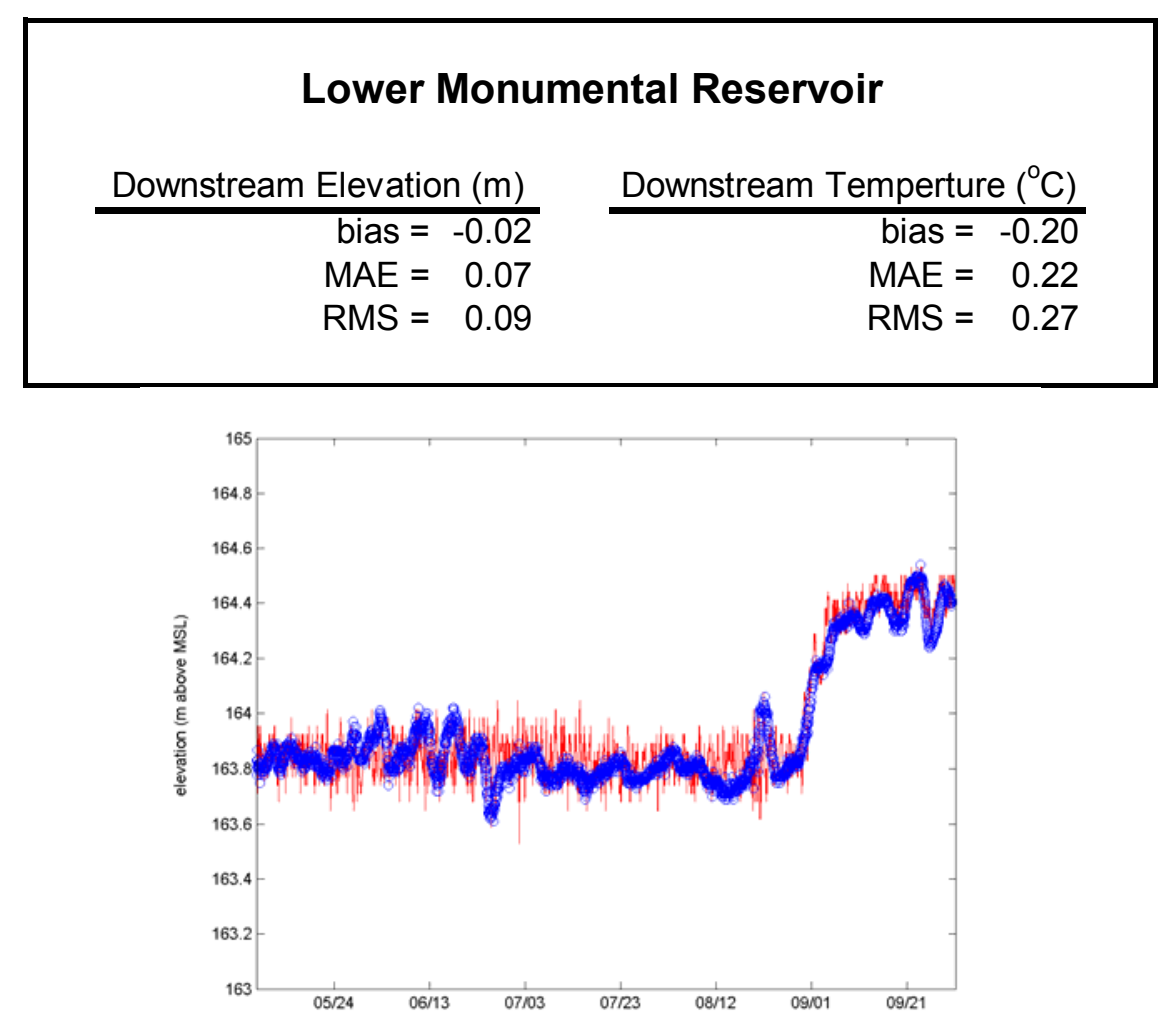

Figure 5.6. Downstream water surface elevation for LMN reservoir. Red line is observed, and blue circles are simulated.

The general pattern of thermal stratification in LMN is similar to that observed in LGS. As with LGS, the model accurately captured the onset and decline of stratification. Temperature errors were less than $1{ }^{\circ} \mathrm{C}$ for most of the thermocline and hypolimnium; however, differences larger than $1^{\circ} \mathrm{C}$ were noted near the surface. Average mean errors and root mean square errors in water temperature were similar to those computed with the LGS model. 

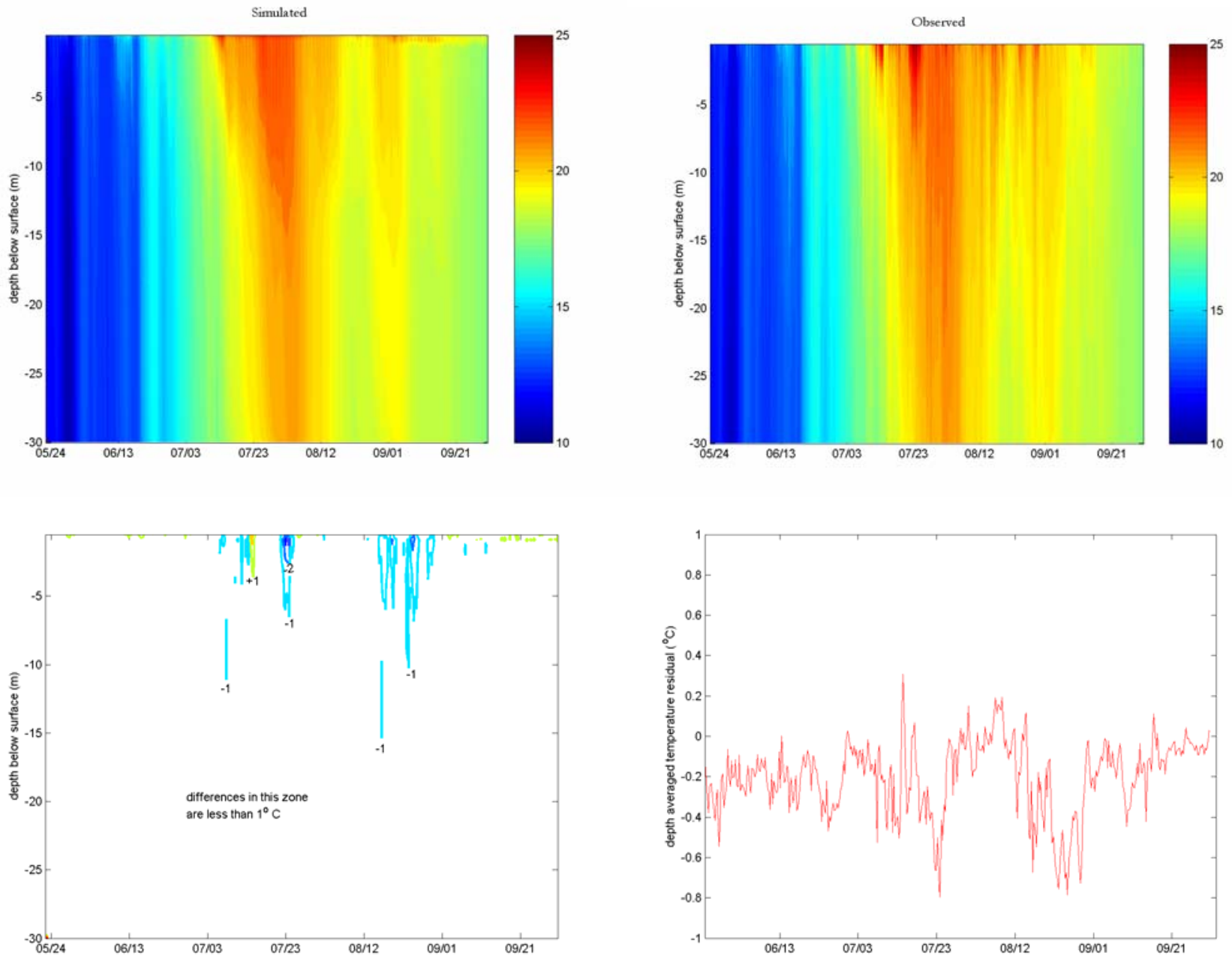

Figure 5.7. LMN reservoir temperature comparison summary. Clockwise from upper left are simulated temperatures, observed temperatures, depth-averaged residuals (simulated minus observed), and difference contours (simulated minus observed). 


\subsubsection{Ice Harbor Simulation Results}

The water surface elevation of IHR reservoir fluctuated the least out of the three Lower Snake reservoirs. The model captured the general rise in water surface elevation observed in late summer. Water surface elevation mean errors, average mean errors, and root mean square errors for IHR were the smallest of all three reservoirs.

Table 5.3. Statistical comparison of results for Ice Harbor reservoir
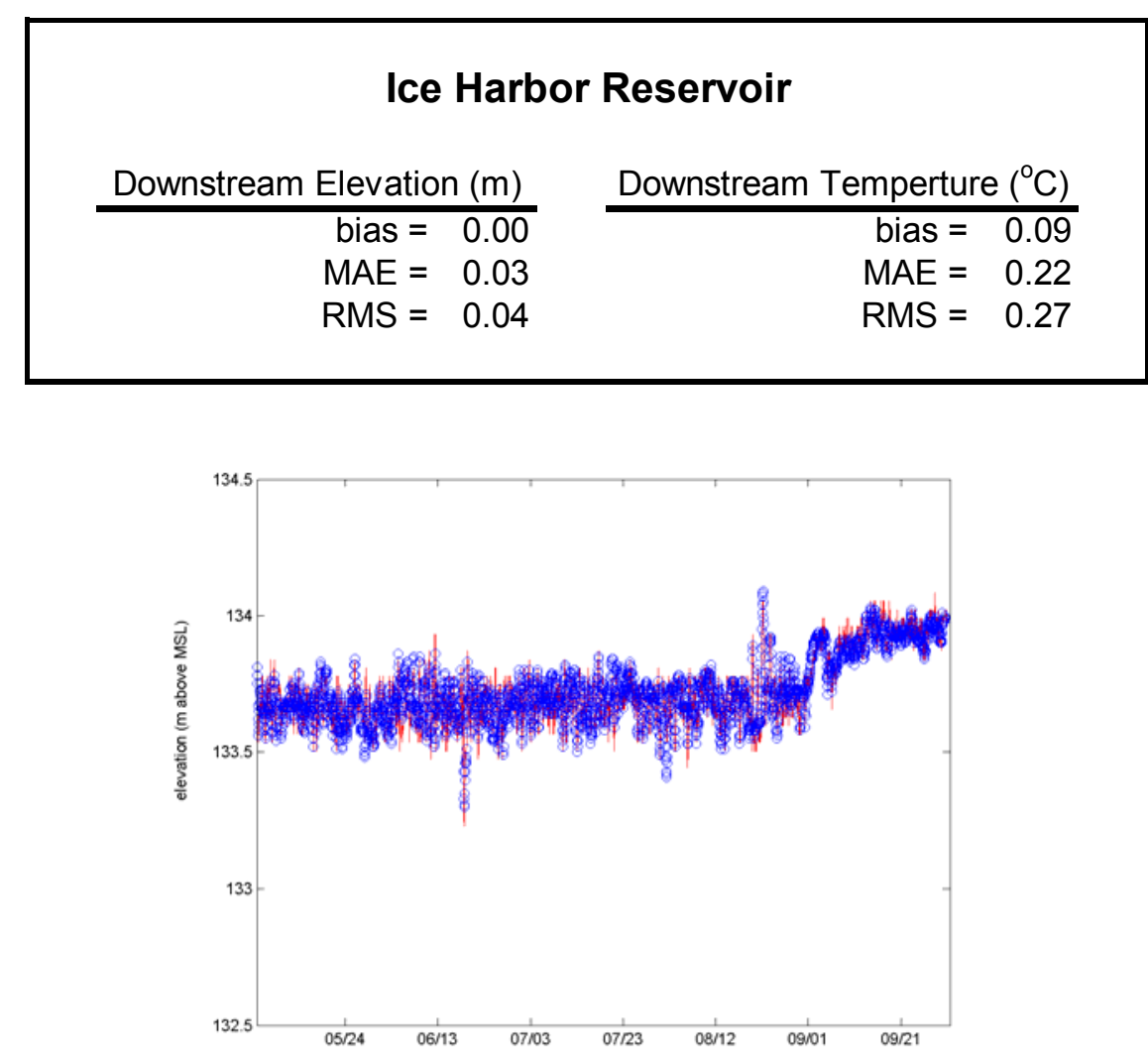

Figure 5.8. Downstream water surface elevation for IHR reservoir. Red line is observed, and blue circles are simulated.

Water temperatures in IHR were the warmest, and stratification was the weakest at the dam out of all three Lower Snake reservoirs during July and August 2002. The numerical model simulated the temperature variations at all depths. As with the other two reservoirs, temperature errors were less than $1^{\circ} \mathrm{C}$ for most of the thermocline and hypolimnium; however, differences larger than $1^{\circ} \mathrm{C}$ were noted near the surface. Average mean errors and root mean square errors in water temperature were similar to those computed with the LGS and LMN models. 

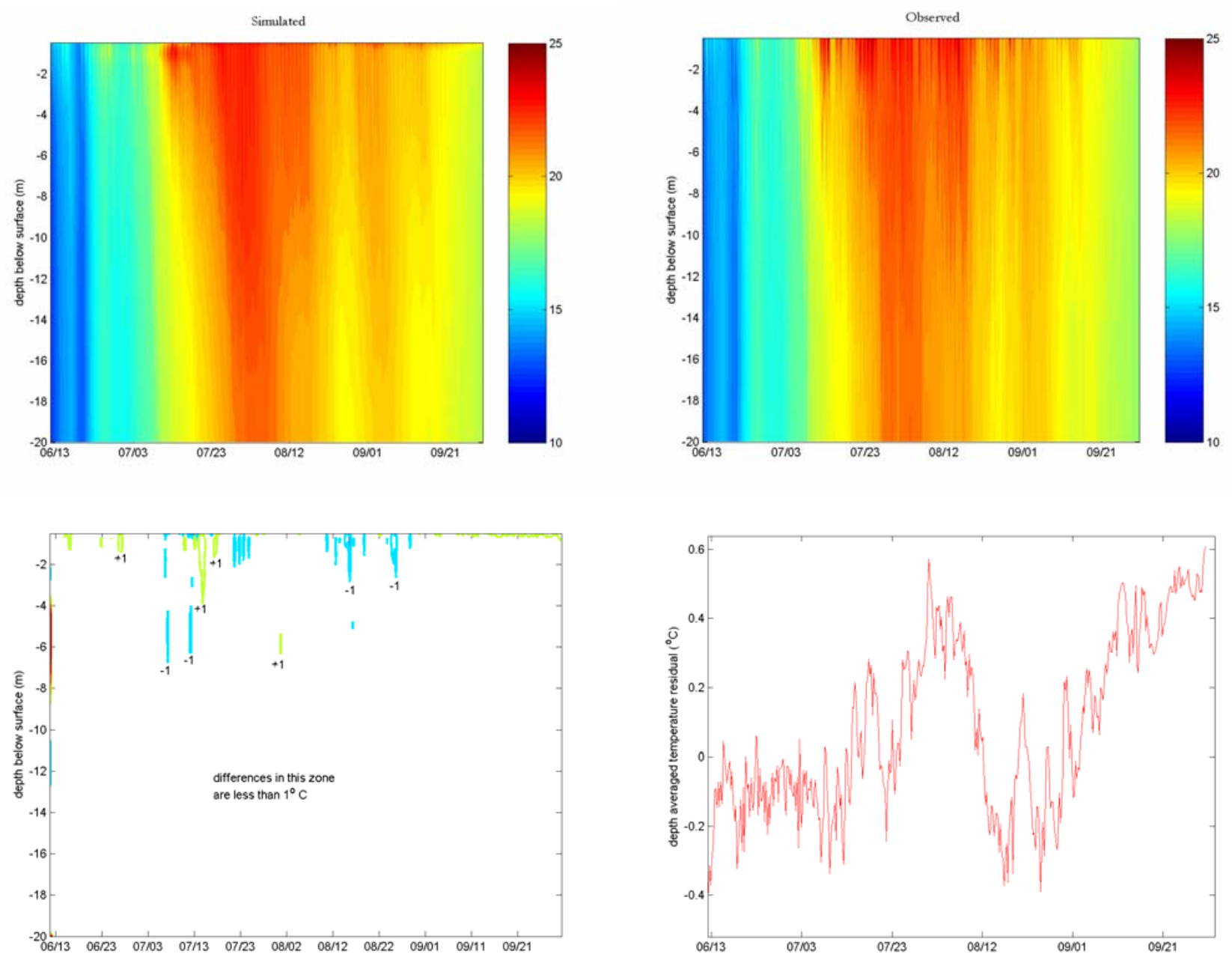

Figure 5.9. IHR reservoir temperature comparison summary. Clockwise from upper left are simulated temperatures, observed temperatures, depth-averaged residuals (simulated minus observed), and difference contours (simulated minus observed). 


\subsection{Conclusions}

During Year 1 of this multi-year project, Pacific Northwest National Laboratory (PNNL) collected bathymetric, meteorological, hydrodynamic, and water quality data in the reservoir upstream of Lower Granite Dam. These data were entered into a database and distributed through the RPA143 Working Group, which focuses on data collection in the Lower Snake River. Through this data-collection effort, several observations regarding the lateral and vertical variations in temperature throughout the Lower Granite Reservoir (LGR) in 2002 were noted. The confluence of the Clearwater and Snake Rivers was found to behave in two modes: weak to no stratification and strong stratification. Satellite images and computational fluid dynamics (CFD) model results were used to better understand these modes and their impacts on downstream hydrodynamics. Cold water was also found to migrate upstream in the Snake River arm under periods of strong stratification. This was predicted by the three-dimensional (3-D) CFD model and confirmed by measurements in the field during August 2002.

The 3-D CFD model, originally developed under a separate project and documented in Perkins et al. (2001), was re-applied to LGR for the extent of the 2002 data-collection period using improved bathymetric data. Model results were generally in good agreement with Acoustic Doppler current profiler (ADCP) field-measured velocities, and velocity magnitude mean square errors (MSEs) were only slightly above $3.5 \mathrm{~cm} / \mathrm{s}$. Field-gathered temperature data were also used to further adjust model parameters. Although simulated and observed temperatures were in good agreement in the downstream portions of the model, work is ongoing to improve agreement in the complex interaction area of the colder Clearwater River flows and the Snake River.

A separate two-dimensional (2-D) laterally-averaged CFD model was applied to the three reservoirs downstream of LGR. This model accurately simulated the onset and decline of stratification in each reservoir during the spring, summer, and fall of 2002. Temperature differences between simulated and observed values were generally less than $1{ }^{\circ} \mathrm{C}$, although some larger differences for brief periods were noted near the water surface. Water surface elevations were also calculated accurately by the model, with average differences generally less than 0.1 meter. The time required to simulate the 6-month period was small compared to the 3-D model, with most execution times requiring less than 15 minutes on a $2.4-\mathrm{GHz}$ Pentium 4 computer.

At the time this report was written, data collection in Lower Granite was already underway for the 2003 field season. Temperature logger strings were deployed during the last week in April 2003 and will be maintained through September. ADCP data collections will be performed in May (weak stratification) and July (strong stratification), and meteorological data will continue to be collected at the AgriMet Station placed on Silcott Island. Multi-dimensional CFD modeling of the Lower Snake will also continue during 2003.

In future months, the CFD models will also be used to simulate alternative release strategies (e.g., increased/decreased flows and/or increased/decreased temperatures) from upstream reservoirs. In combination with fish movement analyses conducted under other Bonneville Power Administration (BPA) and U.S. Army Corps of Engineers (USACE) projects, this work will provide a better understanding of how future flow augmentation strategies could influence the migration and health of migrating salmonids in the Lower Snake River. 


\subsection{References}

Baker, P.F., T.P. Speed, and F.K. Ligon. 1995. "Estimating the Influence of Temperature on the Survival of Chinook Salmon Smolts (Oncorhynchus tshawytscha) Migrating Through the Sacrament-San Joaquin River Delta of California." Canadian Journal of Fisheries and Aquatic Sciences 52:855-863.

Brett, J.R. 1952. “Temperature Tolerance in Young Pacific Salmon, Genus Orcorhynchus." Journal of the Fisheries Research Board of Canada 9:265-322.

Cole, T.M. and S.A. Wells. 2002. CE-QUAL-W2: A Two-Dimensional, Laterally Averaged, Hydrodynamic and Water Quality Model, Version 3.1. Instruction Report EL-2002-1, U.S. Army Engineering Research and Development Center, Vicksburg, Mississippi (August).

Cook, C.B., G.G. He, A.M. Coleman, and P.E. Long. 2003. Use of Satellite Imagery and ThreeDimensional CFD Models to Remotely Quantify Water Quality Variations in the River/Reservoir Environment. FY 2002 Laboratory Directed Research and Development Annual Report, Pacific Northwest National Laboratory, Richland, Washington.

Coutant, C.C. 1973. "Effect of Thermal Shock on Vulnerability of Juvenile Salmonids to Predation." Journal of the Fisheries Research Board of Canada 30:965-973.

Ewing, R.D., S.L. Johnson, H.J. Pribble, and J.A. Lichatowich. 1979. “Temperature and Photoperiod Effects on Gill $(\mathrm{Na}+\mathrm{K})$ - ATPhase Activities in Chinook Salmon (Oncorhynchus Tshawytscha)." Journal of the Fisheries Research Board of Canada 30:1347-1353.

Federal Columbia River Power System (FCRPS). 2000. Biological Opinion: Reinitiating of the Consultation on Operation of the Federal Columbia River Power System, Including the Juvenile Fish Transport System, and 19 Bureau of Reclamation Projects in the Columbia Basin. U.S. Army Corps of Engineers, Bonneville Power Administration, Bureau of Reclamation, National Marine Fisheries Service (December).

Fryer, J.L. and K.S. Pilcher. 1974. Effects of Temperature on Diseases of Salmonids Fishes. EPA-660/3-73-020. Prepared for Office of Research and Development, Environmental Protection Agency, by Western Fish Toxicology Laboratory, Environmental Protection Agency, Corvalis, Oregon, pp. 114.

Hamrick, J. M. 1992. A Three-Dimensional Environmental Fluid Dynamics Computer Code: Theoretical and Computational Aspects. Special Report 317, Virginia Institute of Marine Science, College of William and Mary, Gloucester, Virginia.

Ji, Z., M. Morton, M., and J. Hamrick. 2001. "Wetting and Drying Simulation of Estuarine Processes." Estuarine, Coastal and Shelf Science 53(5):683-700.

Jin, K.-R., J.H. Hamrick, and T. Tisdale. 2000. "Application of Three-Dimensional Hydrodynamic Model for Lake Okeechobee.” Journal of Hydraulic Engineering 126(10):758771. 
Moustafa, M. Z. and J.M. Hamrick. 2000. "Calibration of the Wetland Hydrodynamic Model to the Everglades Nutrient Removal Project." Water Quality and Ecosystems Modeling 1(1-4):141167.

Perkins, W.A., M.C. Richmond, A.M. Coleman, T.D. Scheibe, and C.L. Rakowski. 2001. Relate the Effects of Water Velocity, Temperature, and Dissolved Gas on Migration Patterns of Adult Salmon and Steelhead in the Lower Columbia and Snake River Systems. Battelle Pacific Northwest Division, Richland, Washington (December).

Perkins, W.A. and M.C. Richmond. 2001. Long-Term, One-Dimensional Simulation of Lower Snake River Temperatures for Current and Unimpounded Conditions. PNNL-13443, Pacific Northwest National Laboratory, Richland, Washington.

Richmond, M.C., W.A. Perkins, and Y. Chien. 2000. Numerical Model Analysis of System-wide Dissolved Gas Abatement Alternatives. PNWD-3245, Battelle Pacific Northwest Division, Richland, Washington.

Sylvester, J.R. 1972. "Effect of Thermal Stress of Predator Avoidance in Sockeye Salmon." Journal of the Fisheries Research Board of Canada 29:601-603.

United States Army Corps of Engineers (USACE). 2003. Preliminary Water Quality, Meteorological, Operations and Flow Data for the Snake River System. Carroll, J. and K. Barko, eds., U.S. Army Corps of Engineers (March).

United States Geological Survey (USGS). 2002. Geologic Hazards Information: Geomagnetism. U.S. Geological Survey, U.S. Department of the Interior, Washington, D.C. Available URL: http://geomag.usgs.gov/. 


\section{Appendix A Observed Temperatures in LGR}

Temperature loggers were deployed at the sites listed below throughout the summer and fall of 2002. At the open-water sites (i.e., those not connected to bridge piers), the location changed as the boat drifted slightly during maintenance. All locations were measured with a real-time differential Global Positioning System (GPS) with a horizontal accuracy of approximately 1 meter.

Table A.1. Calendar and location of logger deployments.

\begin{tabular}{|cccc|}
\hline \multicolumn{5}{c}{$\begin{array}{c}\text { June 25-27 to August 6-9, } 2002 \\
\text { Description }\end{array}$} & Latitude & Longitude \\
\hline Site1 & Snake RM 116.5 & 46.581657 & -117.317265 \\
Site2 & Snake RM 124.5 & 46.492753 & -117.232514 \\
Site3 & US Silcott/North Shore & 46.424784 & -117.175136 \\
Site4 & US Silcott/South Shore & 46.423092 & -117.175049 \\
Site5 & Red Wolf Bridge & 46.425195 & -117.072362 \\
Site6 & DS Confluence/North Shore & 46.430115 & -117.044233 \\
Site7 & DS Confluence/South Shore & 46.425551 & -117.040966 \\
Site8 & Interstate 12 (Blue) Bridge & 46.420359 & -117.036626 \\
Site9 & Southway Bridge (Snake) & 46.394983 & -117.039120 \\
Site10 & Railroad Trestle (Clearwater) & 46.426011 & -117.025142 \\
Site11 & Clearwater Mem. Bridge & 46.419430 & -117.000121 \\
\hline \multicolumn{4}{c}{} \\
\hline
\end{tabular}

\begin{tabular}{|cccc|}
\hline \multicolumn{4}{c|}{ August 6-9 to September 25-27, 2002 } \\
\hline Site1 & Snake RM 116.5 & 46.581794 & -117.316967 \\
Site2 & Snake RM 124.5 & 46.492376 & -117.232743 \\
Site3 & US Silcott/North Shore & 46.424758 & -117.175027 \\
Site4 & US Silcott/South Shore & 46.423468 & -117.175128 \\
Site5 & Red Wolf Bridge & 46.425195 & -117.072362 \\
Site6 & DS Confluence/North Shore & 46.430638 & -117.044912 \\
Site7 & DS Confluence/South Shore & 46.425737 & -117.040027 \\
Site8 & Interstate 12 (Blue) Bridge & 46.420359 & -117.036626 \\
Site9 & Southway Bridge (Snake) & 46.394983 & -117.039120 \\
Site10 & Railroad Trestle (Clearwater) & 46.426011 & -117.025142 \\
Site11 & Clearwater Mem. Bridge & 46.419430 & -117.000121 \\
\hline \multicolumn{4}{|}{} \\
\hline
\end{tabular}

\begin{tabular}{|ccrc|}
\hline \multicolumn{4}{c|}{ September 25-27 to December 17, 2002 } \\
\hline Site2 & Snake RM 124.5 & 46.4924053 & -117.2325735 \\
Site5 & Red Wolf Bridge & 46.4251960 & -117.0723647 \\
Site9 & Southway Bridge (Snake) & 46.3950189 & -117.0392866 \\
Site11 & Clearwater Mem. Bridge & 46.4194124 & -116.9999538 \\
\hline
\end{tabular}



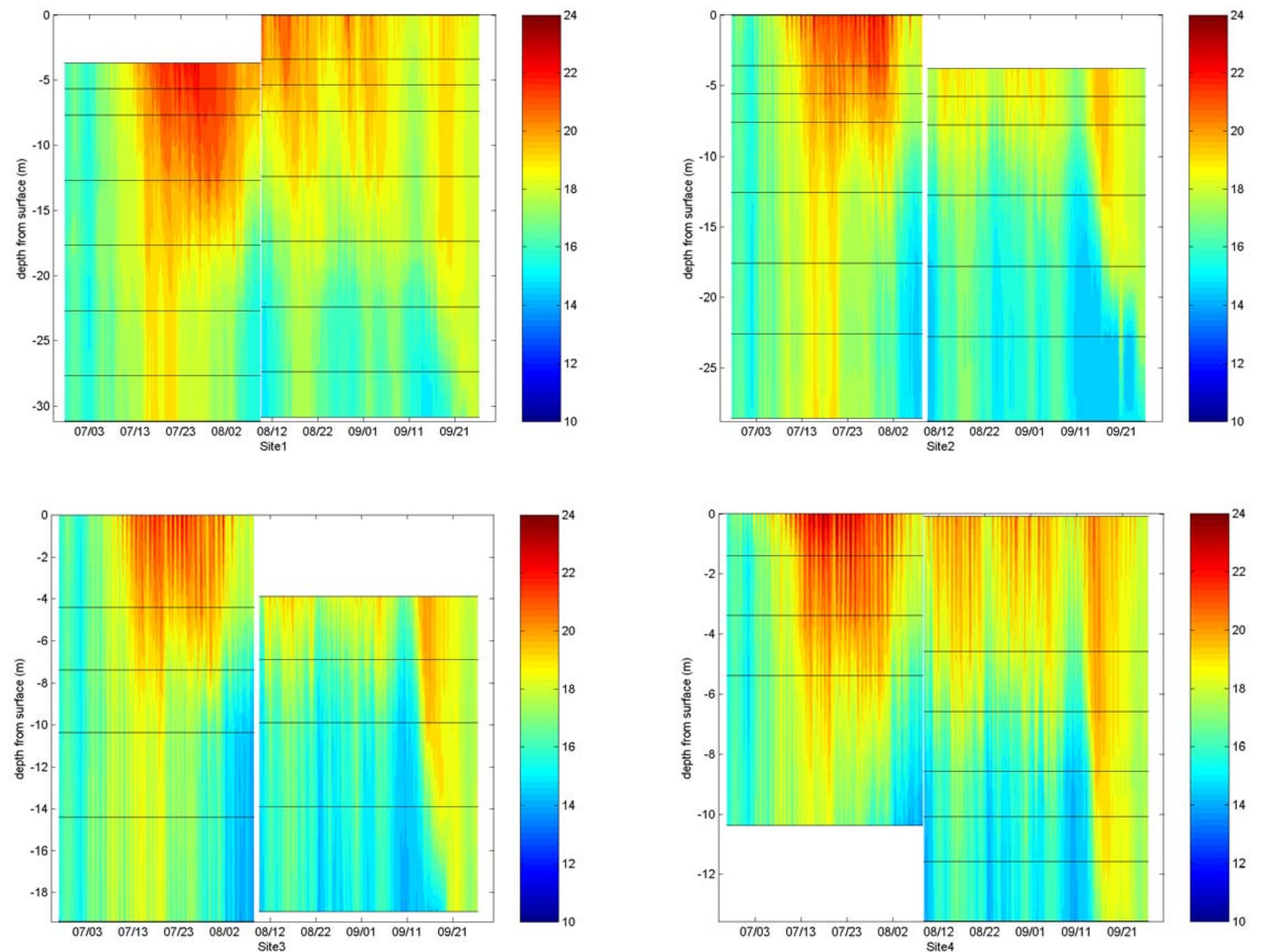

Figure A.1. Summer season temperature results at sites 1 through 4 

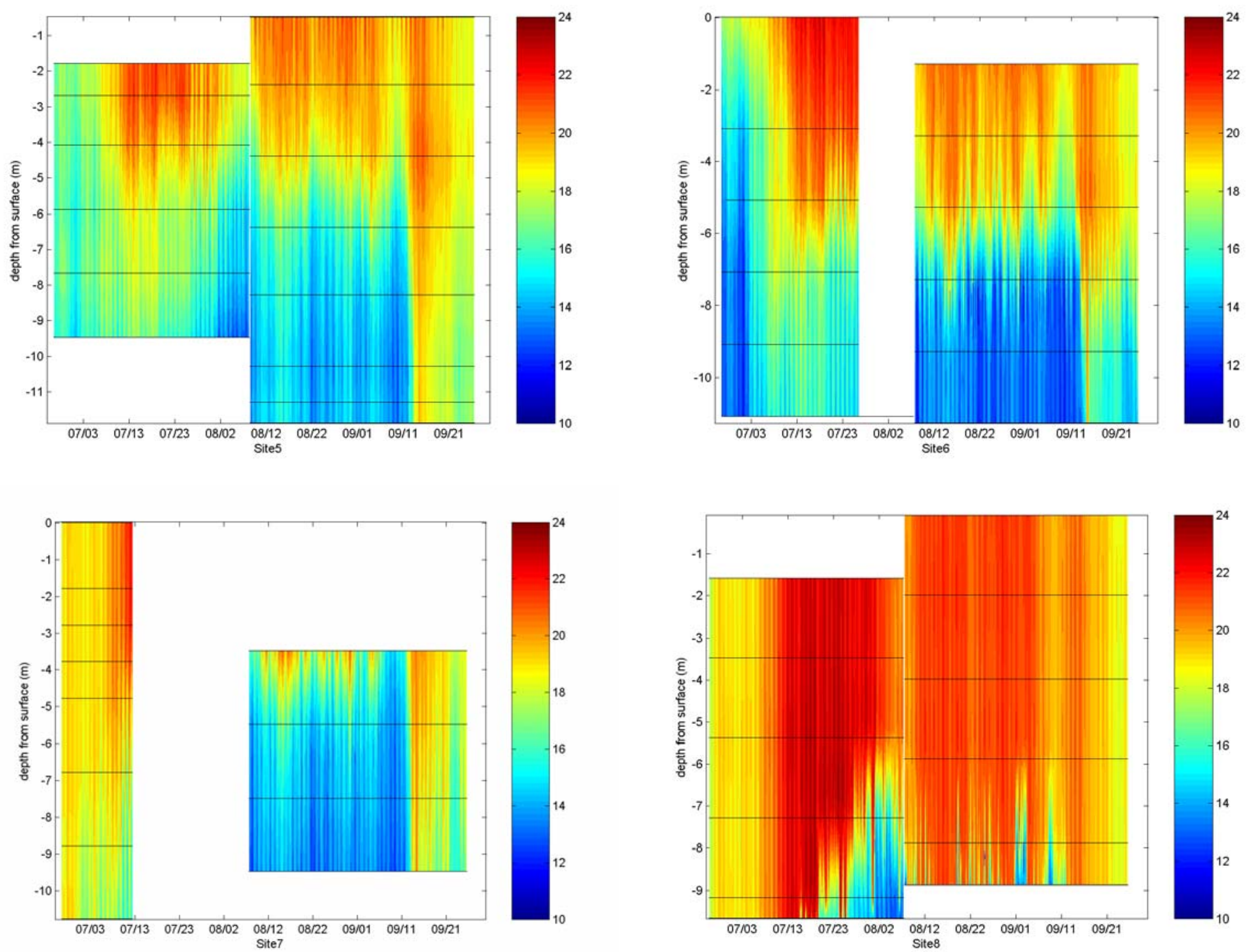

Figure A.1 (continued). Summer season temperature results at sites 5 through 8 . 

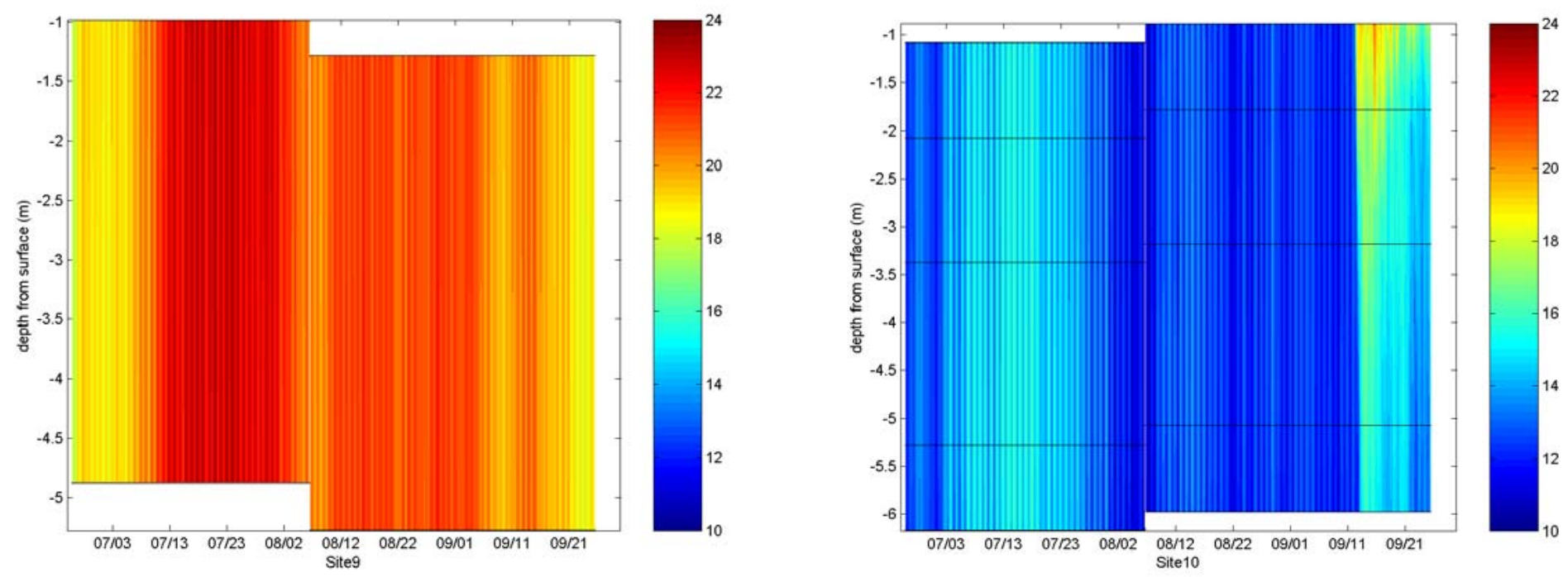

$\stackrel{P}{+}$

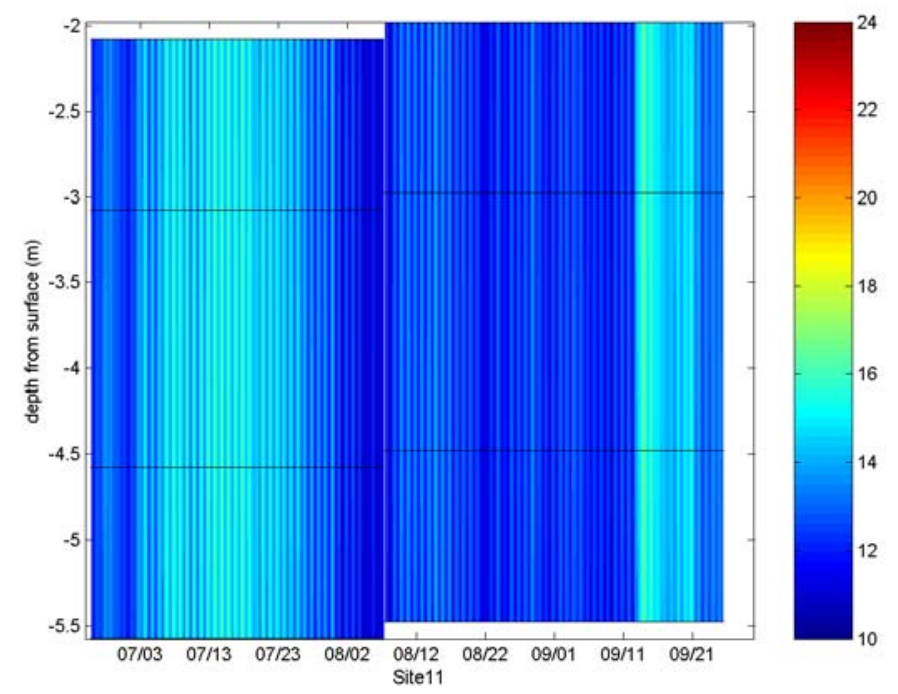

Figure A.1 (continued). Summer season temperature results at sites 5 through 8 . 